Portland State University

PDXScholar

$1-1-2012$

\title{
Fluorescent Indicators for Disease Biomarkers
}

Soojin Lim

Portland State University

Follow this and additional works at: https://pdxscholar.library.pdx.edu/open_access_etds

Let us know how access to this document benefits you.

Recommended Citation

Lim, Soojin, "Fluorescent Indicators for Disease Biomarkers" (2012). Dissertations and Theses. Paper 262. https://doi.org/10.15760/etd.262

This Dissertation is brought to you for free and open access. It has been accepted for inclusion in Dissertations and Theses by an authorized administrator of PDXScholar. Please contact us if we can make this document more accessible: pdxscholar@pdx.edu. 
Fluorescent Indicators for Disease Biomarkers

by

Soojin Lim

A dissertation submitted in partial fulfillment of the requirements for the degree of

Doctor of Philosophy

in

Chemistry

Dissertation Committee:

Robert M. Strongin, Chair

Carl C. Wamser

Reuben H. Simoyi

Erik Johansson

Jun Jiao

Portland State University

(C) 2012 


\begin{abstract}
Xanthene dyes are common fluorophores which have been widely used as molecular probes. The xanthene fluorophores can be used as highly selective optical sensors to detect disease biomarkers. A new fluorogenic dye containing an $\alpha, \beta$ unsaturated aldehyde moiety exhibits selective fluorescent signal enhancement in the presence of cysteine or peptides containing $N$-terminal cysteine residues. The mechanism is based on synergistic covalent and supramolecular interactions.

A unique rhodamine boronic acid indicator is used in an optimized data collection protocol for wavelength- and time-dependent selectivity of various saccharides and nucleosides. One indicator is thereby capable of selectively distinguishing structurally related analytes in mixtures. Moreover, the rhodamine-based boronic acid responds linearly to increasing riboside concentrations in urine samples, potentially enabling the screening for inborn purine metabolism disorders.
\end{abstract}




\section{DEDICATION}

Philippians 4:13| I can do everything through him who gives me strength.

Thank my God.

To my parents, Mun Joo Lim and Hee Sung Choi.

Thank you for all your love and prayers. 


\section{ACKNOWLEDGEMENTS}

First, I would like to give my sincere thanks to my wonderful advisor, Dr. Robert M. Strongin, for his guidance, support and encouragement. His inspiration and confidence led me to achieve a goal.

My special thanks to Dr. Jorge Escobedo and Dr. Mark Lowry. Thanks for all their timely help and support for my research.

My thanks also go to Dr. Martha Sibrian-Vazquez and Dr. Oleksandr Rusin. Thanks for being a great model as real scientists.

I would like to thank my best colleagues, Jialu Wang, Shelly Chu, Aabha Barve, Lovemore Hakuna, Yixing Guo, Lei Wang. Thanks for all their help and friendship.

I would also like to thank Dr. Carl C. Wamser, Dr. Reuben H. Simoyi, Dr. Erik Johansson and Dr. Jun Jiao for being my committee members. I fully appreciate their patience, support and valuable advices.

Finally, to love of my soul, Jeff D. Yoo. Thank you for being with me at the best moment of my life. 


\section{TABLE OF CONTENTS}

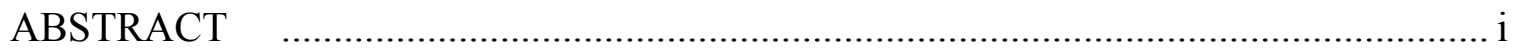

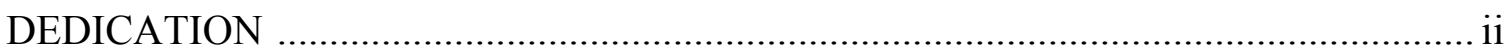

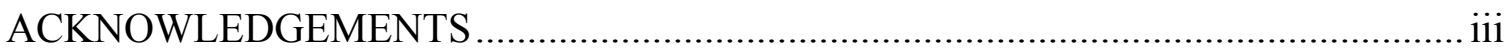

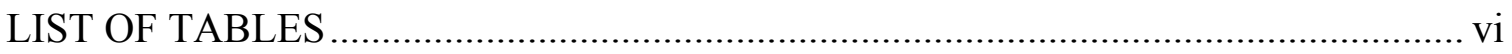

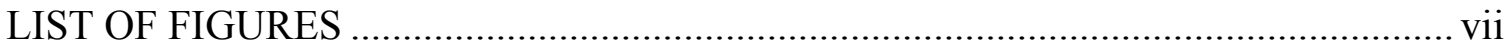

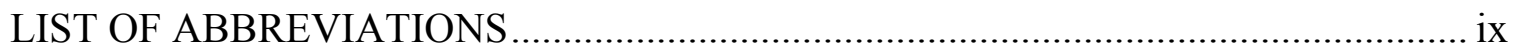

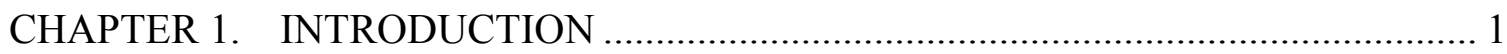

$1.1 \quad$ Fluorescent Indicators ................................................................... 1

1.2 Indicators for the Specific Detection of Cysteine and $N$-Terminal Cysteine Peptide Residues .................................................................... 1

1.3 Multidimensional Multiple Analyte Detection via a Single Indicator...... 2

1.4 Direct Detection of ADSL Deficiency in Human Urine............................. 3

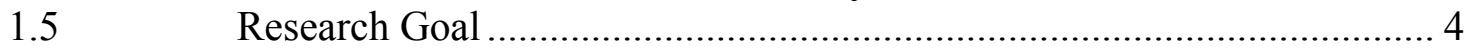

CHAPTER 2. SELECTIVE FLUORESCENCE DETECTION OF CYSTEINE AND $\mathrm{N}$ TERMINAL CYSTEINE PEPTIDE RESIDUES …………………...... 5

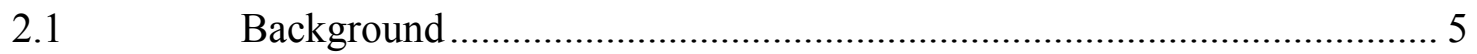

2.1.1 Biological Thiols............................................................................. 5

2.1.2 General Thiol Detection Methods....................................................... 6

2.1.3 Thiol Detection Probes based on Cyclizations with Aldehydes ............... 8

2.1.4 $\alpha, \beta$-unsaturated Aldehydes for Cysteine Detection................................. 11

2.2 Synthesis of an $\alpha, \beta$-unsaturated Fluorescein Monoaldehyde.................. 12

$2.3 \quad$ Results and Discussion .............................................................. 12

2.3.1 Conjugate Addition and Thiazolidine Formation of Cysteine ................... 12

2.3.2 The Absorption and Fluorescence Properties of Mono- $\alpha, \beta$-unsaturated Fluorescein Aldehyde ...................................................................... 14

2.3.3 Selective Detection of Cysteine and Homocysteine ............................... 18

2.3.4 Site-specific Peptide and Protein Residue Detection............................... 21

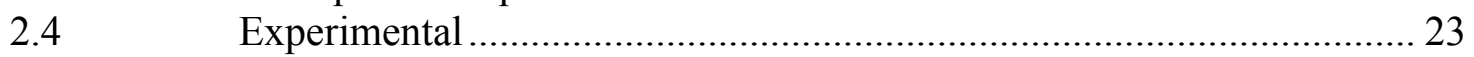

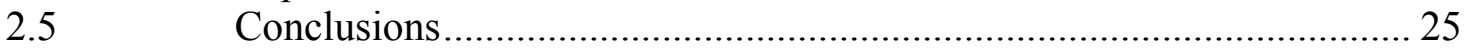

CHAPTER 3. DETECTING SPECIFIC SACCHARIDES VIA A SINGLE

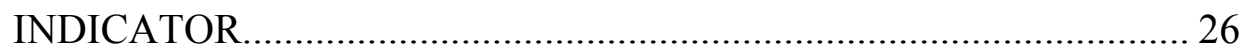

3.1 Introduction: Excitation-Emission Matrices (EEM) ........................... 26

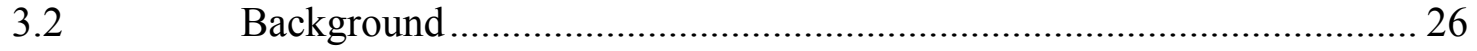

3.2.1 Simple Optical Indicators for Chemosensing ........................................ 26

3.2.2 Development of Rhodmine Boronic Acid Dye....................................... 27 


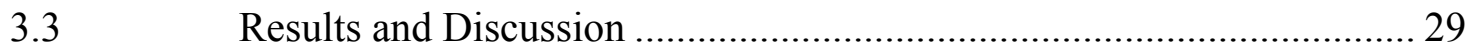

3.3.1 Microwave Assisted Synthesis of Rhodamine Boronic Acid ................. 29

3.3.2 Time and Wavelength Dependent Detection of Multiple Analytes........ 30

3.3.3 Multiple Analyte Detection via a Single Indicator .................................... 33

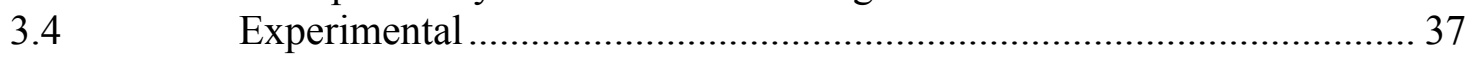

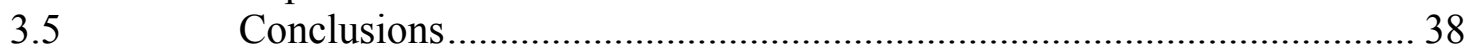

CHAPTER 4. PROGRESS TOWARDS SIMPLE AND DIRECT DETECTION OF ADENYLOSUCCINATE LYASE DEFICIENCY IN HUMAN URINE

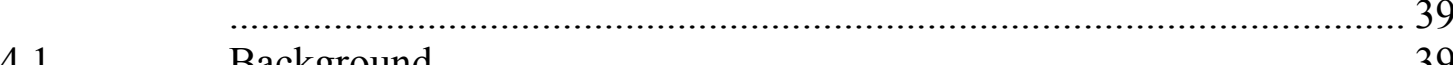

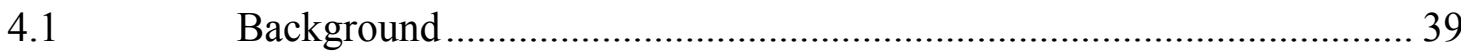

4.1.1 Global Demands of Simple Diagnostic Tests …………………….......... 39

4.1.2 Adenolosuccinate Lyase (ADSL) Deficiency......................................... 41

4.2 An Application of Multidimensional Measurements to Biological Media.

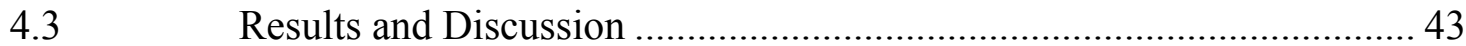

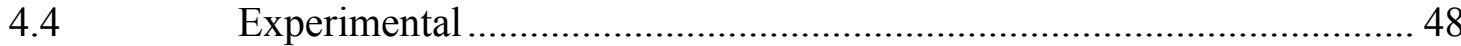

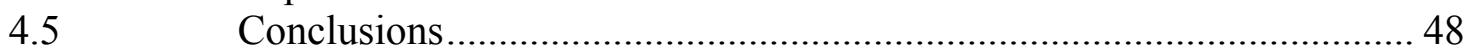

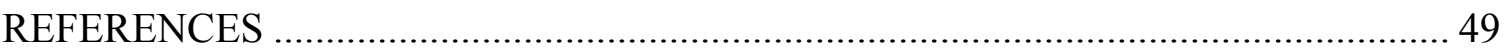

APPENDIX A. CHARACTERIZATION DATA FOR COMPOUND 2.1...................... 55

APPENDIX B. SELECTIVE FLUORESCENCE DETECTION OF CYSTEINE AND $N$ TERMINAL CYSTEINE PEPTIDE RESIDUES ………………….......59

APPENDIX C. COMPUTATIONAL PROCEDURES OF ENERGY-MINIMIZED STRUCTURES OF THE REACTION PRODUCTS OF 2.1 WITH CYS

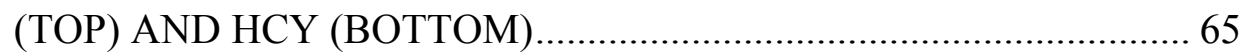

APPENDIX D. CHARACTERIZATION DATA FOR COMPOUND 3.1..................... 74

APPENDIX E. COMPUTATIONAL PROCEDURES OF ENERGY-MINIMIZED MODEL OF THE BORONATE ESTER FORMED AFTER CONDENSATION OF ONE EQUIVALENT OF AN AICAR TO 3.1.....

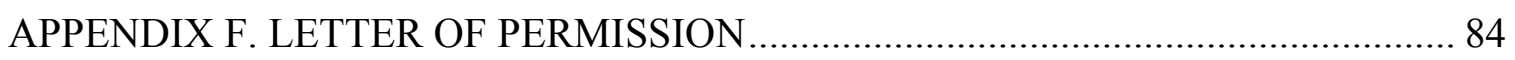

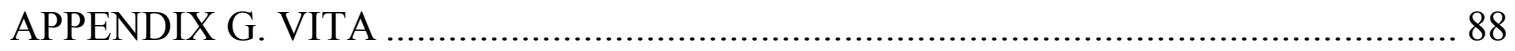




\section{LIST OF TABLES}

Table 2.1 Selected aldehyde functionalized fluorescent probes based on thiol cyclization................................................. 10 


\section{LIST OF FIGURES}

1.1 Chapter 2 describes the selective detection of Cys via an $\alpha, \beta$-unsaturated aldehyde-appended fluorescein derivative....................................

1.2 Chapter 3 describes multidimensional data analysis and its application to multianalyte detection via a single indicator...................................

1.3 Chapter 4 describes the selective detection of AICAr directly in human urine without sample processing, towards the development of a practical assay for

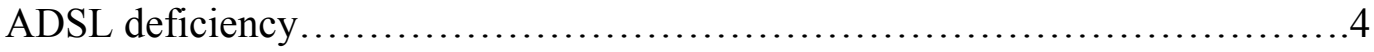

2.1 Some common biological thiols...............................................

2.2 DNBS cleavage type fluorescent probes....................................

2.3 Some dimaleimide derivative probes and a ketocoumarin derivative $\ldots \ldots \ldots \ldots \ldots 7$

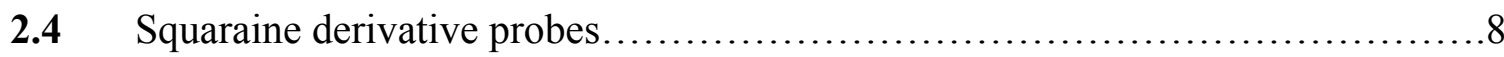

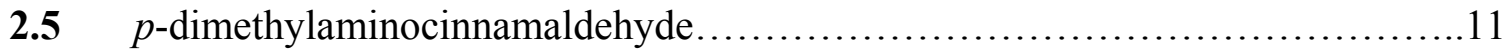

2.6 ${ }^{1} \mathrm{H}$-NMR spectra vs. times in $0.1 \mathrm{M}$ pH 7.4 phosphate buffer $/ \mathrm{D}_{2} \mathrm{O} 9: 1 \ldots \ldots \ldots \ldots 13$

2.7 Absorption of $2.1\left(\varepsilon_{501}=46981 \mathrm{~cm}^{-1} \mathrm{M}^{-1}\right.$ in $0.1 \mathrm{M}$ phosphate buffer $\left.\mathrm{pH} 7.4\right) \ldots \ldots .14$

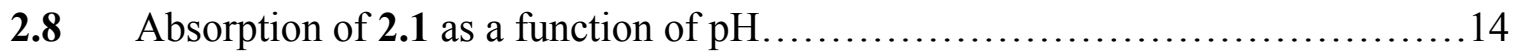

2.9 Spectral properties of fluorescein and compound $2.1\left(2.31 \times 10^{-6} \mathrm{M}\right.$ in $0.1 \mathrm{M}$ phosphate buffer $\mathrm{pH} 7.4)$ in absence and presence of Cys $(10.0 \mathrm{mM}) \ldots \ldots \ldots \ldots . .16$

2.10 Spectral properties of compound $2.1\left(9.38 \times 10^{-7} \mathrm{M}\right)$ in the presence of Cys (10.0

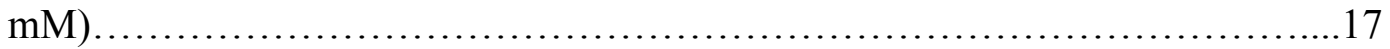

2.11 Response of compound 2.1 to thiols $(10.0 \mathrm{mM})$ of interest and their structural

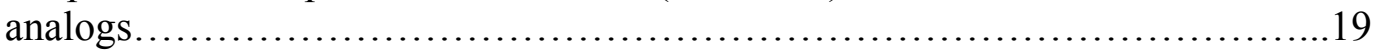

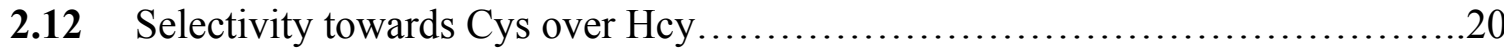

2.13 Energy-minimized structures of the reaction products of $\mathbf{2 . 1}$ with Cys and Hcy showing the distance between the $\mathrm{NH}_{3}{ }^{+}$and the phenolate groups.

2.14 Response of compound 2.1 to thiols $(0.5 \mathrm{mM})$ and peptides $(0.5 \mathrm{mM})$ of

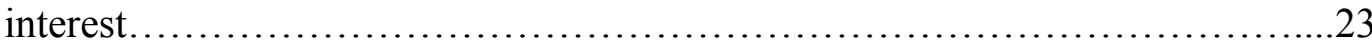


3.1 Rhodamine boronic acid 3.1 and ribose and ribose-containing target molecules..............................................................28

3.2 Energy-minimized model of the boronate ester formed after condensation of one equivalent of a nucleoside (AICAr) to 3.1 .................................29

3.3 Emission spectra demonstrating selective response to various analytes............31

3.4 Intensity as a function of time................................................

3.5 EEMs demonstrating the response of $\mathbf{3 . 1}$ towards various analytes...............34

3.6 Time and wavelength dependent detection.................................36

4.1 ADSL deficiency biomarker SAICAr and S-Ado...........................42

4.2 Rhodamine boronic acid 3.1 and AICAr......................................44

4.3 EEMs and emission spectra demonstrating the responses of $\mathbf{3 . 1}$ to AICAr at $8 \mathrm{~min}$ after mixing in a simple $10 \%$ buffer: $90 \%$ DMSO solvent system...............45

4.4 EEMs and emission spectra demonstrating the responses of $\mathbf{3 . 1}$ to AICAr at 20 min after mixing in 5\% healthy human urine: $5 \%$ buffer: $90 \%$ DMSO ............47 


\section{LIST OF ABBREVIATIONS}

AAAS

Abs

ADSL

AICAr

ASDs

ca.

$\mathrm{CH}_{3} \mathrm{CN}$

$\mathrm{CHCl}_{3}$

Cys

$\delta$

$\mathrm{D}_{2} \mathrm{O}$

DCM

DMF

DMSO

DNBS

$\varepsilon$

e.g.

EEM

Em

ESI

et al.

EtOAc
The American Association for the Advancement of Science

Maximal Absorbance

Adenolosuccinate lyase

5-aminoimidazole-4-carboxamide riboside

The autism spectrum disorders

Approximately (Circa)

Acetonitrile

Chloroform

Cysteine

Chemical shift

Deuterium oxide

Dichloromethane

Dimethylformamide

Dimethyl sulfoxide

2,4-dinitrobenzenesulfonyl

Molar absorptivity (epsilon)

For example (exempli gratia)

Excitation-emission matrix

Maximal Emission

Electron spin resonance

and others (et alii)

Ethyl acetate 


\begin{tabular}{|c|c|}
\hline $\mathrm{EtOH}$ & Ethanol \\
\hline$\phi$ & Quantum yield \\
\hline FTMS & Fourier transform mass spectrometry \\
\hline GC-MS & Gas chromatography - mass spectrometry \\
\hline Glu & Glutamyl \\
\hline Gly & Glycine \\
\hline GSH & Glutathione \\
\hline $\mathrm{h}$ & hour \\
\hline $\mathrm{H}_{2} \mathrm{SO}_{4}$ & Sulfuric acid \\
\hline Hcy & Homocysteine \\
\hline HEPES & 4-(2-hydroxyethyl)-1-piperzineethanesufonic acid \\
\hline HPLC & High performance liquid chromatography \\
\hline HRMS & High performance mass spectrometry \\
\hline $\mathrm{Hz}$ & Hertz \\
\hline ICT & Intramolecular charge transfer \\
\hline$J$ & Coupling constant \\
\hline$\lambda_{\text {ex }}$ & The wavelength of excitation \\
\hline$\lambda_{\max }$ & The wavelength of maximum absorption \\
\hline LOD & Limit of detection \\
\hline LTQ & Linear trap quadrupole \\
\hline M & Moles per liter (molar) \\
\hline$m / z$ & Mass-to-charge ration \\
\hline $\mathrm{MeOH}$ & Methanol \\
\hline
\end{tabular}




\begin{tabular}{|c|c|}
\hline $\mathrm{NaCl}$ & Sodium chloride \\
\hline $\mathrm{NaHCO}_{3}$ & Sodium bicarbonate \\
\hline $\mathrm{NaOH}$ & Sodium hydroxide \\
\hline $\mathrm{NH}_{3}$ & Ammonia \\
\hline NMR & Nuclear magnetic resonance \\
\hline PARAFAC & Parallel factor analysis \\
\hline PET & Photoinduced electron transfer \\
\hline $\mathrm{p} K_{\mathrm{a}}$ & The logarithmic acidity constant \\
\hline PP & Purine and pyrimidine \\
\hline ppm & Parts per million \\
\hline 2-PrOH & Isopropanol \\
\hline $\mathrm{R}_{f}$ & Retardation factor \\
\hline $\mathrm{rt}$ & Room temperature \\
\hline S-Ado & Succinyladenosine \\
\hline SAH & S-adenosyl homocysteine \\
\hline SAICAr & Succinyl-5-amino-4-imidazolecarboxamide riboside \\
\hline SAM & S-adenosyl methionine \\
\hline TLC & Thin layer chromatography \\
\hline TOF & Time of flight \\
\hline UV-Vis & Ultraviolet-visible \\
\hline vs. & Versus \\
\hline
\end{tabular}




\section{CHAPTER 1. INTRODUCTION}

The development of simple optical indicators to detect small molecule disease biomarkers is of great interest. Current clinical chemistry techniques can benefit from user friendly and simple techniques for the direct analysis of analytes in complex biological matrices. Research described herein focuses on the sensing of biological thiols, peptides, and specific ribose-containing molecules via xanthene-based organic dye indicators.

\subsection{Fluorescent Indicators}

Organic and bioorganic molecules as analytes pose unique challenges for the design of selective indicators. They include a wide range of structures, dynamics and interacting moieties. The majority of the indicators reported to date were designed for detecting metal cations and inorganic or highly polar anionic molecules. These latter efforts were inspired, for instance, by Tsien's cation-binding fluorophores. ${ }^{1}$ In fact, fluorescent chemical indicators for sodium, potassium and calcium currently are the platforms for a portable blood gas analyzer for point-of-care use in hospitals and ambulances. $^{2}$

\subsection{Indicators for the Specific Detection of Cysteine and $N$-Terminal Cysteine Peptide Residues}

Biological thiols help modulate many redox processes in nature. Altered levels of thiols signify various disease states including cancer and AIDS. ${ }^{3}$ Thus, the creation of effective probes for biological thiols is an ongoing area of study. Many fluorescent reagents have been reported by several research groups worldwide. The chemical 
mechanisms for signal transduction are diverse. They include cleavage by thiol attack, ring opening reactions, Michael additions, or cyclizations with aldehydes.

Aldehyde-functionalized fluorophores and chromophores can be used for the simple and highly selective detection of cysteine (Cys) and/or homocysteine (Hcy) upon thiazinane or thiazolidine formation. Additionally, Cys vs. Hcy selectivity is also achieved via the use of $\alpha, \beta$-unsaturated aldehydes under mild conditions involving related mechanisms. ${ }^{4,5}$

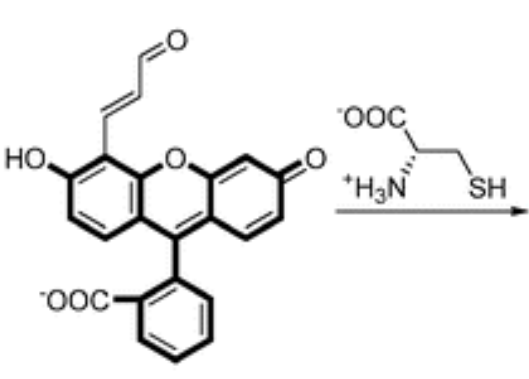

suppressed fluorescence

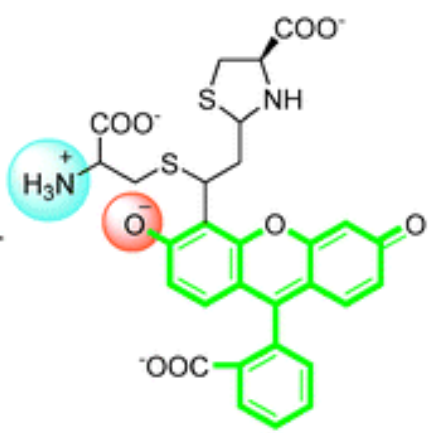

fluorescent

Figure 1.1 Chapter 2 describes the selective detection of Cys via an $\alpha, \beta$-unsaturated aldehyde-appended fluorescein derivative.

\subsection{Multidimensional Multiple Analyte Detection via a Single Indicator}

Generally, fluorescence detection is analyzed by the fluorescence response from the interaction between the analyte and indicator or receptor. However, fluorophores used in complex natural media can form unexpected multi-component complexes that may hinder selective detection and challenge the determination of optimal spectroscopic properties. An improved data collection protocol, such as multidimensional data analysis which measures fluorescence of sample at several different excitation wavelengths for several emission wavelengths, can solve the problems from the presence of a variety of indicator-bound species. Also, this wavelength-tunable detection enables multiple analyte 
detection via a single optical indicator based on the different dynamics of each reaction complex, simultaneously with saving time and materials.

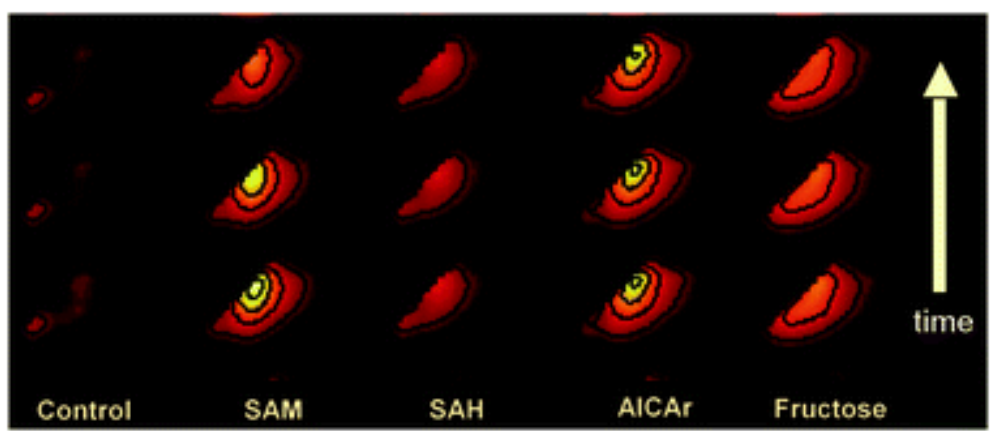

Figure 1.2 Chapter 3 describes multidimensional data analysis and its application to multiple analyte detection via a single indicator.

\subsection{Direct Detection of ADSL Deficiency in Human Urine}

Although rare (approximately 1 in 200,000 births), adenolosuccinate lyase (ADSL) deficiency is a serious inborn error of purine metabolism. It is one of the autism spectrum disorders. ADSL deficiency is associated with mental retardation, congenital blindness, autism and seizure. ${ }^{6}$ It can be diagnosed via massive levels (mM) of succinyl5-amino-4-imidazolecarboxamide riboside (SAICA-riboside) and succinyladenosine (SAdo) in urine of these patients.

Existing screening tests for ADSL deficiency, for example the Bratton-Marshall test, are non-specific and exhibit high rates of false positives. TLC screening with Pauly reagent requires fresh reagent preparation prior to use, and analyte separations. Developing stable and selective reagents for SAICAr and S-Ado directly in urine without separations is necessary for convenient screening for this devastating disease of infants. Such tests would also guide the development of other nucleoside and nucleotide indicators for the detection of various cancers. 


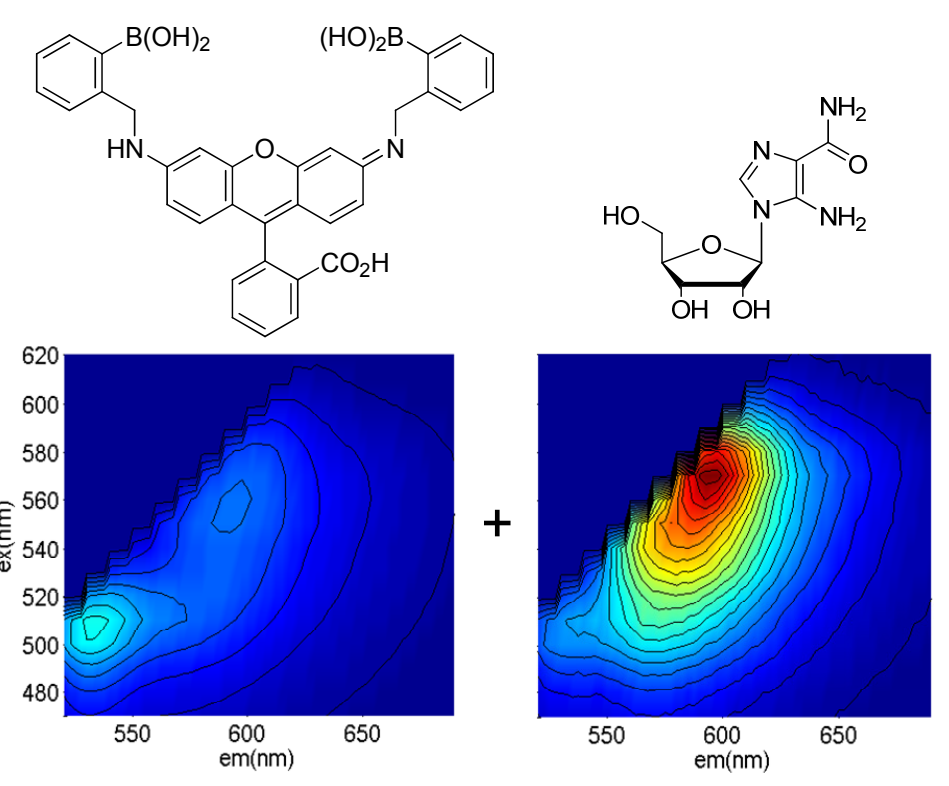

Figure 1.3 Chapter 4 describes the selective detection of AICAr directly in human urine without sample processing, towards the development of a practical assay for ADSL deficiency.

\subsection{Research Goal}

A goal of the work described herein is developing fluorogenic dyes for detecting specific amino acids and saccharides in challenging natural media. This includes (i) understanding synergistic covalent and non-covalent interactions between the fluorophore and bound analyte, (ii) site-specific peptide and protein residue detection, (iii) the advantage of time and wavelength dependent detection for multiple analyte sensing via one indicator, (iv) simple and direct analyses of ADSL deficiency biomarkers in urine, (v) monitoring the concentration of analytes of interests in real clinical samples via quantitative means. 


\section{CHAPTER 2. SELECTIVE FLUORESCENCE DETECTION OF CYSTEINE AND $N$-TERMINAL CYSTEINE PEPTIDE RESIDUES}

An $\alpha, \beta$-unsaturated aldehyde-functionalized fluorescein produces a significant fluorescent signal enhancement in solutions containing cysteine and peptides containing $N$-terminal cysteine residues. A unique combination of covalent and supramolecular interactions between fluorophore and analyte promotes the selectivity among the aminothiols.

\subsection{Background}

\subsubsection{Biological Thiols}

Biological thiols play key roles in the regulation of numerous biochemical redox processes. A deficiency or excess of specific biological thiols is related to various syndromes and the alteration in these thiols serves as evidence of disease states, such as cancer and AIDS. ${ }^{3}$<smiles>N[C@@H](CS)C(=O)O</smiles>

Cysteine<smiles>CC(=O)NC(CS)C(=O)O</smiles>

$\mathrm{N}$-acetylcysteine<smiles>N[C@@H](CCS)C(=O)O</smiles>

Homocysteine

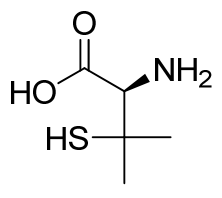

Penicillamine<smiles>N[C@@H](CCC(=O)N[C@@H](CS)C(=O)NCC(=O)O)C(=O)O</smiles>

Glutathione

Figure 2.1 Some common biological thiols.

Cysteine (Cys) is a biosynthesized nonessential amino which is an important catalytic center of many thiol-containing enzymes, and involved in human neuronal celllines. $^{7}$ An excess of Cys in vitro, in the presence of bicarbonate ions, has been reported to 
cause neuronal death by an excitotoxic mechanism in a calcium dependent manner. ${ }^{8}$ Elevation of cysteine concentrations in particular neurons may contribute to neurodegenerative brain disorders, such as Parkinson's, Alzheimer's, or motor neuron disease. ${ }^{9}$ On the other hand, abnormally low levels of plasma cystine and cysteine, and intracellular glutathione were found in patients with HIV infection. ${ }^{10}$

\subsubsection{General Thiol Detection Methods}

The investigation of fluorescent probes for thiol detection is an active area of study. ${ }^{3,11}$ Derivatives of fluorescent reagents have been reported by many groups and the mechanisms for fluorescence modulation are diverse. They include cleavage of electron withdrawing groups by thiols, ${ }^{12-15}$ Michael additions, ${ }^{16-23}$ or cyclizations with aldehydes. $^{24-30}$

Typically the cleavage type turn-on probes are non- or weakly fluorescent when they contain strong electron-withdrawing groups such as 2,4-dinitrobenzenesulfonyl (DNBS). ${ }^{12-14}$ However, they show intensity enhancement upon cleavage of the electronwithdrawing group in the presence of thiols. The DNBS functionalized fluorescein derivative displayed high intensity and short reaction times, but was sensitive to hydrolysis in aqueous solutions. ${ }^{12}$ Abe et al. used a DNBS rhodamine 110 (Fig. 2.2, left bottom), that was used for the monitoring of thiols in living human cells. ${ }^{13}$

Sensors based on Michael addition are also being developed for thiol detection. Various maleimide-base probes have been reported, ${ }^{18-20}$ but often the reaction conditions are limited to $\mathrm{pH}<7$ to avoid hydrolysis of the maleimide. ${ }^{19}$ Keillor et al. synthesized a series of dimaleimide containing fluorophores (Fig. 2.3, top) that react with 2 equiv monothiols or 1 equiv of dithiols. ${ }^{20}$ These fluorogens efficiently labeled a recombinant $\alpha$ - 
helical protein in vitro, which demonstrated potential utility for the labeling of specific proteins.
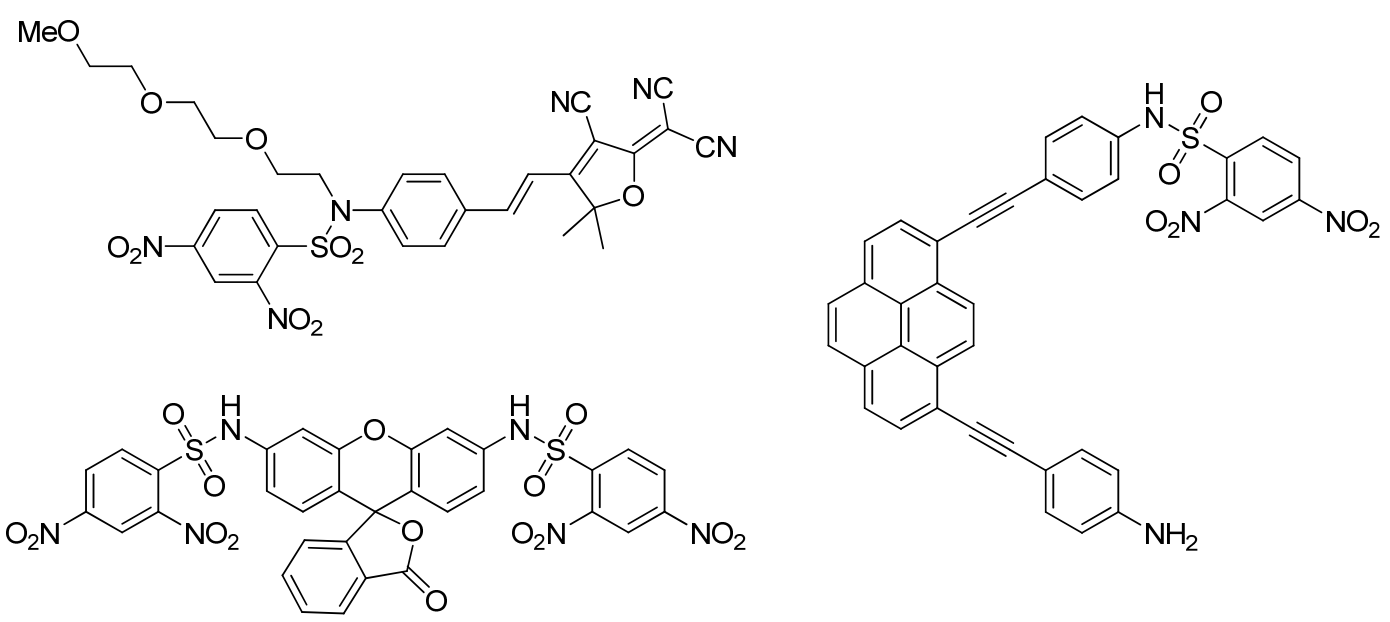

Figure 2.2 DNBS cleavage type fluorescent probes. ${ }^{13}, 14$
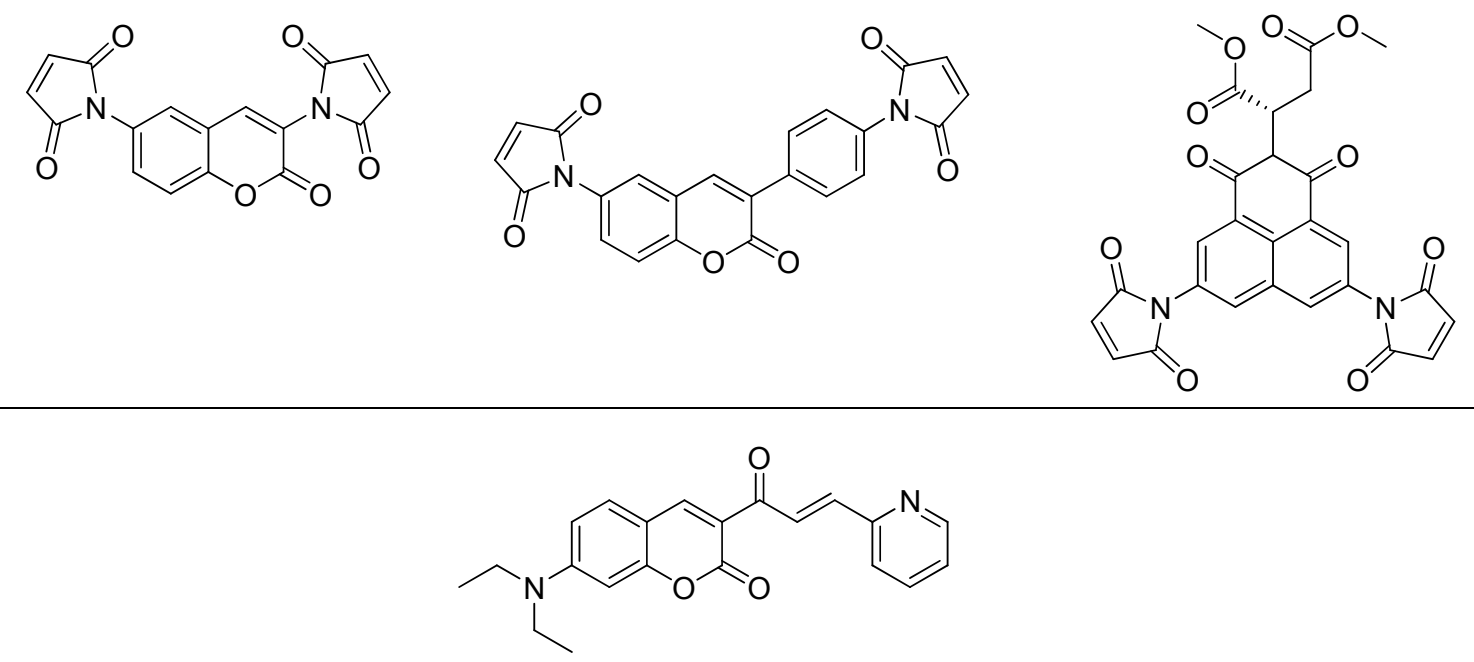

Figure 2.3 Some dimaleimide derivative probes (top) ${ }^{20}$, and a ketocoumarin derivative (bottom) $)^{21}$.

Lin et al. designed an $\alpha, \beta$-unsaturated fluorescent probe (Fig. 2.3, bottom) for the conjugate addition of thiols. ${ }^{21}$ The coumarin based probe is highly sensitive (211-fold enhancements for Cys) for thiols with a low limit of detection (LOD of $9.25 \times 10^{-7} \mathrm{M}$ ) at 
physiological $\mathrm{pH}$, but the relatively small quantum yield of the fluorophore in water limits its use in bioimaging.
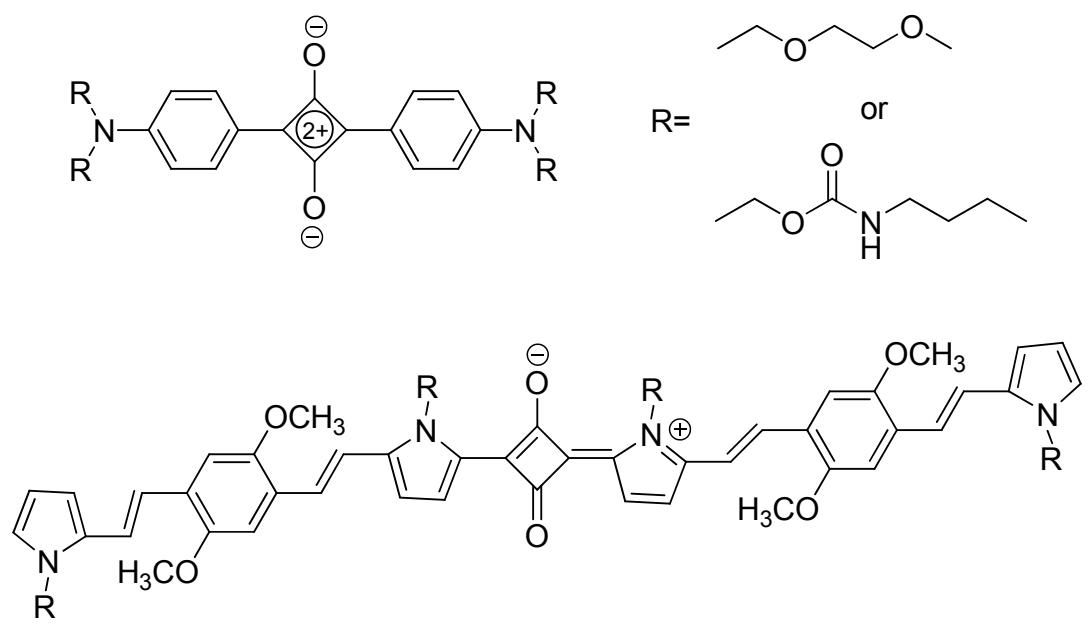

Figure 2.4 Squaraine derivative probes. ${ }^{22,23}$

Martínez-Máñez et al. reported simple, water-soluble, easy synthesized squaraine derivative thiol probes (Fig. 2.4, top). ${ }^{22}$ The squaraine probes showed an intense band at relatively long wavelength $(c a .640 \mathrm{~nm})$. Selective fluorescence quenching was observed in the presence of cysteine among various amino acids. However, squaraines are sensitive to the $\mathrm{pH}$ of the surrounding media. An improved $\pi$-extended squaraine dye (Fig. 2.4, bottom) exhibits absorption shifts and emission changes in the near infrared region in the presence of amino thiols in human blood plasma. ${ }^{23}$

\subsubsection{Thiol Detection Probes based on Cyclizations with Aldehydes}

Aldehyde-functionalized fluorophores and chromophores have been used for highly selective detection of cysteine and/or homocysteine over all other sulfhydryls due to characteristic thiazolidine or thiazinane formation, respectively (Table 2.1).

In 2004, the Strongin group reported a dialdehyde functionalized fluorescein dye for colorimetric and fluorimetric detection of Cys and Hcy. ${ }^{25}$ The probe showed visible 
color changes with added Cys and Hcy ( $25 \mathrm{~nm}$ red shift), and fluorescence quenching in a $\mathrm{pH} 9.5$ buffer solution. These results stimulated the further development of fluorogenic aldehydes for the detection of Cys and Hcy.

Tanaka and Barbas, III et al. introduced a fluorescence enhancement method for the detection of Cys at neutral $\mathrm{pH}^{26}$ The probe reacted with Cys and resulted in a fluorescence increase at $380 \mathrm{~nm}$, and allowed one to determine the concentration of Cys in a range of $100 \mu \mathrm{M}-5 \mathrm{mM}$.

A ratiometric phenanthroline-based probe was designed by Lin et $a l .{ }^{27}$ The probe in the presence of Cys/Hcy showed a large emission blue shift $(125 \mathrm{~nm})$ via an intramolecular charge transfer (ICT). While the phenanthroimidazole moiety works as both a fluorophore and electron donor in the ICT system, the aldehyde group functions as an electron acceptor and reacts with Cys and Hcy, respectively. Upon addition of Cys/Hcy, the probe displayed an intensity decrease at $519 \mathrm{~nm}$ with the growth of a locally excited band at $394 \mathrm{~nm}$.

Two coumarin-based fluorescent probes exhibiting photoinduced electron transfer (PET) effects were reported for the detection of amino thiols. ${ }^{28,}{ }^{29} \mathrm{~A}$ salicylaldehyde functionalized turn-on probe showed a more than 100-fold fluorescence enhancement in the presence of homocysteine. ${ }^{29}$ This fluorescence intensity enhancement was also monitored in human blood plasma with excess GSH. 


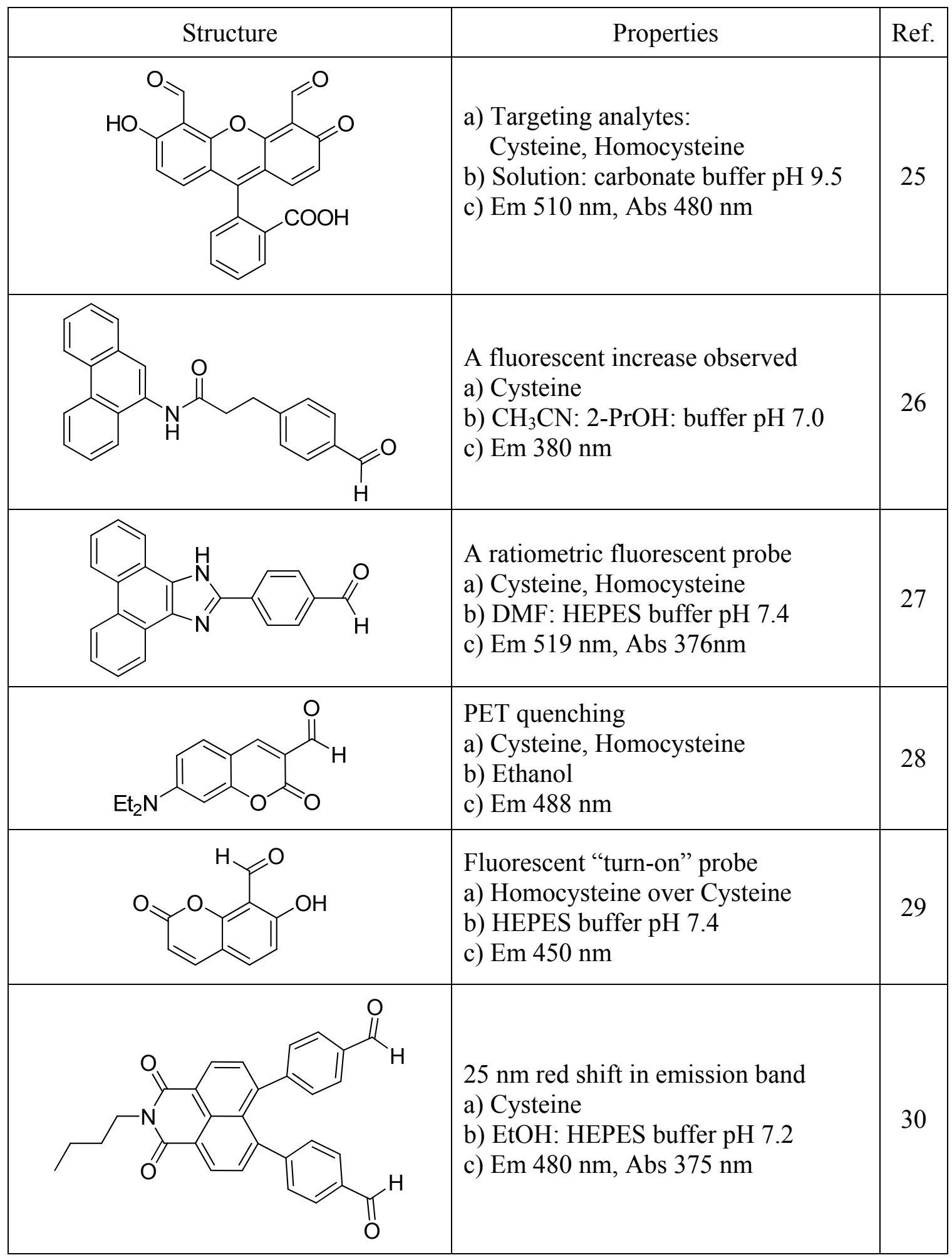

Table 2.1 Selected aldehyde functionalized fluorescent probes based on thiol cyclization. 
Qian et al. designed a 1,8-naphthylamide-based fluorescent probe for the determination of cysteine. ${ }^{30}$ The probe showed an increase in fluorescence intensity with a $25 \mathrm{~nm}$ red shift in emission (from 455 to $480 \mathrm{~nm}$ ) along with a fluorescence color change from blue to cyan. The probe was proposed as potential bioimaging indicator for cellular cysteine, and showed an intense intracellular fluorescence after $2 \mathrm{~h}$ incubation in cell culture.

\subsection{4 $\alpha, \beta$-unsaturated Aldehydes for Cysteine Detection}

In 1976 Scholz and co-works successfully investigated the reaction of cysteine with $\alpha, \beta$-unsaturated aldehydes based on the knowledge of well known reaction between thiols and saturated aldehydes or ketones. ${ }^{31} \mathrm{~A}$ decade later, the concept was turned into first colorimetric assay that cysteine reacts with cinnamaldehyde (Fig. 2.5) at $60^{\circ} \mathrm{C}$ in methanol, in presence of catalytic amounts of sulfuric acid. ${ }^{32}$ The absorption max of reaction product was observed at $587 \mathrm{~nm}$. This method has been widely used as the detection method for free cysteine in solutions and TLC tests.

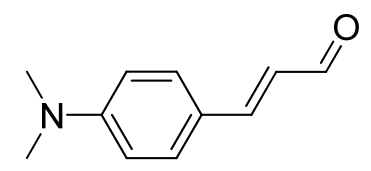

Figure 2.5 p-dimethylaminocinnamaldehyde.

Moreover, selectivity for Cys using $\alpha, \beta$-unsaturated aldehydes has been directly achieved at room temperature via visible detection. ${ }^{5}$ Non-fluorescent $p$ dimethylaminocinnamaldehyde (Fig. 2.5) exhibited high selectivity for cysteine in the presence of homocysteine with color bleaching (from yellow to colorless). This result led to the application of $\alpha, \beta$-unsaturated aldehydes appended to fluorescein, a common fluorophore. 
Unlike previous work in which the response toward thiols resulted in fluorescence quenching, ${ }^{25}$ a new fluorogenic fluorescein derivative $\mathbf{2 . 1}$ exhibits a combination of covalent and non-covalent interactions between the fluorophore and bound analyte. This generates a turn-on fluorescence response. These unique interactions result in heightened selectivity, emission, site-specific peptide and protein residue detection and amplified selectivity as a function of bound analyte complexity.

\subsection{Synthesis of an $\alpha, \beta$-unsaturated Fluorescein Monoaldehyde}

Compound 2.1 is synthesized via the Reimer-Tiemann formylation of fluorescein to afford the intermediate aldehyde followed by heating with triphenylphosphoranylidene acetaldehyde in $\mathrm{CHCl}_{3}$.

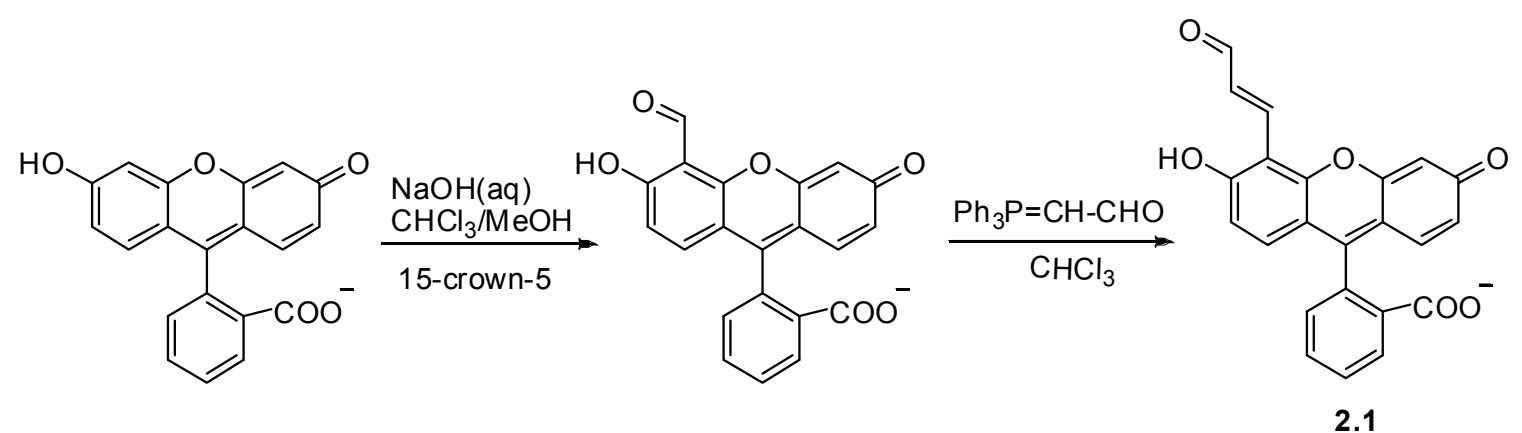

Scheme 2.1 Synthesis of Mono- $\alpha, \beta$-unsaturated Fluorescein Aldehyde 2.1.

\subsection{Results and Discussion}

\subsubsection{Conjugate Addition and Thiazolidine Formation of Cysteine}

The reaction mechanism proposed is nucleophilic attack by the Cys sulfhydril on the $\beta$-carbon of $\mathbf{2 . 1}$ followed by thiazolidine formation with a second Cys molecule via the aldehyde carbonyl (Scheme 2.2). The disappearance of the corresponding aldehyde resonances at $9.29 \mathrm{ppm}(\mathrm{d}, J=8.4 \mathrm{~Hz}, 1 \mathrm{H})$, and olefin resonances at $7.97 \mathrm{ppm}(\mathrm{d}, J=15.8$ $\mathrm{Hz}, 1 \mathrm{H})$ and $7.24 \mathrm{ppm}(\mathrm{dd}, J=8.4,15.8 \mathrm{~Hz}, 1 \mathrm{H})$ of $\mathbf{2 . 1}$, with the simultaneous appearance 
of thiazolidine resonances in the ${ }^{1} \mathrm{H}$ NMR centered at $c a .6 .72 \mathrm{ppm}$ confirms 2 equiv Cys reacted with 2.1 (Fig. 2.6). This assignment is confirmed with ESI-TOF HRMS evidence (Fig. A4 in Appendix), showing a prominent peak at $\mathrm{m} / \mathrm{z} 609.3$ (the calculated exact mass of Cys- 2.1 complex is 609.0992) representing the reaction as 2 equiv Cys with 2.1. The signal of $1: 1$ adduct at $\mathrm{m} / \mathrm{z} 488.3$ is only $10 \%$ of that of the bis-adduct.

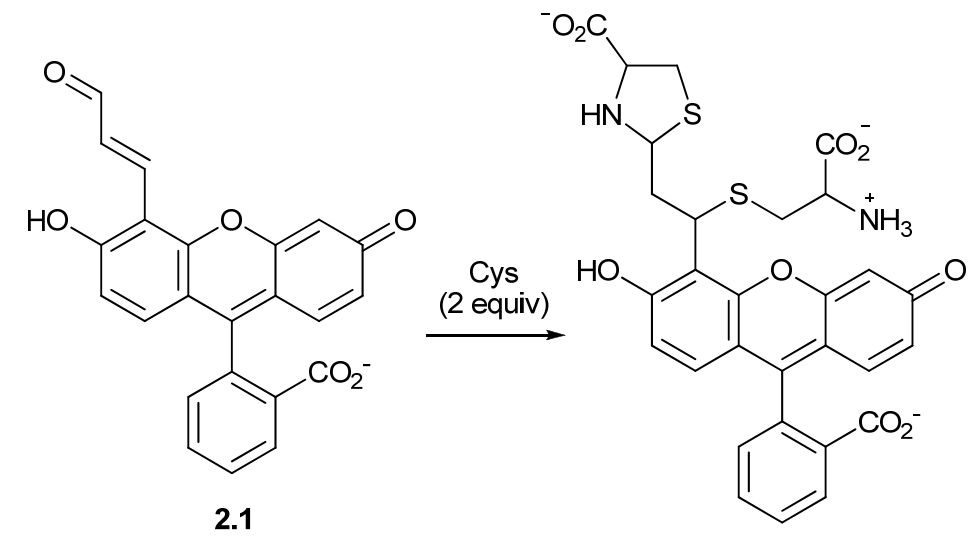

Scheme 2.2 The reaction of 2.1 with Cys (excess) in $0.1 \mathrm{M}$ phosphate buffer $\mathrm{pH} 7.4$ at rt.

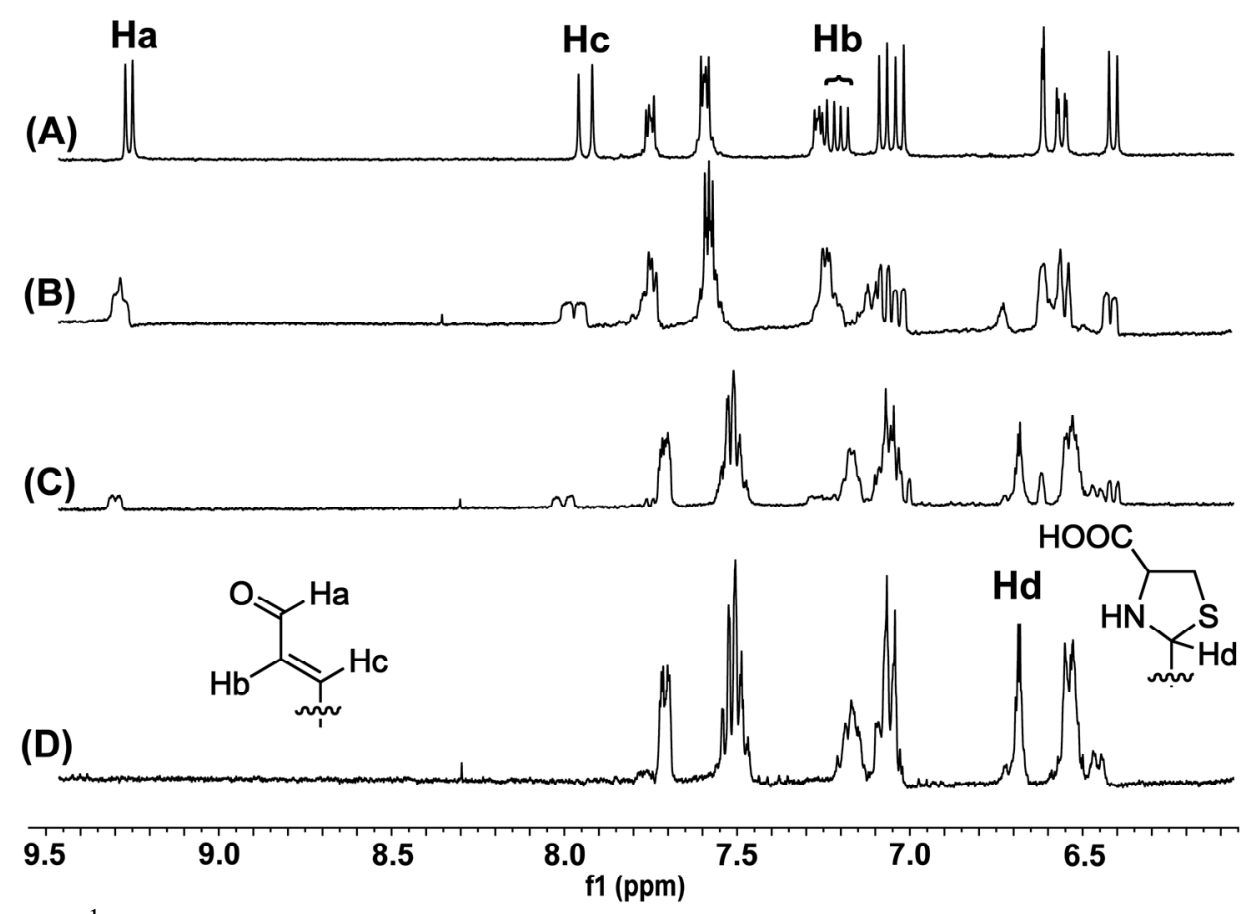

Figure 2.6 ${ }^{1} \mathrm{H}-\mathrm{NMR}$ spectra vs. times in $0.1 \mathrm{M}$ pH 7.4 phosphate buffer $/ \mathrm{D}_{2} \mathrm{O}$ 9:1; (A) compound 2.1 only; (B) 2.1 and Cys after 5 min; (C) 2.1 and Cys after 1 h; (D) 2.1 and Cys after $4 \mathrm{~h}$. 


\subsubsection{The Absorption and Fluorescence Properties of Mono- $\alpha, \beta-$ unsaturated Fluorescein Aldehyde}

The absorption properties are similar to those of typical fluoresceins. ${ }^{33}$ The fluorescein concentration is adjusted so that it has an equal absorbance to that of 2.1 at $463 \mathrm{~nm}(\mathrm{abs}=0.042)$. It is clear that epsilon values are similar with $2.1\left(\varepsilon_{501}=46981 \mathrm{~cm}^{-1}\right.$ $\mathrm{M}^{-1}$ in $0.1 \mathrm{M}$ phosphate buffer $\mathrm{pH}$ 7.4, Fig. 2.7) being slightly red shifted as compared to fluorescein (abs $\max \sim 502 \mathrm{~nm}$ ). The absorption spectra of $\mathbf{2 . 1}$ as a function of $\mathrm{pH}$ reveal an isosbestic point at $463 \mathrm{~nm}$ (Fig. 2.8).

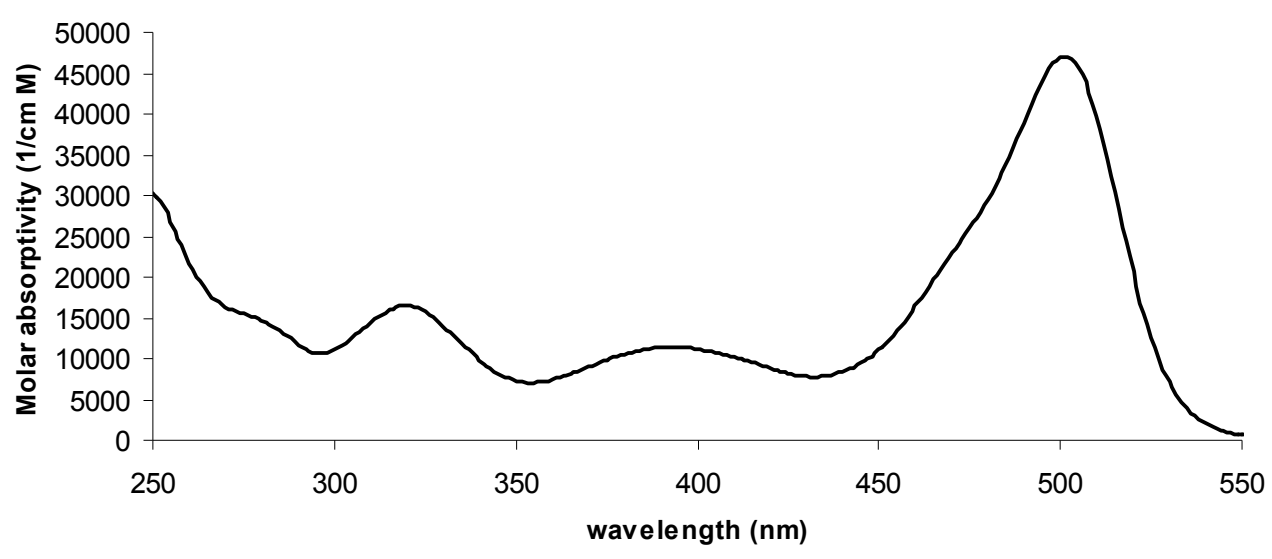

Figure 2.7 Absorption of $2.1\left(\varepsilon_{501}=46981 \mathrm{~cm}^{-1} \mathrm{M}^{-1}\right.$ in $0.1 \mathrm{M}$ phosphate buffer $\left.\mathrm{pH} 7.4\right)$.

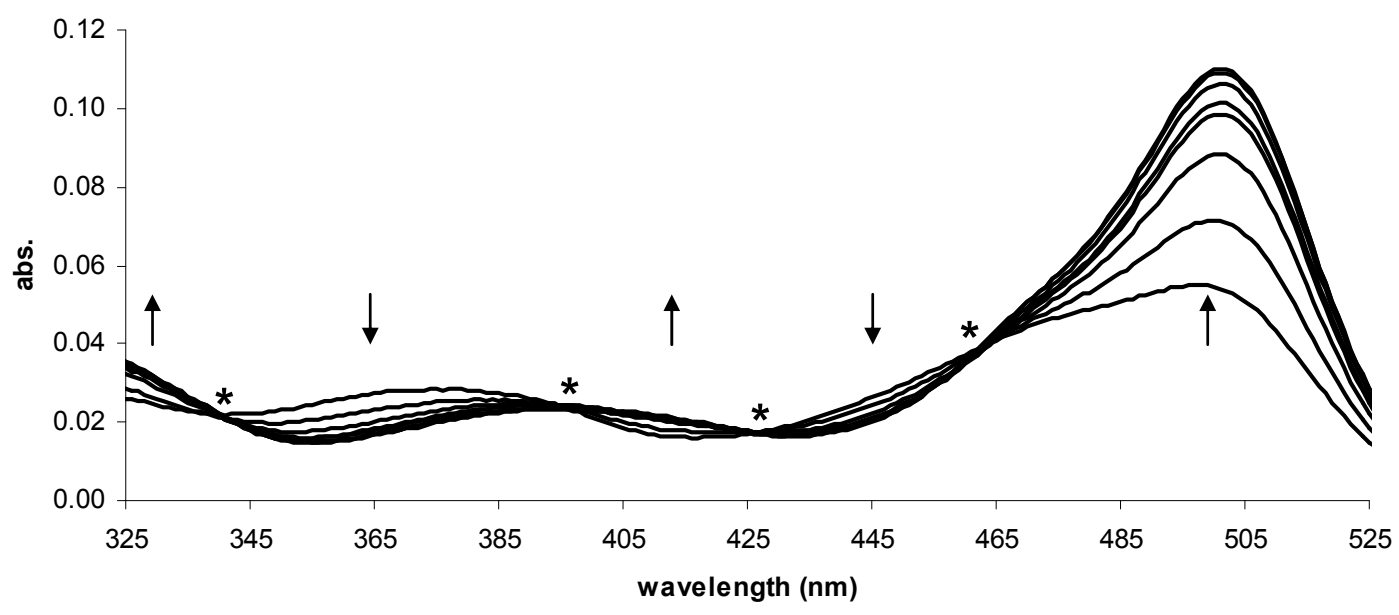

Figure 2.8 Absorption of 2.1 as a function of $\mathrm{pH}(2 \mu \mathrm{M} 2.1$ in $0.1 \mathrm{M}$ phosphate buffer $\mathrm{pH} 5.5$ - 9.0). Arrows indicate direction of change with increasing $\mathrm{pH}$. * marks the location of well defined isosbestic points at $340 \mathrm{~nm}, 396 \mathrm{~nm}, 426 \mathrm{~nm}, 463 \mathrm{~nm}$. 
In the absence of analyte, the emission of 2.1 is suppressed as compared to fluorescein as a result of the extended conjugation and electron withdrawing aldehyde, however, the spectral shape is similar (slight red shift of $<5 \mathrm{~nm}$ ). Based on the $\lambda_{\max }$ intensities, fluorescein is 23.09 times brighter than $\mathbf{2 . 1}$ (based on integrated intensities fluourescein is 16.35 times brighter). The addition of a large excess of Cys (10 $\mathrm{mM})$ to a $2 \mu \mathrm{M}$ solution of 2.1 resulted in a negligible change in absorbance at the $463 \mathrm{~nm}$ excitation wavelength (with a relatively small $20 \%$ increase in absorbance and slight 3 nm blue shift at the peak max) but restores much the fluorescence (Fig. 2.9). Therefore, the emission intensities are directly proportional to the relative quantum yields of the system. The quantum yield of $\mathbf{2 . 1}$ is calculated to be 0.054 and that of Cys with $\mathbf{2 . 1}$ reaction product is calculated to be 0.289 , as compared to fluorescein $\left(\phi_{\text {fluorescein }} \mathrm{pH} 7.4=\right.$ $0.876){ }^{33}$ under the same conditions $\left(\lambda_{\mathrm{ex}}=463 \mathrm{~nm}, 0.1 \mathrm{M}\right.$ phosphate buffer $\mathrm{pH}$ 7.4).

We optimized the fluorogenic response of compound 2.1 to Cys through investigation of the absorption and excitation properties of $\mathbf{2 . 1}$ and of its reaction product with Cys as it formed over time. In the absence of Cys, the excitation spectrum of 2.1 is blue shifted as compared to the corresponding absorption spectrum (Inset Fig. 2.10 A, $\lambda_{\max \text { abs }}=501 \mathrm{~nm}$ vs. $\lambda_{\max \text { ex }}=485 \mathrm{~nm}$ ) with a shape similar to that of the absorption spectrum of 2.1 in acidic buffer (see $\mathrm{pH}$ titration in Fig. 2.7). Interestingly, under these conditions, excitation near the absorption maximum resulted in little emission from 2.1 indicating that the major component, 2.1 with the phenol ionized $\left(\mathrm{p} K_{\mathrm{a}}=6.22\right)$, is strongly absorbing but with limited or no emission. The weak emission of 2.1 at these conditions is largely from the minor species. 


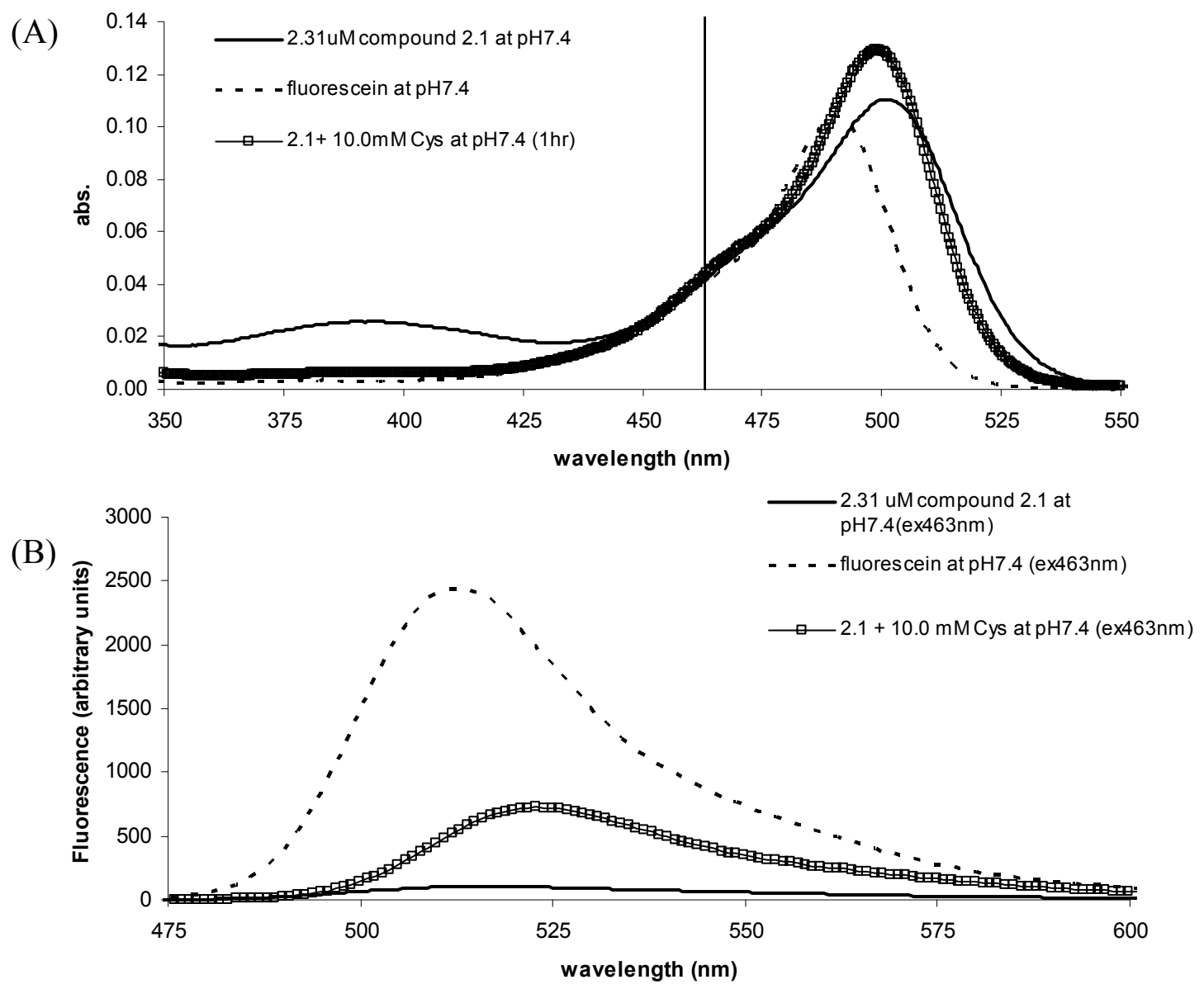

Figure 2.9 Spectral properties of fluorescein and compound $2.1\left(2.31 \times 10^{-6} \mathrm{M}\right.$ in $0.1 \mathrm{M}$ phosphate buffer $\mathrm{pH} 7.4$ ) in absence and presence of Cys (10.0 mM). (A) Absorption spectra. (B) Emission spectra excited at $463 \mathrm{~nm}$. The vertical line in (A) represents the wavelength chosen for excitation in (B). All spectra were collected at room temperature. Excitation and emission bandpass $=5 \mathrm{~nm}$.

The fluorescence intensity of the reaction product monitored over time at its 525 $\mathrm{nm}$ emission maximum increased by $\sim 41$-fold as the excitation spectra shifted to more closely resemble the corresponding absorption spectra (reaction product $\lambda_{\max \text { abs }}$ and $\lambda_{\max }$ ex from Fig. 2.10 are both $499 \mathrm{~nm}$ ). This indicates that emission of the dianion (carboxylate and phenolate both ionized) of the reaction product is not suppressed as it was for 2.1 in the absence of thiol. Differences between the absorption and excitation spectra of 2.1, combined with opposite shifts in the absorption and excitation spectra 
(blue vs. red, respectively) as the Cys reaction product formed afforded a window of excitation wavelengths wherein the fluorogenic response could be maximized. The enhancement factor increased from as little as a few fold when excited near $400 \mathrm{~nm}$ to $>40$-fold when excited near $510 \mathrm{~nm}$ (Inset, Fig. $2.10 \mathrm{~B}$ ). The optimized enhancement is much greater than the $\sim 5$-fold difference between the quantum yield of $2.1(0.054)$ and the reaction product $(0.289)$.
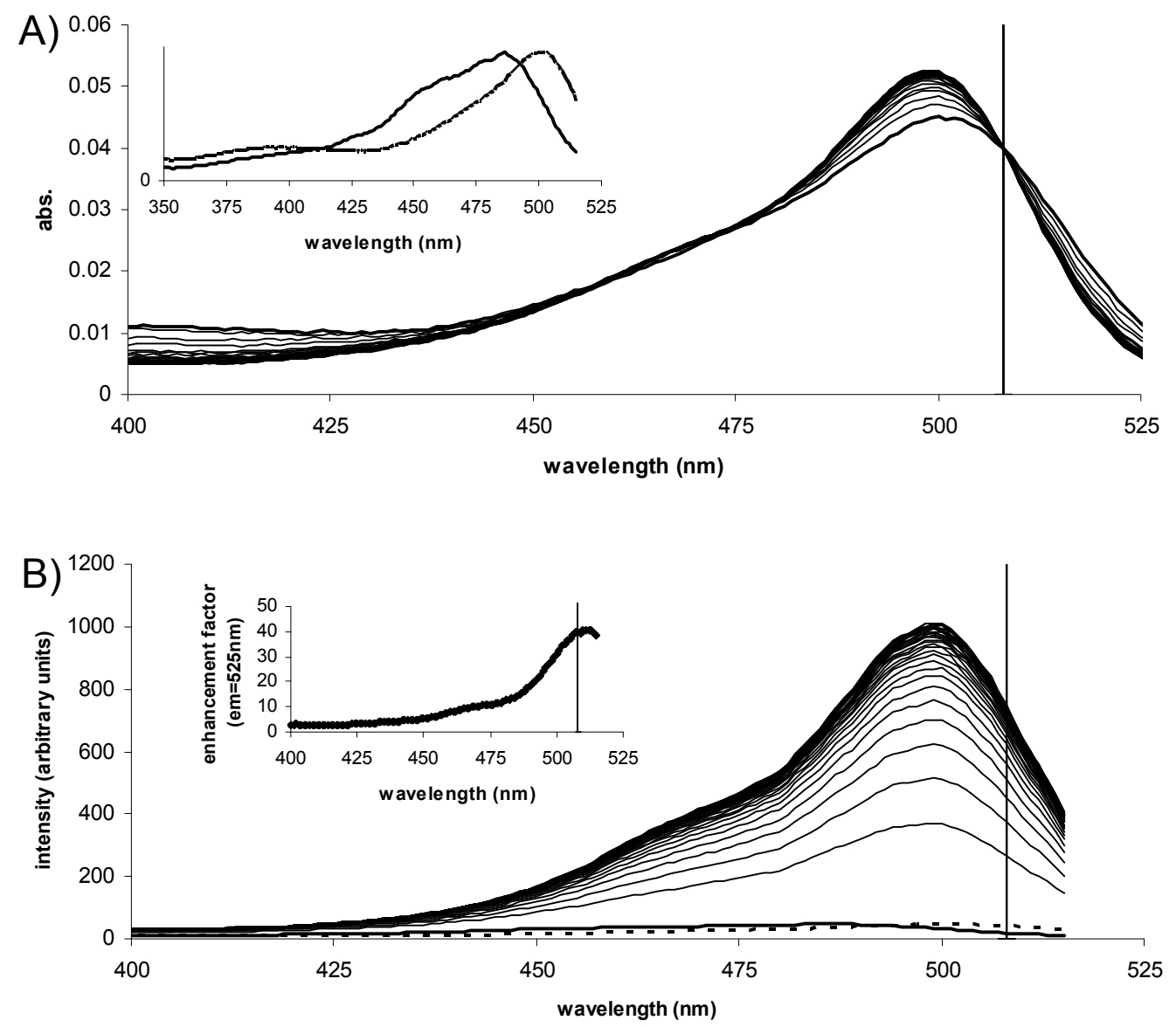

Figure 2.10 Spectral properties of compound 2.1 $\left(9.38 \times 10^{-7} \mathrm{M}\right)$ in the presence of Cys $(10.0 \mathrm{mM})$. A) absorption spectra as a function of time $(60 \mathrm{~min})$. Inset: normalized absorption and excitation spectra of 2.1. B) excitation spectra monitored at the $525 \mathrm{~nm}$ emission peak of the reaction product as a function of time $(60 \mathrm{~min})$. Inset: fluorescence enhancement factor of compound $\mathbf{2 . 1}$ as a function of excitation wavelength. Vertical lines represent the optimized wavelength of $508 \mathrm{~nm}$ chosen for excitation of all subsequent emission spectra. All spectra were collected at rt. Excitation and emission bandpass $=5 \mathrm{~nm}$. 
Interestingly, excitation wavelengths at (i) the $\lambda_{\max }$ ex of 2.1, (ii) the $\lambda_{\max }$ abs of 2.1, or (iii) within the spectral region which displayed the greatest increase in absorbance in response to Cys $(\sim 495 \mathrm{~nm})$ did not result in the greatest fluorescence intensity enhancements. Therefore, these are not the best choices for excitation wavelengths as might initially be assumed. A well-defined isosbestic point in the absorption spectra was observed at $508 \mathrm{~nm}$. Constant absorbance combined with this wavelength being (i) near the maximum in the excitation spectrum of the reaction product and (ii) in the region where the fluorescence enhancement was the largest was chosen as the excitation wavelength for all further experiments.

\subsubsection{Selective Detection of Cysteine and Homocysteine}

The fluorogenic response of $\mathbf{2 . 1}$ towards other thiols was investigated following optimization using Cys. Emission of 2.1 in the presence of various thiols $\left(\lambda_{\mathrm{em}}=524 \mathrm{~nm}\right.$ upon excitation at $508 \mathrm{~nm}$ ) demonstrated that compound $\mathbf{2 . 1}$ displayed selectivity towards specific biothiols of interest including Cys and Hcy (Fig. 2.11, see also complete emission and absorption spectra in Appendix Fig. B1). After the completed reaction, 2.1 displayed 1.43-fold selectivity for Cys over Hcy as a result of different quantum yields of the reaction products $\left(\phi_{2.1-\mathrm{Cys}}=0.289\right.$ vs. $\left.\phi_{2.1-\mathrm{Hcy}}=0.202\right)$. The Cys reaction product forms at a faster rate resulting in selectivity over Hcy as great as $\sim 2.9$-fold early in the course of the reaction (Fig. 2.11 A, Fig. 2.12, Fig. B2 in Appendix). Importantly, the response of 2.1 to Cys and Hcy was found to be linear with concentration $(100 \mu \mathrm{M}-1.0 \mathrm{mM})$. Selectivity towards Cys of greater than 2-fold was observed for concentrations as low as $100 \mu \mathrm{M}$ (Fig. 2.12) and although not yet optimized, the limit of detection for Cys was 
found to be $\sim 3$-fold lower than that of Hcy (39 $\mu \mathrm{M}$ vs. $114 \mu \mathrm{M}$ following 20 min of reaction, see Appendix Fig. B3).
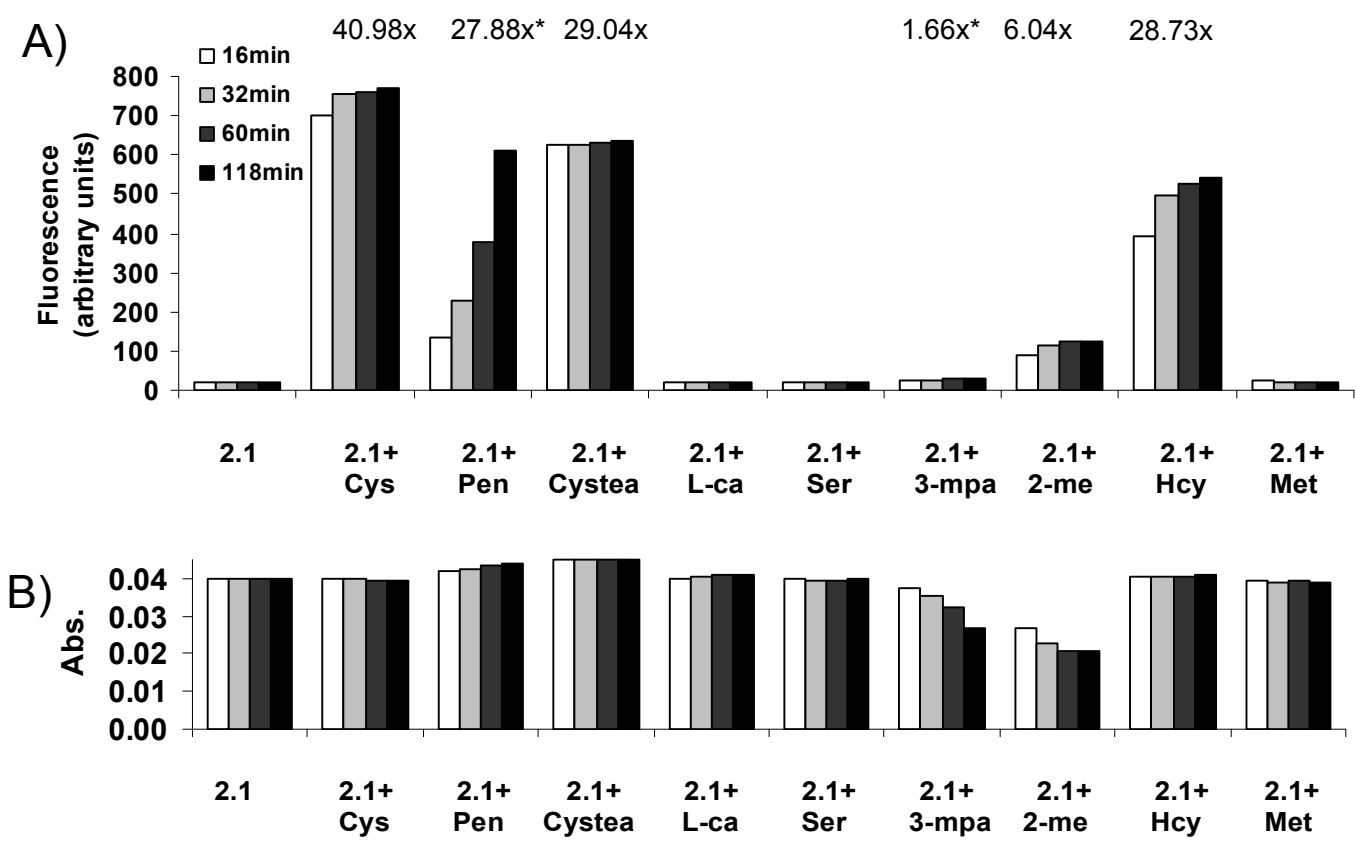

C)

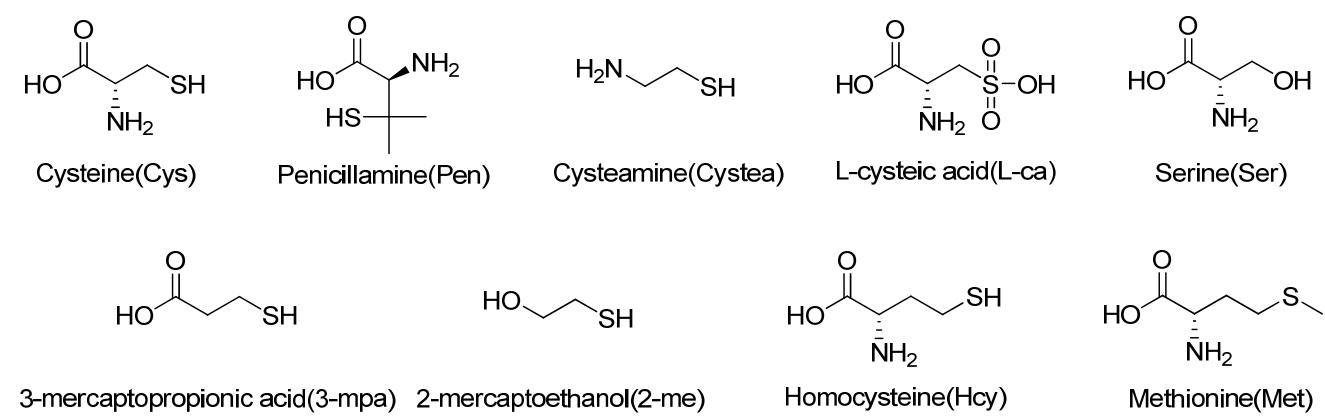

Figure 2.11 Response of compound 2.1 to thiols $(10.0 \mathrm{mM})$ of interest and their structural analogs. A) fluorescence emission at $524 \mathrm{~nm}$. B) absorbance at the $508 \mathrm{~nm}$ excitation wavelength.* Signal still increasing after $2 \mathrm{~h}$. C) Structures of targeting thiols and analogs for the mechanism study. Abbreviations: pen $=$ penicillamine, cystea $=$ cysteamine, L-ca = L-cysteic acid, 3-mpa = 3-mercaptopropionic acid, 2-me = 2mercaptoethanol.

Close inspection of Fig. 2.11 reveals that a significant fluorogenic response results only from compounds containing both a free thiol and amine in which a thiazinane or thiazolidine heterocycle could form. The mechanism behind this selectivity was 
investigated and confirmed through a series of structurally related analogs containing various functional groups and combinations thereof and through computer-assisted molecular modeling (vide infra).

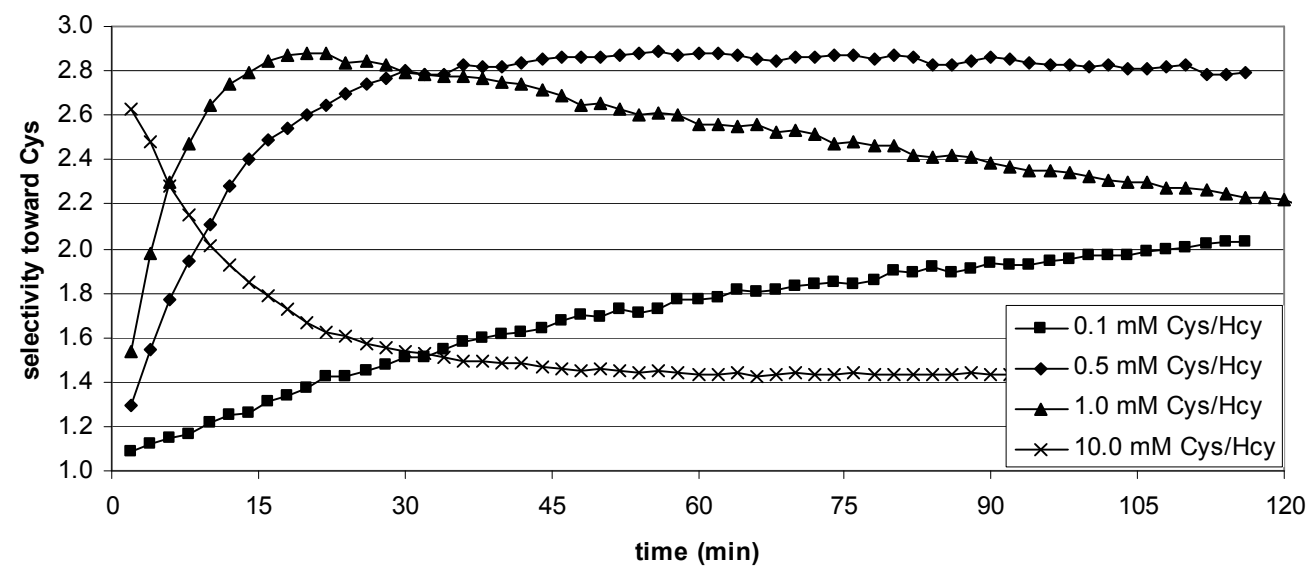

Figure 2.12 Selectivity towards Cys over Hcy. Ratio of fluorescence emission $\left(\lambda_{\mathrm{em}}=524\right.$ $\mathrm{nm}$ upon $508 \mathrm{~nm}$ excitation) of Cys and Hcy reaction products with $\mathbf{2 . 1}$ as they formed over time.

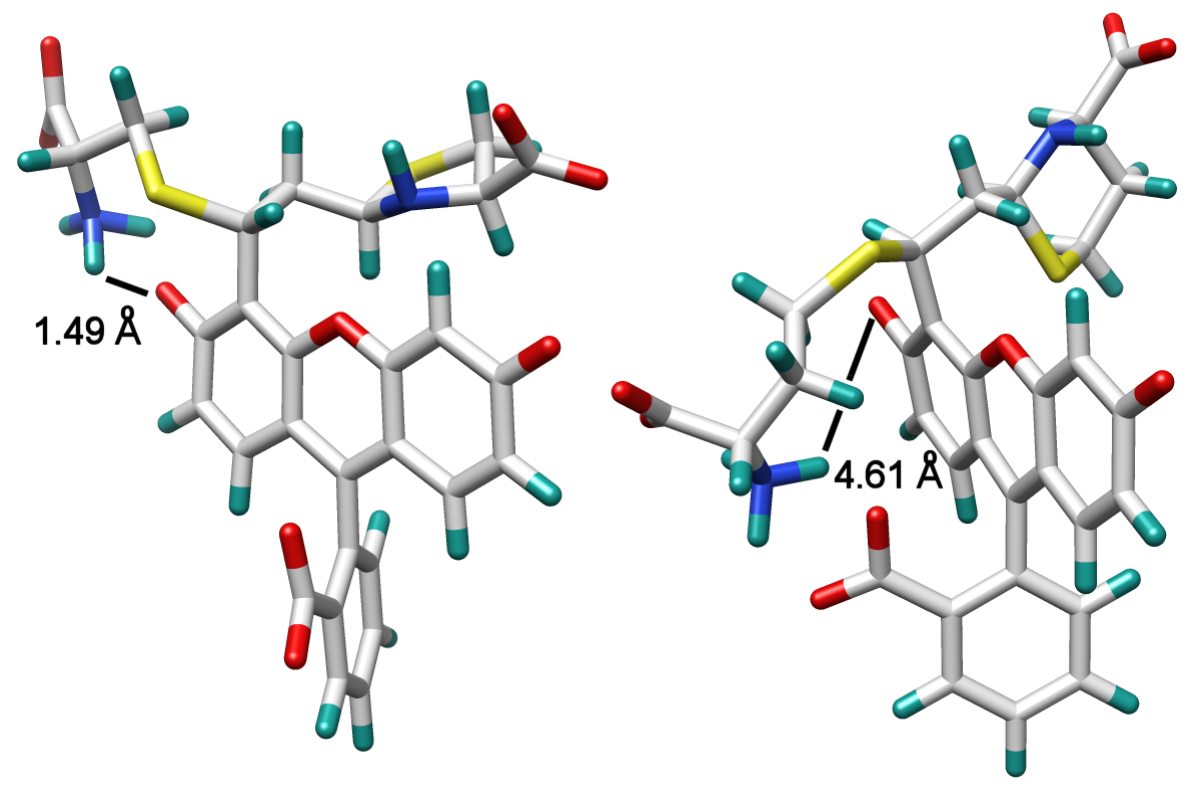

Figure 2.13 Energy-minimized structures of the reaction products of 2.1 with Cys (left) and Hcy (right) showing the distance between the $\mathrm{NH}_{3}{ }^{+}$and the phenolate groups. The electrostatic interactions between $\mathrm{NH}_{3}{ }^{+}$and the carboxylate and/or phenolate groups of 2.1 are influenced by increased ionic strength (addition of $1 \mathrm{M} \mathrm{NaCl}$ ) resulting in a corresponding decrease in selectivity toward Cys (see Appendix Figures B4-B6). 
Thiols attack the $\beta$ carbon of aldehyde 2.1, thereby restoring xanthene emission. Once formed, the covalent complexes can undergo further interaction with the chromophore thereby affording increased selectivity by affecting the ionization state of the phenolic hydroxyl. Energy-minimized simulations (Sybyl 8.0, Tripos Inc.) indicate that for amino thiols in general at neutral $\mathrm{pH}$, depending on the length of the alkyl chain, electrostatic interactions between the $\mathrm{NH}_{3}{ }^{+}$group with both the phenolate and the carboxylate moieties of $\mathbf{2 . 1}$ occur (Fig. 2.13).

In the case of Cys and Hcy there is a greater fluorescence response for the Cysadduct (Fig. 2.11, also see Appendix Fig. B1). The Cys side chain is shorter than that of Hcy, allowing the $\mathrm{NH}_{3}{ }^{+}$group to more tightly bind the xanthene phenolate oxygen rather than the carboxylate, thereby directly enhancing fluorophore ionization and emission. In contrast, the alkyl chain in Hcy is longer allowing the $\mathrm{NH}_{3}{ }^{+}$group to instead favor formation of a salt bridge with the carboxylate moiety of $\mathbf{2 . 1}$, which has a relatively minor effect on fluorophore moiety ionization (Fig. 2.13). In the case of thiols without cationic character, such as mercaptoethanol and mercatopropionate, emission is relatively lower as electrostatic interactions with the phenolate oxygen are relatively diminished. The observed trend in emission enhancement of 2.1 is thus Cys $(40.98$-fold $)>$ Hcy (28.73-fold) $>$ mercaptoethanol (6.04-fold) $>$ mercaptopropionate (1.66-fold) after complete reaction with excess thiol ( $1 \mu \mathrm{M}$ compound $2.1: 10.0 \mathrm{mM}$ thiol $)$.

\subsubsection{Site-specific Peptide and Protein Residue Detection}

The reaction of $N$-terminal cysteine residues with aldehydes has been applied to

the site-specific modification, ligation, and labeling of peptides and proteins. ${ }^{34}$ The 
selectivity of $\mathbf{2 . 1}$ for $N$-terminal cysteine-containing peptides is evidenced by observing the fluorescence emission in the presence of $N$ - and $C$-terminal dipeptides (Fig. 2.14).

In solutions containing 2.1 and Cys-Gly (an $N$-terminal cysteine dipeptide) or Glu-Cys (a $C$-terminal cysteine dipeptide), only the solution containing Cys-Gly exhibits significant fluorescence emission enhancement. A similar result is obtained for a solution of 2.1 and laminin-11 (a synthetic nonapeptide containing an $N$-terminal cysteine residue, also known as peptide 11). Laminin-11 has been used for the development of antimetastatic drugs. ${ }^{35}$ Interestingly, the reaction of $\mathbf{2 . 1}$ with $\mathrm{N}$-terminal Cys-containing peptides affords greater signal enhancement compared to simple thiols. The greatest signal enhancement of all analytes resulted from the nonapeptide (Fig. 2.14, see also complete emission and absorption spectra in Appendix Fig. B7). Previously reported functional xanthenes ${ }^{36}$ that exhibit analyte-dependent emission based on an analogous combination of supramolecular and covalent interactions between sugar-derived boronate ester complexes and a rhodamine fluorophore also exhibit significantly enhanced emission in the presence of polysaccharides as compared to mono- and disaccharides. ${ }^{37}$

We propose that this increased fluorescence from larger analytes is due to more complex non-covalent interactions and/or better shielding from solvent molecules, other fluorophores, or other potential sources of non-radiative decay including dynamic quenching by dissolved oxygen as compared to smaller analyte complexes. Further studies of the impact of probe-bound analytes on the spectral properties of fluorophores are currently underway in our laboratory. 


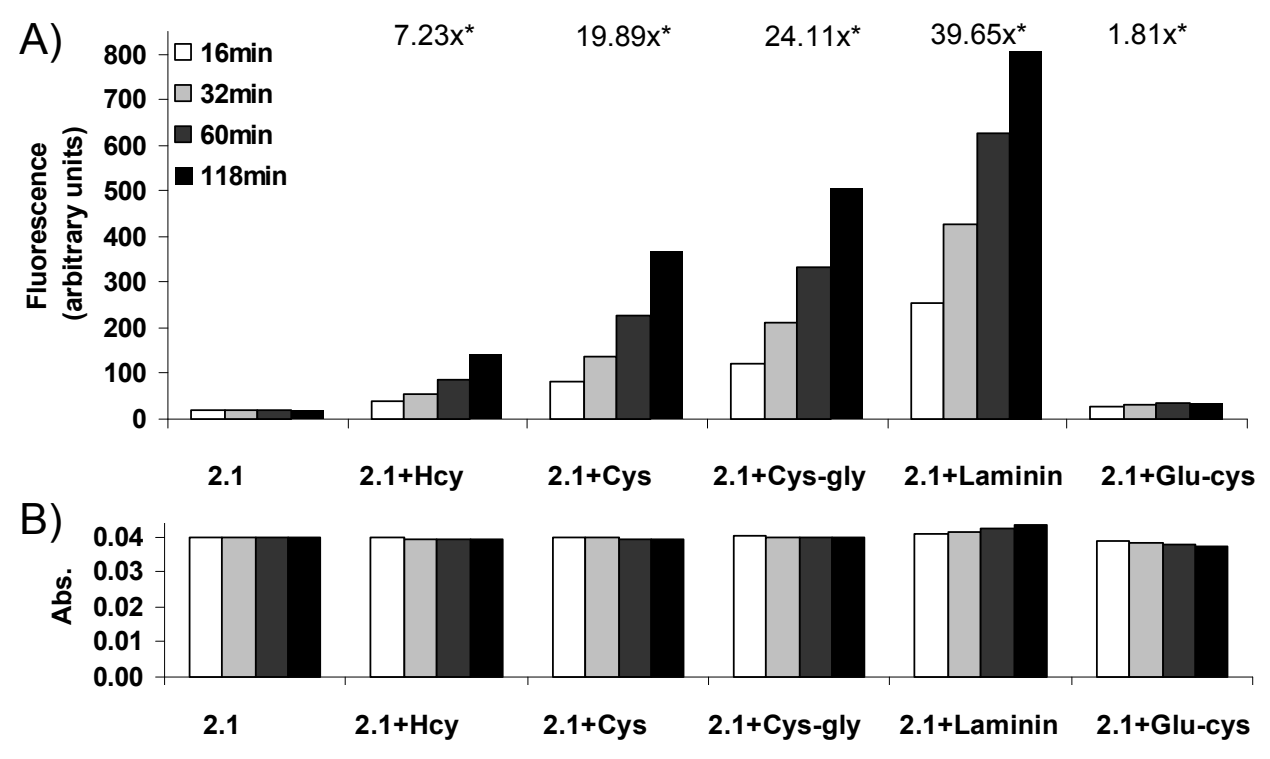

C)<smiles>NC(CS)C(=O)NCC(=O)O</smiles><smiles>NC(CCC(=O)NC(CS)C(=O)O)C(=O)O</smiles>

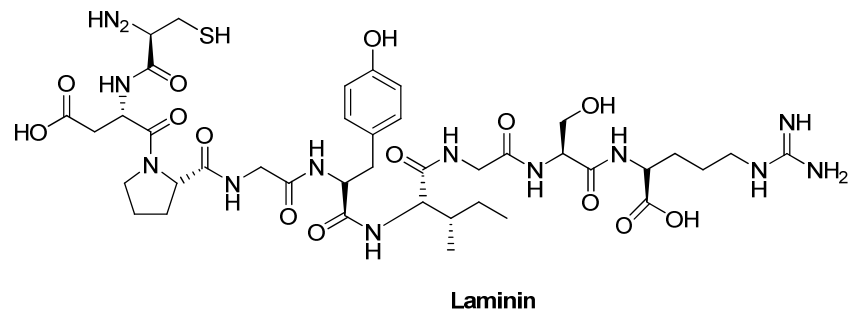

Figure 2.14 Response of compound 2.1 to thiols $(0.5 \mathrm{mM})$ and peptides $(0.5 \mathrm{mM})$ of interest. A) fluorescence emission at $524 \mathrm{~nm}$. B) absorbance at the $508 \mathrm{~nm}$ excitation wavelength.* Signal still increasing after $2 \mathrm{~h}$. C) Structures of studying peptides.

\subsection{Experimental}

- Instrumentation

All chemicals were purchased from Sigma-Aldrich and Cambridge Isotope Labs and used without further purification. NMR spectra were acquired in DMSO- $d_{6}$ or $0.1 \mathrm{M}$ pH 7.4 phosphate buffer/ $\mathrm{D}_{2} \mathrm{O}(9: 1)$ on a Bruker AMX-400 NMR spectrometer. ESIHRMS (high-resolution mass spectrometry) spectra were obtained at a Thermo Electron LTQ Orbitrap hybrid mass spectrometer and a Waters Micromass Q-TOF micro (ESI-Q- 
TOF). UV-visible measurements were collected on a UV-Vis Cary 50 and Fluorescence spectra were collected on Cary Eclipse (Varian, Inc.).

\section{- Synthesis of Fluorescein Monoaldehyde}

Fluorescein $(2.5 \mathrm{~g}, 7.75 \mathrm{mmol})$ and $3 \mathrm{~mL}$ of $\mathrm{MeOH}$ were placed in a $100 \mathrm{~mL}$

three-neck round-bottom flask and $10 \mathrm{~g}$ of a $50 \% \mathrm{NaOH}$ solution along with $0.03 \mathrm{~mL} 15$ crown-5 were added. $2.42 \mathrm{~mL}(30 \mathrm{mmol}) \mathrm{CHCl}_{3}$ was added dropwise while maintaining at $55{ }^{\circ} \mathrm{C}$ temperature. The mixture was stirred at this temperature for $5 \mathrm{~h}$. After cooling, the mixture was acidified with $10 \mathrm{M} \mathrm{H}_{2} \mathrm{SO}_{4}$ and the product precipitated. The solid was filtered and dried in vacuo overnight. Chromatography on silica gel (15:85 EtOAc:DCM) yielded a light yellow solid, $910 \mathrm{mg}$ (32.6\%). $R_{f}=0.28$ (15:85 EtOAc:DCM). ${ }^{1} \mathrm{H}$ NMR (400 MHz, DMSO- $\left.d_{6}\right) \delta(\mathrm{ppm}): 11.87(\mathrm{~s}, 1 \mathrm{H}), 10.63(\mathrm{~s}, 1 \mathrm{H}), 10.24(\mathrm{~s}, 1 \mathrm{H}), 8.01(\mathrm{~d}, J=$ $7.4 \mathrm{~Hz}, 1 \mathrm{H}), 7.77(\mathrm{dtd}, J=30.1,7.4,1.1 \mathrm{~Hz}, 2 \mathrm{H}), 7.31(\mathrm{~d}, J=7.6 \mathrm{~Hz}, 1 \mathrm{H}), 6.94(\mathrm{~d}, J=$ $8.9 \mathrm{~Hz}, 1 \mathrm{H}), 6.84(\mathrm{~d}, J=1.9 \mathrm{~Hz}, 1 \mathrm{H}), 6.70(\mathrm{~d}, J=8.9 \mathrm{~Hz}, 1 \mathrm{H}), 6.61(\mathrm{~d}, J=2.2 \mathrm{~Hz}, 2 \mathrm{H})$.

- Synthesis of Compound 2.1 ( $\alpha, \beta$-unsaturated Monoaldehyde Fluorescein)

To a solution of monoaldehyde (144 mg, $0.4 \mathrm{mmol})$ in $\mathrm{CHCl}_{3}(25 \mathrm{~mL})$, triphenylphosphoranylidene acetaldehyde $(152 \mathrm{mg}, 0.5 \mathrm{mmol})$ was added resulting in a red solution. The mixture was stirred at $50{ }^{\circ} \mathrm{C}$ under $\mathrm{N}_{2}$ for $24 \mathrm{~h}$, cooled to rt and the solvent removed in vacuo. Chromatography on silica gel (10:90 MeOH:DCM) yielded compound $2.1(94.7 \mathrm{mg}, 61.3 \%)$ as a red solid. ${ }^{1} \mathrm{H}$ NMR $(400 \mathrm{MHz}, 0.1 \mathrm{M} \mathrm{pH} 7.4$ phosphate buffer/ $\left.\mathrm{D}_{2} \mathrm{O} 9: 1\right) \delta(\mathrm{ppm}): 9.29(\mathrm{~d}, J=8.4 \mathrm{~Hz}, 1 \mathrm{H}), 7.97(\mathrm{~d}, J=15.8 \mathrm{~Hz}, 1 \mathrm{H})$, $7.78(\mathrm{dd}, J=5.7,3.3 \mathrm{~Hz}, 1 \mathrm{H}), 7.63(\mathrm{dd}, J=5.7,3.3 \mathrm{~Hz}, 2 \mathrm{H}), 7.30(\mathrm{dd}, J=5.7,3.3 \mathrm{~Hz}$, 1H), $7.24(\mathrm{dd}, J=15.8,8.4 \mathrm{~Hz}, 1 \mathrm{H}), 7.09(\mathrm{dd}, J=19.1,9.5 \mathrm{~Hz}, 2 \mathrm{H}), 6.65(\mathrm{~d}, J=2.1 \mathrm{~Hz}$, $1 \mathrm{H}), 6.59(\mathrm{dd}, J=9.2,2.1 \mathrm{~Hz}, 1 \mathrm{H}), 6.44(\mathrm{~d}, J=9.5 \mathrm{~Hz}, 1 \mathrm{H}) .{ }^{13} \mathrm{C} \mathrm{NMR}(101 \mathrm{MHz}, 0.1 \mathrm{M}$ 
pH 7.4 phosphate buffer/ $\left.\mathrm{D}_{2} \mathrm{O} 9: 1\right) \delta$ (ppm): 199.69, 180.57, 179.09, 175.00, 158.86, $157.77,157.58,147.77,139.48,132.71,131.20,131.07,130.01,129.70,129.44,128.37$, $127.11,123.93,123.17,112.61,111.77,109.68,103.51$. ESI-FTMS $m / z=385.0706$ [M$\mathrm{H}^{-}$, calc. 385.0718 for $\mathrm{C}_{23} \mathrm{H}_{14} \mathrm{O}_{6}$.

\section{- Preparation of the Reaction Product of Compound 2.1 with Thiol/Analogs}

Freshly prepared solutions of cysteine or homocysteine $(200 \mu \mathrm{M}-20 \mathrm{mM}$ in $0.1 \mathrm{M} \mathrm{pH} 7.4$ phosphate buffer) were mixed with solutions of compound 2.1 ( 2 or $4 \mu \mathrm{M}$ in $0.1 \mathrm{M} \mathrm{pH} 7.4$ phosphate buffer) in a 1:1 volume ratio at room temperature. Other thiols and analogs $(20 \mathrm{mM}$ in $0.1 \mathrm{M} \mathrm{pH} 7.4$ phosphate buffer $)$ and peptides $(1 \mathrm{mM}$ in $0.1 \mathrm{M} \mathrm{pH}$ 7.4 phosphate buffer) were mixed with solutions of compound $2.1(2 \mu \mathrm{M}$ in $0.1 \mathrm{M}$ pH 7.4 phosphate buffer) in a 1:1 volume ratio at room temperature.

\subsection{Conclusions}

We have synthesized a new fluorogenic dye that displays signal amplification in the presence of biothiols. Fluorescence signaling in the presence of analytes of interest including Cys, Hcy, and $N$-terminal cysteine peptides was observed to be in excess of 40 times that of compound $\mathbf{2 . 1}$ alone. The fluorescence intensity was directly proportional to the analyte concentration and a greater than 2-fold selectivity towards cysteine over homocysteine was achieved. Importantly, compound 2.1 did not respond to structurally similar analogs. Additionally, fluorescence resulting from the reaction of $\mathbf{2 . 1}$ and $\mathrm{N}$ terminal cysteine dipeptides and larger peptides was observed to be greater than upon reaction with simple thiols. The design of new dyes to attain specific signal transduction in the presence of bioactive analytes is ongoing.

* Reproduced by permission of The Royal Society of Chemistry http://pubs.rsc.org/en/content/articlelanding/2010/cc/c0cc01398f 


\section{CHAPTER 3. DETECTING SPECIFIC SACCHARIDES VIA A SINGLE INDICATOR}

\subsection{Introduction: Excitation-Emission Matrices (EEM)}

Fluorescence is generally measured at one excitation wavelength, and analyzed by the signal response to an analyte of interest at the corresponding emission wavelength (see Chapter 2). Typically, experimental conditions including excitation wavelengths and emission ranges are somewhat arbitrarily chosen when developing a sensor system. Excitation near the absorption maximum of a dye in buffer solution without interferences or the analyte of interest is often used. However, relying on the absorption maximum of an indicator in a simple buffer may not be optimal for attaining selectivity towards an analyte of interest. For example, the optimum excitation wavelength for fluorogenic $\alpha, \beta$ unsaturated monoaldehyde was found to be different than the maximum absorption (Chapter 2).

Changing the excitation wavelength or analyzing the data in a different emission region may improve the selectivity of the signal generation. When measuring the fluorescence of a sample at several different excitation wavelengths for several emission wavelengths, an excitation-emission matrix (EEM) is obtained. An EEM contains detailed information about samples in two-dimensional data matrices. EEMs are also used for bioprocess samples monitored both qualitatively and quantitatively. Recent and ongoing work uses this principle.

\subsection{Background}

\subsubsection{Simple Optical Indicators for Chemosensing}


The development of simple optical indicators is of great current interest for the detection of small molecule disease biomarkers. ${ }^{38}$ Selective detection is usually attributed to the distinctive interaction between the analyte and indicator or receptor. However, several indicator-biomolecule complexes may co-exist in a dynamic equilibrium. This is particularly relevant in complex natural sample matrices and wherein supramolecular or reversible covalent interactions are the basis of the analyte-selective signaling.

Although the presence of a variety of indicator-bound species may hinder selective detection, the structural differences between the various complexes may afford distinctive absorption and emission profiles, thereby potentially allowing for multiple analyte detection via a single optical indicator. Herein we describe how judicious selection of specific excitation and emission wavelengths allows one to use a single indicator dye for the tunable detection of specific saccharides. The use of wavelength switching, rather than indicator or receptor structure changes, embodies a relatively streamlined approach to chemosensing.

\subsubsection{Development of Rhodmine Boronic Acid Dye}

Xanthene dyes such as fluorescein and rhodamine derivatives are the most commonly-used fluorescent dyes due to their bright fluorescence and compatibility with common laser line excitations. Fluorescein emission generally falls in the green or yellow spectral region while some rhodamines exhibit red emission $(>600 \mathrm{~nm})$.

In 2006 the Strongin group published the first report of a rhodamine boronic acid (reversibly-covalent) indicator 3.1 (Fig. 3.1) that was more selective for ribose, adenosine, nucleosides and nucleotides (including AICAr, the commercially available 
model succinylpurine metabolite for the rare autism spectrum disorder ADSL deficiency) as compared to fructose, the compound for which typical boronic acid compounds are inherently selective. ${ }^{36}$<smiles>O=C(O)c1ccccc1CNc1ccc2c(-c3ccccc3C(=O)O)c3ccc(=NCc4ccccc4B(O)c4ccccc4)cc-3oc2c1</smiles>

3.1

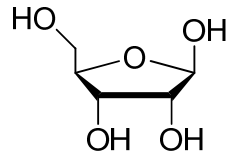

Ribose

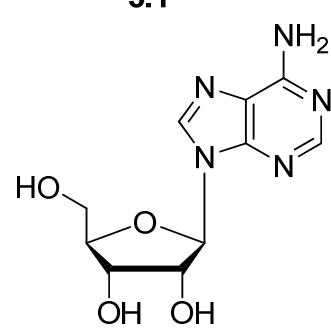

Adenosine

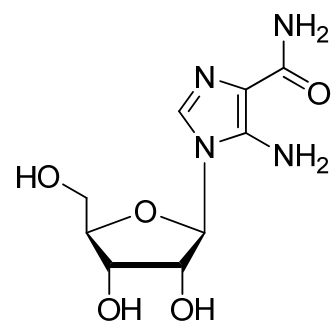

AICA-riboside

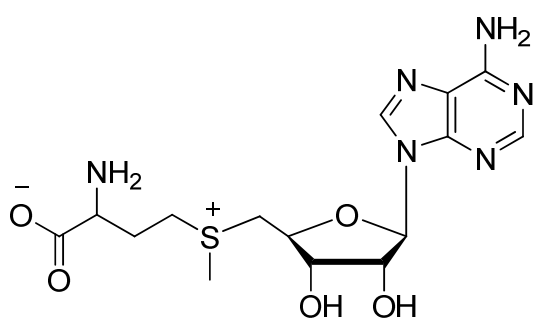

S-Adenosyl-methionine(SAM)

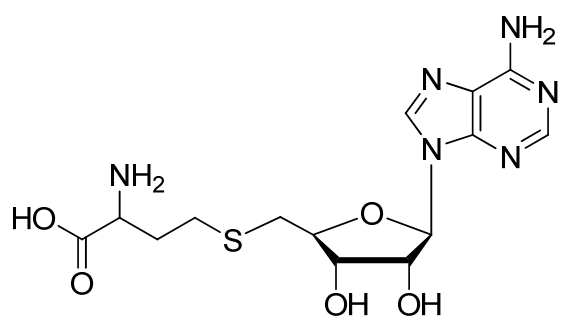

S-Adenosyl-homocysteine(SAH)

Figure 3.1 Rhodamine boronic acid 3.1 and ribose and ribose-containing target molecules.

Probing the mechanism for attaining unique selectivity towards ribose and congeners using 3.1 as a platform has been of ongoing interest in our labs. This effort is to aid the design of indicators for specific nucleosides as well as thiol-derived biomarkers ${ }^{39}$ of methylation status and oxidative stress (e.g., SAM and SAH). ${ }^{40}$

According to very strong preliminary results, as well as more recent mechanistic studies, rhodamine modified with a phenyl boronic acid can exhibit unprecedented 
affinity for ribose and similar compounds as compared to fructose. ${ }^{36}$ Computer assisted molecular simulations suggest that apart from the preference of the boronic acid to react with the 2,3-cis diol of the furanose form of ribose and the strong electrostatic interaction B--O---H-N ${ }^{+}$, non-covalent secondary interactions play an important role in modifying the ionization state of the chromophore. Charged H-bonding can occur between the nucleosides and the dye carboxylate. This is a critical feature in determining selectivity; when the carboxylate is esterified in the rhodamine boronic acid dye, it reverts to fructose selectivity (Fig. 3.2).

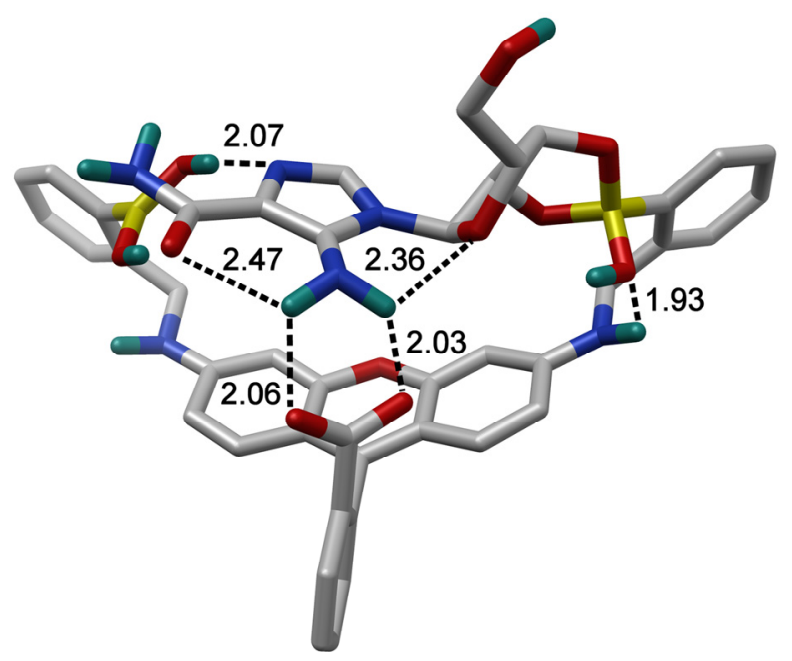

Figure 3.2 Energy-minimized model of the boronate ester formed after condensation of one equivalent of a nucleoside (AICAr) to 3.1. Color atom codes: $\mathrm{B}=$ yellow, $\mathrm{C}=$ white, $\mathrm{N}=$ blue, $\mathrm{O}=$ red, $\mathrm{H}=$ cyan. Only hydrogen atoms involved in H-bond formation are displayed for simplicity. Dashed lines represent distance in angstroms.

\subsection{Results and Discussion}

\subsubsection{Microwave Assisted Synthesis of Rhodamine Boronic Acid}

An improved synthesis of a rhodamine boronic acid indicator was developed. A one-pot microwave-assisted synthesis was used for the preparation of 3.1, in a reductive amination procedure. Conversion to 3.1 occurs with better yield (70\%) and reaction time 
(20 min compared to $>24 \mathrm{~h}$ previously). ${ }^{41}$ The one-pot microwave-assisted reaction product is purified via simple filtration rather than via the previously reported chromatographic methods (Scheme 3.1).

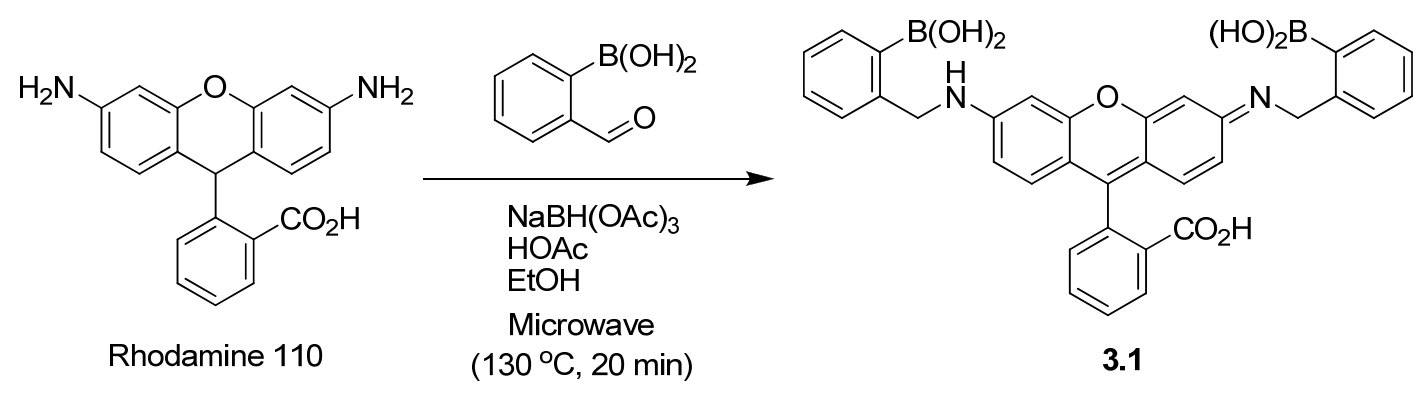

Scheme 3.1 Microwave-assisted reaction of compound 3.1.

\subsubsection{Time and Wavelength Dependent Detection of Multiple Analytes}

Previously the selectivity of rhodamine boronic acid $\mathbf{3 . 1}$ for ribose was measured via fluorescence excitation at $565 \mathrm{~nm}$. We have shown that the small non-specific interference from fructose signal in this wavelength region can be removed via the addition of non-fluorescent boronic acid derivatives. ${ }^{36}$

However, we surprisingly found wavelength-dependent selectivity of $\mathbf{3 . 1}$ for different sugars and ribosides through EEMs obtained in the excitation range from 470 to $620 \mathrm{~nm}$ and in the emission range from 520 to $690 \mathrm{~nm}$. Fructose promotes a selectively high intensity at $510 \mathrm{~nm}$, whereas AICA-riboside promotes relatively low signals (Fig. 3.3). These data are also time-dependent and display the different selectivities of $\mathbf{3 . 1}$ when monitored over time. For example, compound 3.1 responds to fructose in a different spectral region than ribose-derivatives, i.e. near $550 \mathrm{~nm}$ when excited at shorter wavelength near $510 \mathrm{~nm}$ in a time dependent manner with the peak increasing over time. When plotted as a function of time at an excitation wavelength of $510 \mathrm{~nm}$, ribose 
derivative-3.1 solutions do not exhibit significant emission responses in this region (Fig.

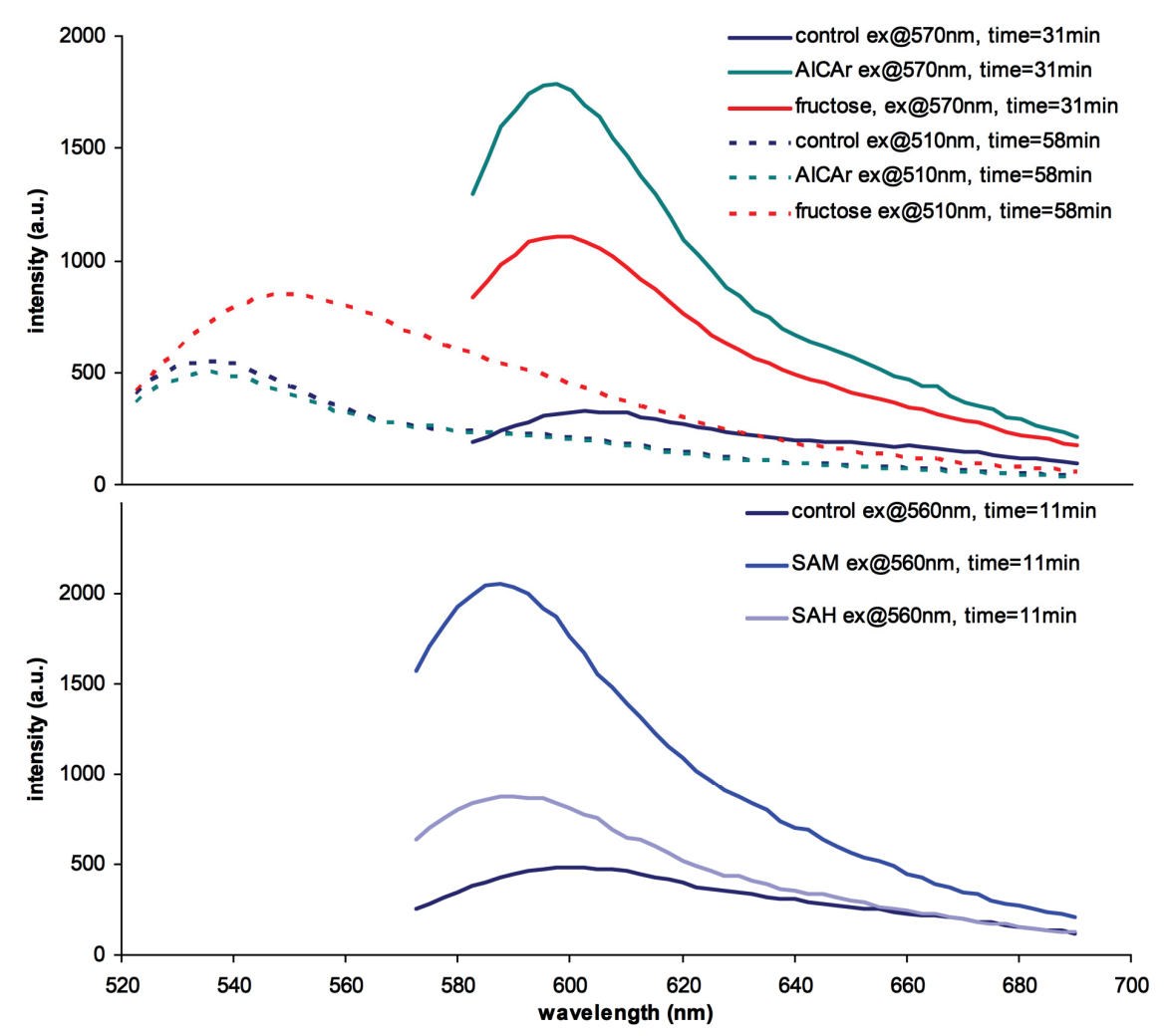

Figure 3.3 Emission spectra demonstrating selective response to various analytes. (top) Control, AICAr and fructose emission spectra at given excitation wavelengths (510 or $570 \mathrm{~nm}$ ) and times (31 or $58 \mathrm{~min}$ ) after mixing. (bottom) Control, SAM, and SAH emission spectra upon excitation at $560 \mathrm{~nm}$ and 11 min after mixing. Final concentration of 3.1 was $20 \mu \mathrm{M}$ with each analyte at a concentration of $100 \mu \mathrm{M}$ in $90 \%$ DMSO : 10\% $25 \mathrm{mM} \mathrm{pH} 7.5$ phosphate buffer. One part aqueous analyte was added to 9 parts $\mathbf{3 . 1}$ in DMSO followed by $15 \mathrm{sec}$ vortexing. EEMs were collected sequentially every 4 min for $1 \mathrm{~h}$.

Fig. 3.3 demonstrates that 3.1 displays an increased response toward both AICAr or fructose as a function of time and wavelength. It also shows the selectivity of $\mathbf{3 . 1}$ for SAM versus $\mathrm{SAH}$. The ratio of SAM:SAH is frequently used as an indicator of cellular methylation potential. ${ }^{40}$ Interestingly, SAM and SAH can be distinguished from AICAr by a wavelength shift of approximately $10 \mathrm{~nm}$ in both excitation and emission $\left(\lambda_{\mathrm{ex}}=560\right.$ $\mathrm{nm}, \lambda_{\mathrm{em}}=587.5 \mathrm{~nm}$ ) as can be seen in the contour plots of these analytes in Fig. 3.5. 

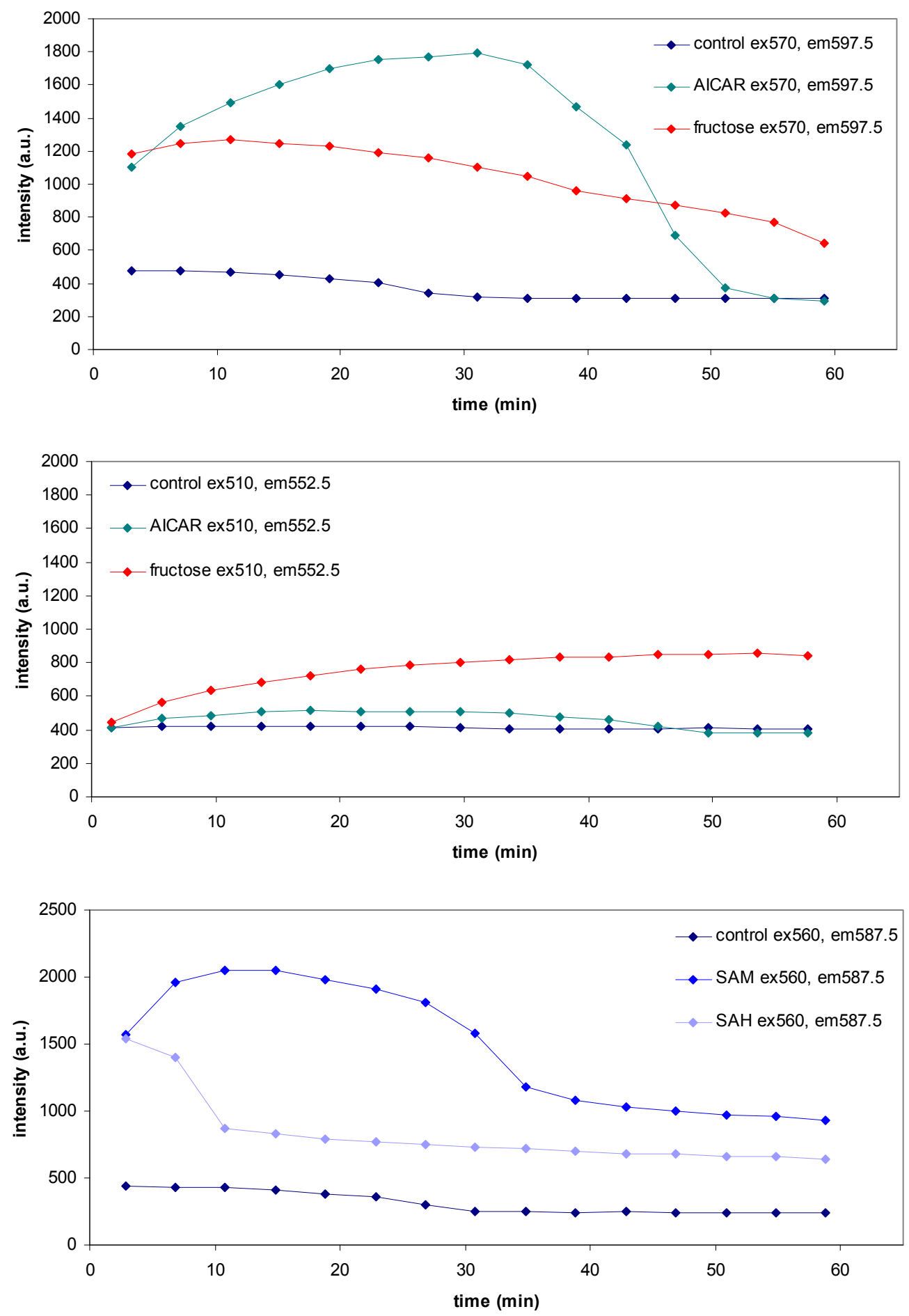

Figure 3.4 Intensity as a function of time. (top) Control, AICAr and fructose emission at $597.5 \mathrm{~nm}$ upon excitation at $570 \mathrm{~nm}$. (center) Control, AICAr and fructose emission at $552.5 \mathrm{~nm}$ upon excitation at $510 \mathrm{~nm}$. (bottom) Control, SAM, and SAH emission at 587.5 $\mathrm{nm}$ upon excitation at $560 \mathrm{~nm}$. 


\subsubsection{Multiple Analyte Detection via a Single Indicator}

Solutions of $\mathbf{3 . 1}$ containing various analytes, when monitored over time at several different excitation and emission wavelengths, afford us large multidimensional data sets specific for various analytes. Accordingly, the observation makes the specific detection of fructose, in addition to ribose derivatives, possible with this probe. Data were collected as EEMs as a function of time. From this large multidimensional data set, spectra can be extracted at a specific times or the intensity at a specific wavelength monitored as a function of time. These data provide specific analyte dependent features such as the excitation and emission wavelengths resulting in the greatest signal and the time at which this signal occurs.

A subset of this data is presented in Fig. 3.5. According to the contour plots of excitation-emission matrices (EEMs) obtained in the excitation range 470 to $620 \mathrm{~nm}$ and emission range from 520 to $690 \mathrm{~nm}$, solutions of 3.1, and 3.1 with various analytes, display patterns which are distinguishable for each analyte. There are differences in fluorescence intensity; however, there are also clearly different spectral signatures. Fig. 3.5 reveals a relatively higher emission response for the AICA-riboside and SAM as compared to fructose in the emission region near $600 \mathrm{~nm}$ when excited near $565 \mathrm{~nm}$.

The most dramatic example of time and wavelength dependent detection in using a single indicator is shown in Fig. 3.6. It is constructed simply by scanning the EEM of each solution every 4 min for $1 \mathrm{~h}$. One can visually distinguish each of the analyte-3.1 solutions qualitatively (Fig. 3.6 A). 

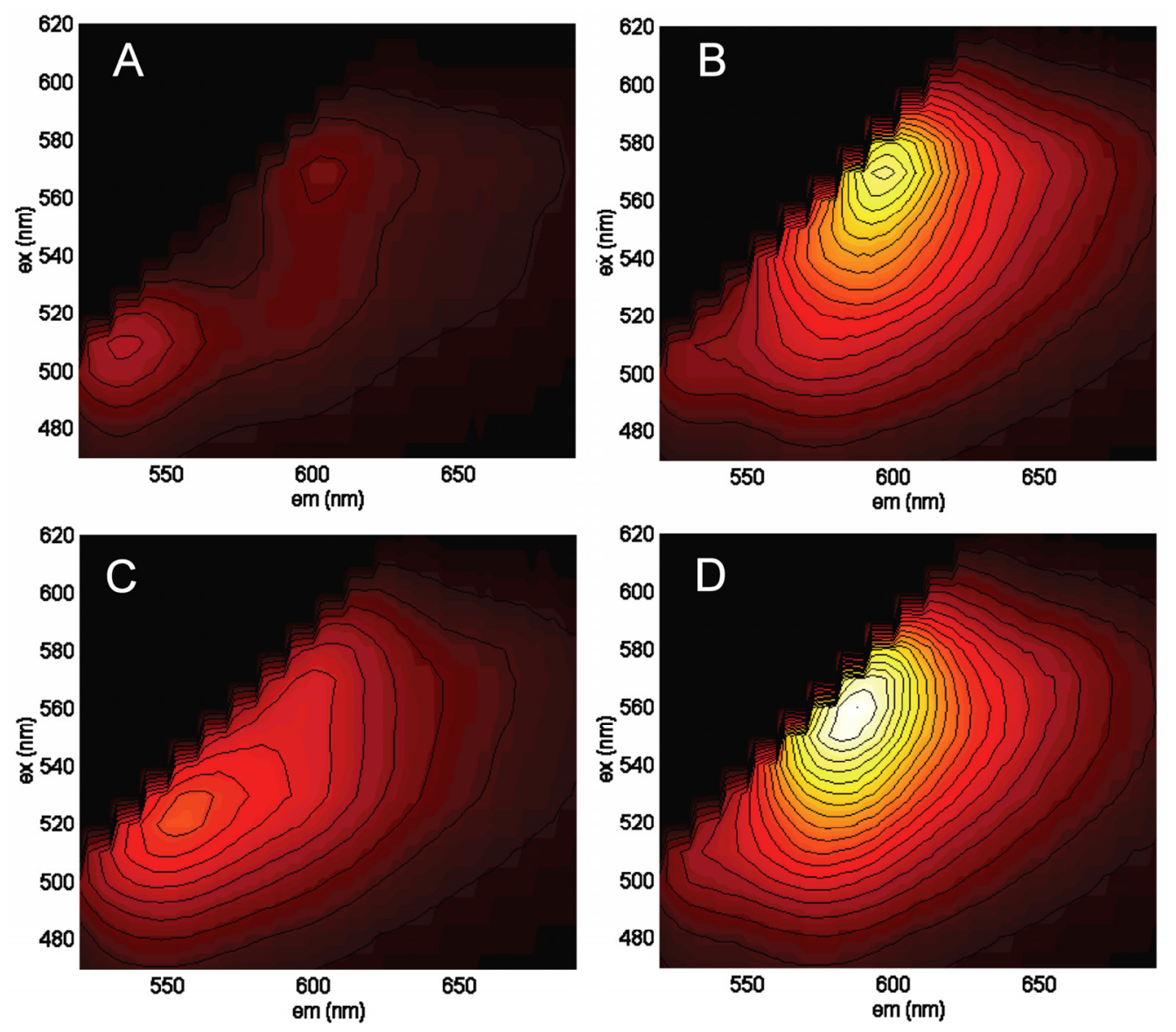

Figure 3.5 EEMs demonstrating the response of $\mathbf{3 . 1}$ towards various analytes. (A) $\mathbf{3 . 1}$ at $31 \mathrm{~min}$, (B) 3.1 plus AICAr at $31 \mathrm{~min}$, (C) 3.1 plus fructose at $58 \mathrm{~min}$, and (D) 3.1 plus $\mathrm{SAM}$ at $11 \mathrm{~min}$. The $x$-axis represents emission wavelength while the $y$-axis is excitation wavelength such that vertical and horizontal slices represent typical excitation and emission spectra respectively. Excitation and emission step sizes of $10 \mathrm{~nm}$ and $5 \mathrm{~nm}$, respectively with a bandpass of $5 \mathrm{~nm}$ for each. Fluorescence intensity is represented on the $z$-axis as various colors.

Initial results also indicate that the system will function in a more complex setting, i.e. when two analytes are present at the same time. As proof of concept, mixtures of two analytes (fructose and AICAr) were investigated. Sample mixtures enriched in either AICAr or fructose display signatures of both individual analytes but with features of the major analyte more dominant. Although the response is complicated, advanced data processing (i.e. chemometrics) should simplify interpretation. Efforts to quantify 
mixtures are ongoing. Work is also ongoing to better understand the dynamic processes including supramolecular and reversible covalent interaction involved in these unique analyte dependent signals and their changes over time. Our previous studies attributed the selectivity of the compound $\mathbf{3 . 1}$ emission upon excitation at $565 \mathrm{~nm}$ to the fact that its ribose complex can exhibit tighter binding to the fluorophore as compared to the corresponding fructose and glucose complexes. ${ }^{36}$ Simulations showed that this can occur via a charged hydrogen bond to the carboxylate moiety of 3.1. Favorable ion pairing interactions are thus likely responsible for the differences in the response of $\mathbf{3 . 1}$ toward positively charged SAM vs. neutral SAH. Energy minimization studies afford an analogous explanation for the selectivity for AICAr over fructose $(570 \mathrm{~nm}$ excitation, Fig. 3.3) that involves AICAr-3.1 extended intramolecular interactions of the aminoimidazole carboxamide moiety with both, the carboxylate oxygen and the remaining free boronic acid (Fig. 3.2). 


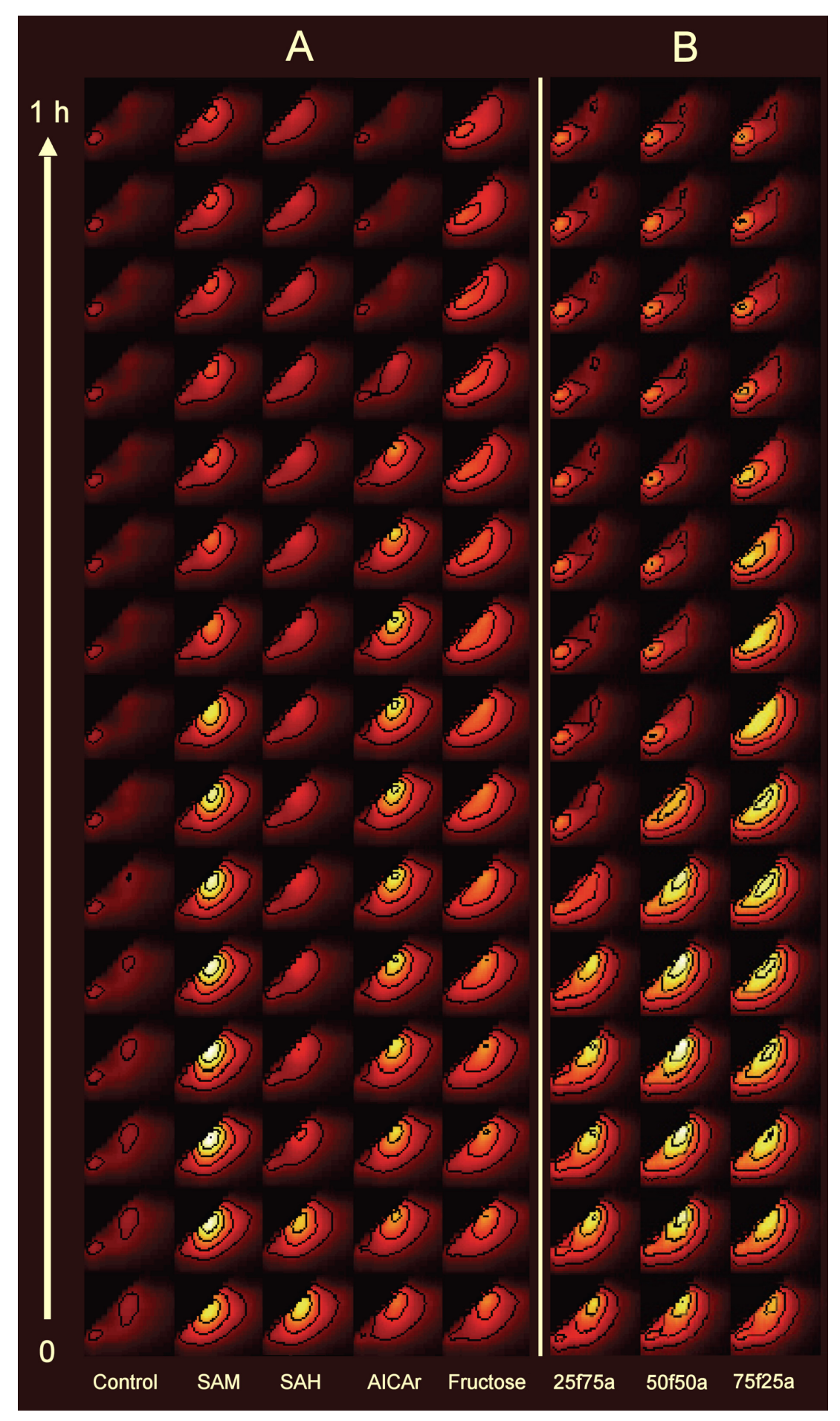

Figure 3.6 Time and wavelength dependent detection. (A) EEMs of control and 3.1 plus $100 \mu \mathrm{M}$ of analyte. (B) EEMs of $\mathbf{3 . 1}$ plus fructose and AICAr mixtures. Total concentration of each analyte mixture is $100 \mu \mathrm{M}$. The ratio of fructose to AICAr is increased toward the right as indicated. The first EEM in time is plotted at the bottom with time increasing toward the top. 


\subsection{Experimental}

- Instrumentation

All chemicals were purchased from Sigma-Aldrich and Cambridge Isotope Labs and used without further purification. Microwave synthetic procedures were performed in an Initiator ${ }^{\mathrm{TM}}$ microwave synthesizer (Biotage). NMR spectra were acquired on a Bruker AMX-400 NMR spectrometer. High-resolution mass spectrometry spectra were obtained from the Georgia State University Mass Spectrometry Facility. Absorbance spectra were collected on a Cary $50 \mathrm{UV}-\mathrm{Vis}$ spectrophotometer and Fluorescence spectra were collected on Cary Eclipse fluorescence spectrophotometer (Agilent Technologies). HPLC was carried out using a Nova Pak C18 $300 \AA, 4 \mu \mathrm{m}, 3.9 \times 150 \mathrm{~mm}$ (Waters, USA) column on a Waters 1525 Binary pump equipped with a Waters 2996 Photodiode Array Detector.

- Synthesis of Compound 3.1, Rhodamine (bis) Boronic Acid ((E)-2-(6-((2boronobenzyl)amino)-3-((2-boronobenzyl)imino)-3H-xanthen-9-yl)benzoic acid).

Rhodamine 110 (45 mg, $0.136 \mathrm{mmol}$ ), 2-formylphenyl boronic acid (100 mg, $0.667 \mathrm{mmol}$ ), sodium triacetoxyborohydride (90 mg, $0.425 \mathrm{mmol})$ and $\mathrm{CH}_{3} \mathrm{CN}(1.7 \mathrm{~mL})$ were mixed in a microwave vial (max. capacity: $2.0 \mathrm{~mL}$, Biotage) containing a magnetic stir bar. Concentrated acetic acid $(50 \mu \mathrm{L}, 52 \mathrm{mg}, 0.873 \mathrm{mmol})$ was then added and the vial sealed with a microwave proof cap (Biotage). The vial was stirred and irradiated while keeping the temperature at $130^{\circ} \mathrm{C}$ for $20 \mathrm{~min}$. The vial then cooled to $\mathrm{rt}$ and the cap removed. The reaction mixture was quenched with saturated $\mathrm{NaHCO}_{3}$ aqueous solution and extracted in EtOAc, dried with anhydrous $\mathrm{Na}_{2} \mathrm{SO}_{4}$ and filtered. The solvent was removed in vacuum to yield a dark red solid. Yield: $57 \mathrm{mg}(70 \%) .{ }^{1} \mathrm{H}$ NMR $(400 \mathrm{MHz}$, 
$\left.\mathrm{CD}_{3} \mathrm{OD}\right) \delta(\mathrm{ppm}):$, 7.52-7.65 (m, 3H), 7.36-7.48 (m, 3H), 7.06-7.35 (m, 10H), $6.69(\mathrm{~m}$, 1H), $5.90(\mathrm{~s}, 1 \mathrm{H}), 5.02(\mathrm{~s}, 4 \mathrm{H}) .{ }^{13} \mathrm{C}$ NMR $\left(101 \mathrm{MHz}, \mathrm{CD}_{3} \mathrm{OD}\right) \delta(\mathrm{ppm}) 173.02,155.33$, $134.72,133.31,132.25,131.82,131.39,131.25,130.99,130.28,129.61,128.88,128.07$, $125.18,123.96,122.19,117.40,72.33$. HRMS ESI-FTMS $m / z=599.2087[\mathrm{M}+\mathrm{H}]^{+}$, calcd. 599.2161 for $\mathrm{C}_{34} \mathrm{H}_{29} \mathrm{~B}_{2} \mathrm{~N}_{2} \mathrm{O}_{7}$.

\subsection{Conclusions}

We have developed an improved synthesis of $\mathbf{3 . 1}$ via a microwave-assisted reductive amination and an optimal data collection method for wavelength-time dependent selectivity via EEMs. The results herein show that it is possible to use such data sets to develop strategies for allowing one indicator to be used to selectively distinguish structurally related sugar analytes. The dramatic advantage of time and wavelength dependent detection is using one sensor for selectivity of multiple analytes simultaneously with saving time and materials. Further understanding the equilibria involved which lead to this wavelength dependent selectivity and better taking advantage of the tremendous amount of information contained in these large data sets are ongoing in our group.

*Reproduced by permission of The Royal Society of Chemistry http://pubs.rsc.org/en/content/articlelanding/2011/cc/c1cc11343g 


\section{CHAPTER 4. PROGRESS TOWARDS SIMPLE AND DIRECT DETECTION OF ADENYLOSUCCINATE LYASE DEFICIENCY IN HUMAN URINE}

The rhodamine boronic acid fluorophore described in the previous chapter linearly responds to increasing 5-aminoimidazole-4-carboxamide riboside (AICAr) concentrations in buffer solution. In this chapter an advance in detecting adenylosuccinate lyase deficiency in natural media, using AICAr is a model for the ADSL substrates succinyladenosine (S-Ado) and succinylaminoimidazolecarboxamide riboside (SAICAr) is described.

Adenylosuccinate lyase (ADSL) deficiency is a rare but devastating disease of de novo purine synthesis in infants. Its diagnosis is also significant as it is one of the autism spectrum disorders (ASDs). Our experience in the selective detection of sugars and ribosides has resulted in progress towards a simple test for these infants who excrete massive (mM levels), of SAICAr and S-Ado in their urine. These tests would also serve to guide development of other nucleoside and nucleotide indicators for the detection of other diseases such as cancer.

\subsection{Background}

\subsubsection{Global Demands of Simple Diagnostic Tests}

There is a global need for more simple, reliable and inexpensive diagnostic tests in patient samples. In the US and other developed nations, there is growing interest in point-of-care and personalized medicine. At a 2008 AAAS symposium entitled "HighTech, Low-Cost Medicine: A New Paradigm for Global Health,” medical practitioners and researchers emphasized that significant effort is still needed towards the creation of practical diagnostic devices. According to Whitesides, "the first-world health care system 
is too expensive. We need better ways of anticipating and forestalling disease to address the problem before it becomes something that consumes enormous resources". ${ }^{17}$ A major expected outcome of my research is new inexpensive and reliable diagnostics via creating a new class of fluorophores that function in challenging media and functionalizing the new dyes appropriately to achieve simple prototype indicators.

The current clinical chemistry technologies require significant sample preparation and handling for the analysis of complex biological samples. Sample preparation remains a big issue in simplified diagnostics. One approach receiving a great deal of current attention uses highly integrated miniaturized diagnostic devices that incorporate sample fractionation and purification components into microfluidic paper. ${ }^{42}$ However, recognition and signaling elements are often comprised of relatively fragile and expensive biological materials such as antibodies and enzymes.

The "gold standard" in user friendly diagnostics is often considered to be the home pregnancy test, which consists of lateral flow technology and a biological recognition element. There are formats wherein using biotic recognition elements are of great utility and impact. However, in general, synthetic materials are less expensive and more robust. It has been noted by Lakowicz that indicator fluorophores for specific biomarkers which may function directly in the analyte's medium without sample handling or separation steps require "fewer manipulations, resulting in fewer sources of error, shorter times to results, and reduced health hazards due to the handling of samples" ${ }^{43}$ However, surprisingly little progress has been made in this area. A goal of this project is to create useful new prototype disease indicators which function in 
complicated sample matrices with minimal sample preparation for use in settings that do not require highly trained personnel or elaborate equipment.

\subsubsection{Adenolosuccinate Lyase (ADSL) Deficiency}

Devastating inborn errors of purine metabolism such as adenolosuccinate lyase (ADSL) deficiency are very serious disorders that are generally under-diagnosed. According to a very recent (2009) review, ${ }^{44}$ genetic defects in purine and pyrimidine (PP) metabolism may often be misdiagnosed or remain undiagnosed. Dysfunction in PP metabolism may affect any system in a variety of manners, and often mimic other, more recognizable disorders. If undiagnosed, these disorders can be devastating to patients and their families, resulting in early death or institutionalization for the rest of the patient's life.

ADLS deficiency is a rare (approximately 1 in 200,000) inborn error of purine metabolism first reported in 1984 in a group of children patients with hereditary psychomotor retardation, autism and seizure. ${ }^{6}$ Manifestations include mental retardation, congenital blindness, epilepsy, and dysmorphism. It is recommended that routine screening for ADSL deficiency be done in all cases of psychomotor retardation, and in neurologic disease with convulsions and hypertonia. ADSL deficiency can be an underdiagnosed metabolic disorder which should be included in the screening program of metabolic investigations, in all infants with unexplained neonatal seizures, severe infantile epileptic encephalopathy, developmental delay, hypotonia, and/or autistic features. ${ }^{45}$ This disorder is characterized by urinary excretion of succinyl-5-amino-4imidazolecarboxamide riboside (SAICAr) and succinyladenosine (S-Ado), the nucleosides corresponding to SAICA-ribotide (SAICAR) and adenylosuccinate. 


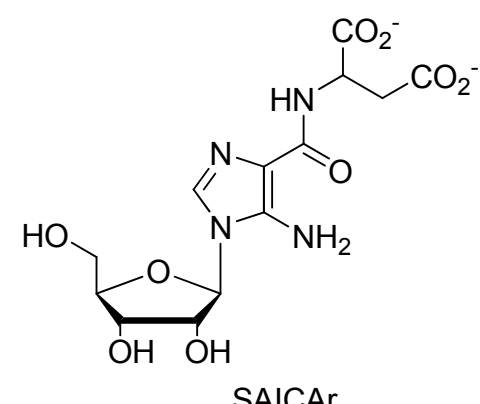

SAICAr

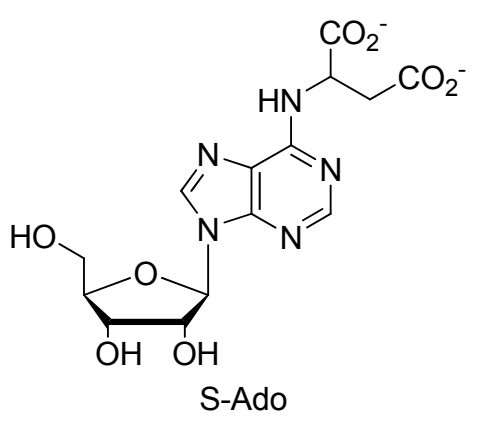

S-Ado

Figure 4.1 ADSL deficiency biomarker SAICAr and S-Ado.

Initially testing for ADSL deficiency via SAICAr and S-Ado identification relied on separations since the Bratton-Marshall test is a non-specific reaction leading to a high rate of false positives. TLC has most recently been used $^{46}$ and recommended ${ }^{6}$ as a simple screening method for these metabolites; however, it relies on the Pauly reagent for spray visualization. The Pauly reagent is diazotized sulfanilic acid. It has been noted as explosive, and needs fresh preparation prior to use. It is thus not amenable to point-ofcare or personalized medicine, and necessitates analyte separation. We propose developing stable and selective reagents for SAICAr and S-Ado that will function in urine and not require separations. The hypothesis is benzoxanthene dyes functionalized with covalent and supramolecular binding sites targeted for specific nucleosides can serve as simple indicators for adenylosuccinate lyase deficiency.

\subsection{An Application of Multidimensional Measurements to Biological Media}

Multidimensional fluorescence measurements have been widely used in clinical analysis, ${ }^{47,48}$ food science, ${ }^{49}$ and environmental analysis. ${ }^{50}$ Excitation-emission matrices (EEMs) in which the fluorescence response of a sample is monitored at multiple emission wavelengths upon excitation at multiple different wavelengths have a greater information content as compared to more conventional emission spectra collected upon excitation at a 
single wavelength. This greater information content allows for characterization or determination of substances in complex multi-component mixtures or samples in biological media with a complex background, i.e. methotrexate in urine, ${ }^{47}$ or salicylate in plasma samples. ${ }^{48}$

Previously we employed the multidimensional nature of fluorescence in the detection of multiple disease biomarkers using a single indicator via an optimized data collection protocol which scanned EEMs monitoring the indicator's time- and wavelength dependent response every 4 min for $1 \mathrm{~h}$ (Chapter 3 ). Upon further investigation it was discovered different biomarker analytes displayed distinct time- and wavelengthdependent spectral features. For example, the indicator was shown to simultaneously respond to both fructose and a ribose nucleoside (5-aminoimidazole-4-carboxamide riboside) in mixtures with the response of each occurring in characteristically different spectral regions (Chapter 3). This raises the possibility of detecting an important ribosecontaining biomarker in more complex biological media containing many potential interferences.

\subsection{Results and Discussion}

Herein we investigate the feasibility of using $\mathbf{3 . 1}$ for the detection of 5aminoimidazole-4-carboxamide riboside (AICAr) in human urine. AICAr is a dephosphorylated form of AICAR (AICA-ribotide, also known as ZMP) that is biomarker of purine biosynthetic pathway disorder, AICA-ribosiduria. ${ }^{51}$ It is also a commercially available surrogate of succinyladenosine (S-Ado) and SAICAr which accumulate at extremely high $\mathrm{mM}$ levels in urine of adenylosuccinate lyase (ADSL) deficient patients. ${ }^{52}$ Some chromatographic techniques such as TLC, GC-MS or HPLC 
are currently used for detection, ${ }^{44}$ but simple and improved methods to detect elevated level of S-Ado and SAICAr at physiologically relevant concentrations (mM in ADSL deficient as compared to undetectable levels in that of healthy groups) directly in urine of potentially ill patients without the need for separations or sample processing are desired.<smiles>O=C(O)c1ccccc1CN=c1ccc2c(-c3ccccc3[B]O)c3ccc(NCc4ccccc4Br)cc3oc-2c1</smiles>

3.1<smiles></smiles>

AICAr

Figure 4.2 Rhodamine boronic acid 3.1 and AICAr.

Rhodamine boronic acid 3.1 responds to increasing AICAr concentrations with increased fluorescence emission near $590 \mathrm{~nm}$ upon excitation in the region of 560-570 nm (Fig. 4.3). Increasing concentrations of buffered aqueous AICAr solutions were added to DMSO solutions of 3.1 such that the final solvent composition was 90\% DMSO: 10\% $25 \mathrm{mM}$ pH 7.5 phosphate buffer with a final dye concentration of $40 \mu \mathrm{M}$ and AICAr ranging from $0-200 \mu \mathrm{M}$. It is clear the fluorescence intensity increased linearly as the concentration of AICAr increased. Regression analysis (inset Fig. 4.3 D) of Intensity vs. AICAr concentration yielded a straight line $\left(y=5.1822 x+66.453 ; R^{2}=0.983\right)$ with a limit of detection of $\sim 20 \mu \mathrm{M}$, three orders of magnitude below SAICAr and S-Ado concentrations in the urine of ADSL deficient patients. 


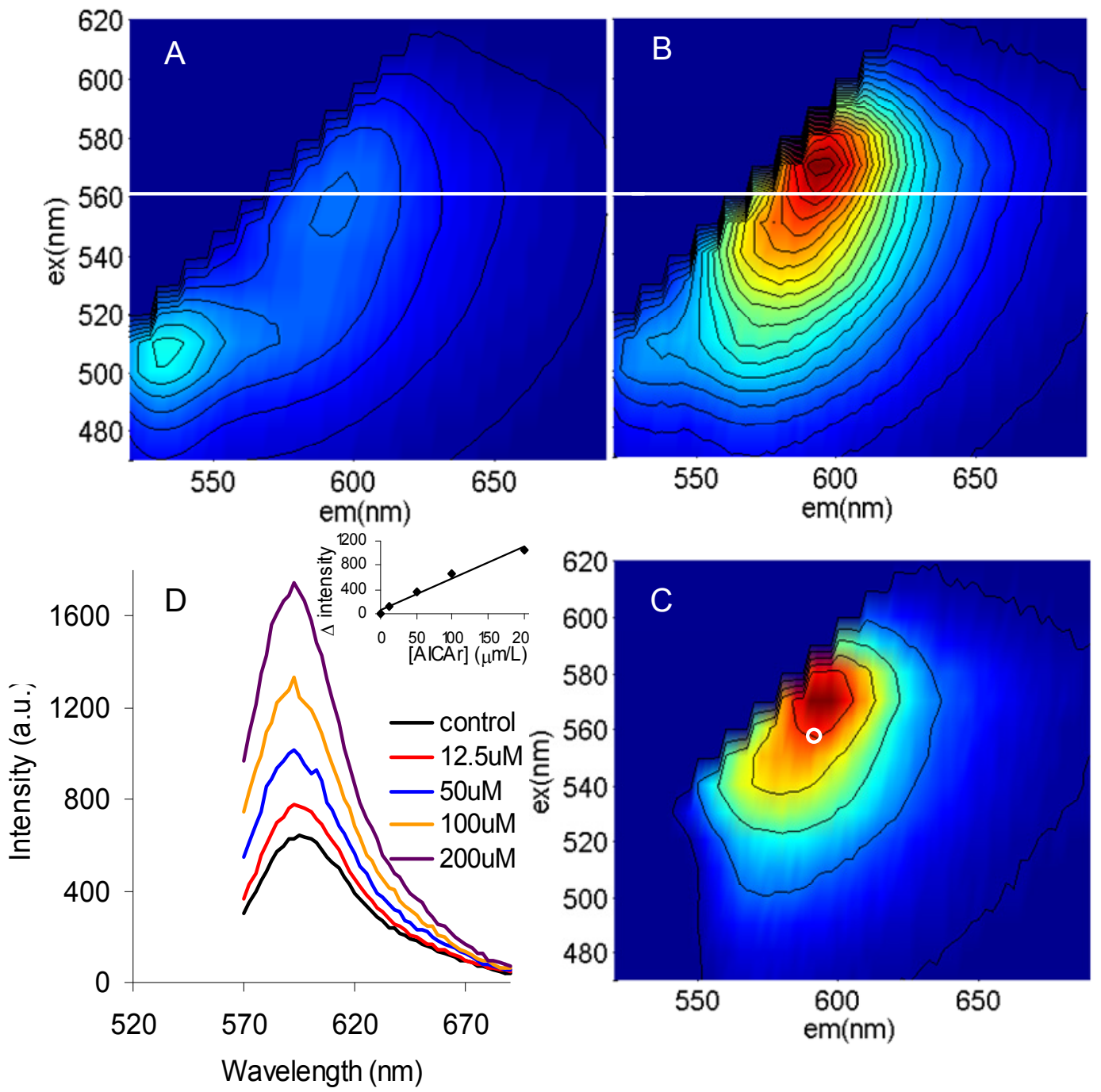

Figure 4.3 EEMs and emission spectra demonstrating the responses of $\mathbf{3 . 1}$ to AICAr at 8 min after mixing in a simple $10 \%$ buffer: $90 \%$ DMSO solvent system. Clockwise from top-left: (A) $40 \mu \mathrm{M}$ 3.1, (B) 3.1 plus $200 \mu \mathrm{M}$ AICAr, (C) $\Delta$ Intensity, B minus A, (D) emission spectra as a function of AICAr concentrations when excited at $560 \mathrm{~nm}$ and linear regression (inset). White lines in $\mathrm{A}$ and $\mathrm{B}$ represent the excitation wavelength and emission range for spectra plotted in $\mathrm{D}$. White circle in $\mathrm{C}$ represent the data point used for the regression analysis in $\mathrm{D}$.

3.1 also responds to increasing AICAr in a biological matrix, i.e. human urine (Fig. 4.4). Because (i) the limit of detection for AICAr in an ideal solvent system containing no interferences is much lower than required, and (ii) urine contains many potential interferences and possible quenchers of the fluorescence signal which makes it a 
difficult matrix to work in, diluted samples containing $5 \%$ human urine were chosen as a starting point for investigation in this proof of concept. It is clear from Fig. 3a that the indicator responds strongly in the short wavelength region (emission near $540 \mathrm{~nm}$ upon excitation near $510 \mathrm{~nm}$ ) to unidentified interferences present in the urine sample. This region, however, is far removed from the spectral region where the indicator responds to AICAr (emission near $590 \mathrm{~nm}$ upon excitations in the region of $560-570 \mathrm{~nm}$ ). It is interesting to note that response in the short wavelength region is similar to that which was previously reported for fructose. ${ }^{4}$ Comparison of Fig. 4.4 A and 4.4B demonstrates increased in long wavelength emission for an AICAr-spiked urine sample. Intensity plots (Fig. $4.3 \mathrm{C}$ and $4.4 \mathrm{C}$ ) are very similar in shape for the system containing only buffer and that containing urine and its associated interferences.

When increasing concentrations of buffered aqueous AICAr solutions were combined with healthy human urine and added to DMSO solutions of $\mathbf{3 . 1}$ such that the final solvent composition was 90\% DMSO: $5 \% 25 \mathrm{mM} \mathrm{pH} 7.5$ phosphate buffer: $5 \%$ urine with a final dye concentration of $40 \mu \mathrm{M}$ and AICAr ranging from $0-200 \mu \mathrm{M}$, the longer wavelength fluorescence signal was observed to increase. Regression analysis (inset Fig. 4.4 D) of $\Delta$ Intensity vs. AICAr concentration in the long wavelength region yielded a straight line $\left(y=0.5557 x+8.8252 ; \mathrm{R}^{2}=0.982\right)$. The short wavelength region was not sensitive to the addition of AICAr (Fig. 4.4 E). Concentrations noted in Fig. 4.4 correspond to AICAr levels above undiluted healthy urine ranging from $0.25-4.0 \mathrm{mM}$. A similar detection limit of $\sim 20 \mu \mathrm{M}$ was observed which corresponds to detecting 0.4 mM AICAr above that of healthy human urine. 

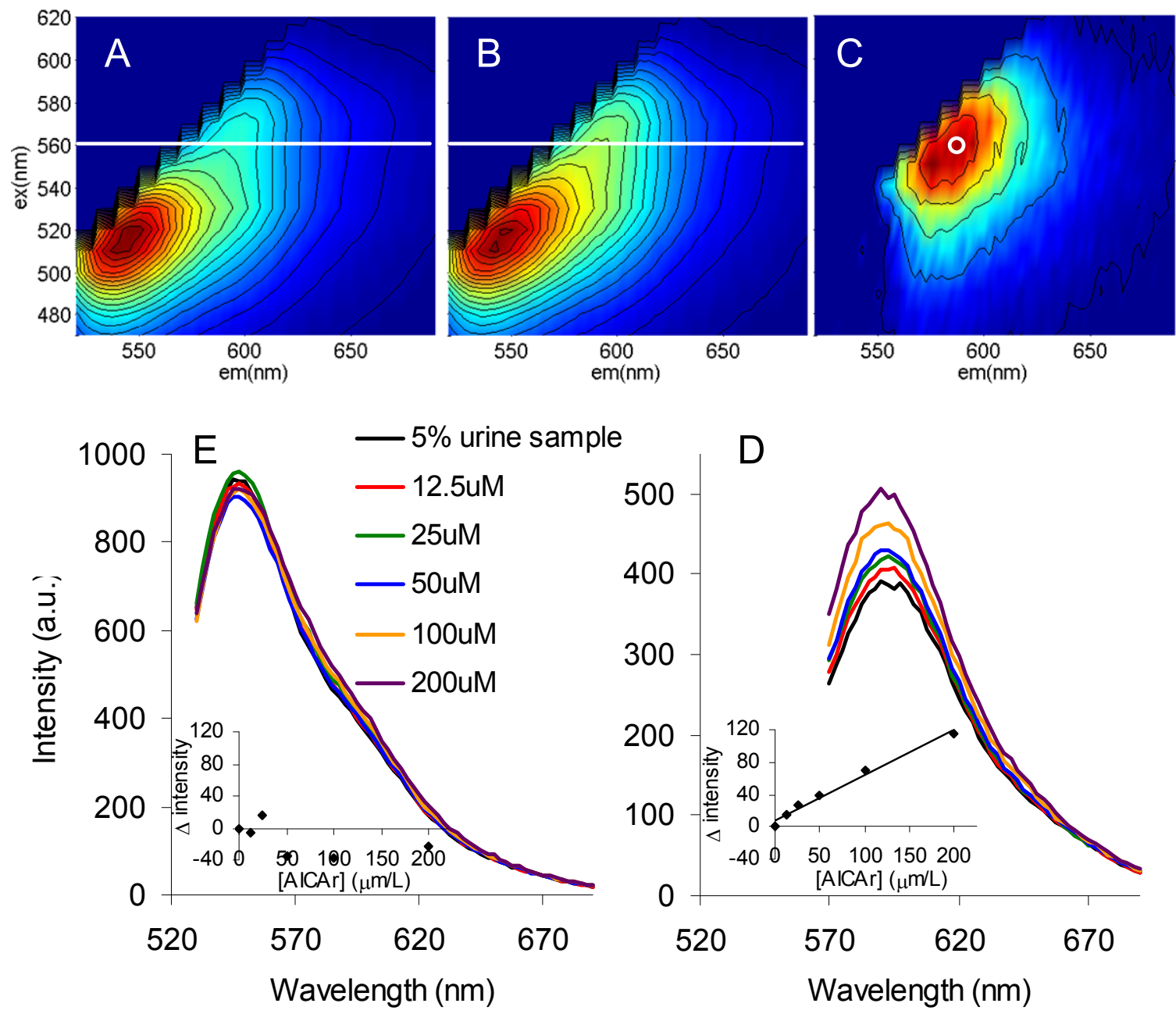

Figure 4.4 EEMs and emission spectra demonstrating the responses of 3.1 to AICAr at 20 min after mixing in 5\% healthy human urine: 5\% buffer: $90 \%$ DMSO. Clockwise from top-left: (A) $40 \mu \mathrm{M}$ of $\mathbf{3 . 1}$ in presence of 5\% urine, (B) $\mathbf{3 . 1}$ in presence of $5 \%$ urine plus $200 \mu \mathrm{M}$ AICAr, (C) $\Delta$ Intensity, B minus A, (D) emission spectra as a function of AICAr concentrations when excited at $560 \mathrm{~nm}$ and linear regression (inset). (E) emission spectra as a function of AICAr concentrations when excited at $520 \mathrm{~nm}$. White lines in A and $\mathrm{B}$ represent the excitation wavelength and emission range for spectra plotted in $\mathrm{D}$. White circle in $\mathrm{C}$ represent the data point used for the regression analysis in $\mathrm{D}$.

These results provide a method to screen for elevated AICAr in a urine sample without the need for separation or sample processing. Work is ongoing to improve the quantification of AICAr with calibration tools such as PARAFAC. ${ }^{48,53}$ Data processing 
combined with normal standard addition protocols should allow efficient extraction of the analyte response distinct from interferences and indicator background signals.

\subsection{Experimental}

- Instrumentation

All chemicals were purchased from Sigma-Aldrich and used without further purification. Normal human urine was purchased from Innovative research. Compound 3.1 was prepared via microwave-assisted synthesis according to procedures reported earlier. ${ }^{54}$ An Initiator ${ }^{\mathrm{TM}}$ microwave synthesizer (Biotage) was used. Fluorescence spectra were measured on Varian Cary Eclipse fluorescence spectrophotometer (Agilent Technologies). EEMs were collected every $4 \min$ for $1 \mathrm{hr}$; excitation at $470-620 \mathrm{~nm}$ each $10 \mathrm{~nm}$, emission at $520-690 \mathrm{~nm}$ each $2.5 \mathrm{~nm}$, both bandpass $=5 \mathrm{~nm}$. EEM data were processed in MATLAB Version 7.9.0 (R2009b).

\section{- Preparation of the Reaction Product}

Dye was dissolved in DMSO and either buffered AICAr solutions or healthy human urine spiked with buffered AICAr was added. One part buffer or aqueous buffer/urine was added to 9 parts dye in DMSO. All samples were vortexed for $15 \mathrm{sec}$ before fluorescence scanning.

\subsection{Conclusions}

We have demonstrated the ability to detect elevated levels of AICAr, a commercially available surrogate of S-Ado and SAICAr, in healthy human urine. This is a step towards a simple screen for elevated S-Ado and SAICAr.

*Reproduced by permission of Australian Jornal of Chemistry http://www.publish.csiro.au/paper/CH11328.htm 


\section{REFERENCES}

1. Grynkiewicz, G.; Poenie, M.; Tsien, R. Y., "A New Generation of Ca-2+ Indicators with Greatly Improved Fluorescence Properties". J. Biol. Chem. 1985, 260, (6), 3440.

2. de Silva, A. P.; Gunaratne, H. Q. N.; Rice, T. E., "Proton-controlled switching of luminescence in lanthanide complexes in aqueous solution: $\mathrm{pH}$ sensors based on long-lived emission". Angew. Chem. Int. Ed. 1996, 35, (18), 2116.

3. Chen, X.; Zhou, Y.; Peng, X. J.; Yoon, J., "Fluorescent and colorimetric probes for detection of thiols". Chem. Soc. Rev. 2010, 39, (6), 2120.

4. $\quad$ Lim, S.; Escobedo, J. O.; Lowry, M.; Strongin, R., "Detecting specific saccharides via a single indicator". Chem. Commun. 2011, 47, 8295.

5. Wang, W. H.; Rusin, O.; Xu, X. Y.; Kim, K. K.; Escobedo, J. O.; Fakayode, S. O.; Fletcher, K. A.; Lowry, M.; Schowalter, C. M.; Lawrence, C. M.; Fronczek, F. R.; Warner, I. M.; Strongin, R. M., "Detection of homocysteine and cysteine". J. Am. Chem. Soc. 2005, 127, (45), 15949.

6. Jaeken, J.; Vandenberghe, G., "An Infantile Autistic Syndrome Characterized by the Presence of Succinyl Purines in Body-Fluids". Lancet 1984, 2, (8411), 1058.

7. Parsons, R. B.; Waring, R. H.; Ramsden, D. B.; Williams, A. C., "Toxicity of cysteine and cysteine sulphinic acid to human neuronal cell-lines". J. Neurol. Sci. 1997, 152, S62.

8. Olney, J. W.; Zorumski, C.; Price, M. T.; Labruyere, J., "L-Cysteine, a Bicarbonate-Sensitive Endogenous Excitotoxin". Science 1990, 248, (4955), 596.

9. $\quad$ (a) Heafield, M. T.; Fearn, S.; Steventon, G. B.; Waring, R. H.; Williams, A. C.; Sturman, S. G., "Plasma Cysteine and Sulfate Levels in Patients with MotorNeuron, Parkinsons and Alzheimers-Disease". Neurosci. Lett. 1990, 110, (1-2), 216.

(b) Janaky, R.; Varga, V.; Hermann, A.; Saransaari, P.; Oja, S. S., "Mechanisms of L-cysteine neurotoxicity". Neurochem. Res. 2000, 25, (9-10), 1397.

10. Droge, W.; Holm, E., "Role of cysteine and glutathione in HIV infection and other diseases associated with muscle wasting and immunological dysfunction". FASEB J. 1997, 11, (13), 1077.

11. Beija, M.; Afonso, C. A. M.; Martinho, J. M. G., "Synthesis and applications of Rhodamine derivatives as fluorescent probes". Chem. Soc. Rev. 2009, 38, (8), 2410 . 
12. Maeda, H.; Matsuno, H.; Ushida, M.; Katayama, K.; Saeki, K.; Itoh, N., "2,4dinitrobenzenesulfonyl fluoresceins as fluorescent alternatives to Ellman's reagent in thiol-quantification enzyme assays". Angew. Chem., Int. Ed. Engl. 2005, 44, (19), 2922.

13. Shibata, A.; Furukawa, K.; Abe, H.; Tsuneda, S.; Ito, Y., "Rhodamine-based fluorogenic probe for imaging biological thiol". Bioorg. Med. Chem. Lett. 2008, $18,(7), 2246$.

14. (a) Bouffard, J.; Kim, Y.; Swager, T. M.; Weissleder, R.; Hilderbrand, S. A., "A highly selective fluorescent probe for thiol bioimaging". Org. Lett. 2008, 10, (1), 37.

(b) Ji, S. M.; Yang, J.; Yang, Q.; Liu, S. S.; Chen, M. D.; Zhao, J. Z., "Tuning the Intramolecular Charge Transfer of Alkynylpyrenes: Effect on Photophysical Properties and Its Application in Design of OFF-ON Fluorescent Thiol Probes". J. Org. Chem. 2009, 74, (13), 4855.

15. (a) Tang, B.; Yin, L. L.; Wang, X.; Chen, Z. Z.; Tong, L. L.; Xu, K. H., "A fastresponse, highly sensitive and specific organoselenium fluorescent probe for thiols and its application in bioimaging". Chem. Commun. 2009, (35), 5293.

(b) Jiang, W.; Cao, Y. T.; Liu, Y. A.; Wang, W., "Rational design of a highly selective and sensitive fluorescent PET probe for discrimination of thiophenols and aliphatic thiols". Chem. Commun. 2010, 46, (11), 1944.

16. (a) Corrie, J. E. T., "Thiol-Reactive Fluorescent-Probes for Protein Labeling". Journal of the Chemical Society-Perkin Transactions 1 1994, (20), 2975.

(b) Hewage, H. S.; Anslyn, E. V., "Pattern-Based Recognition of Thiols and Metals Using a Single Squaraine Indicator". J. Am. Chem. Soc. 2009, 131, (36), 13099.

(c) Yi, L.; Li, H. Y.; Sun, L.; Liu, L. L.; Zhang, C. H.; Xi, Z., "A Highly Sensitive Fluorescence Probe for Fast Thiol-Quantification Assay of Glutathione Reductase". Angew. Chem., Int. Ed. 2009, 48, (22), 4034.

17. Arnaud, C. H., "Making Diagnostics Affordable". Chem. Eng. News 2009, 87, (11), 50 .

18. (a) Kanaoka, Y.; Machida, M.; Ando, K.; Sekine, T., "Fluorescence and Structures of Proteins as Measured by Incorporation of Fluorophore .4. Synthesis and Fluorescence Characteristics of N-Para-(2-Benzimidazolyl)Phenyl) Maleimide". Biochim. Biophys. Acta 1970, 207, (2), 269.

(b) Sippel, T. O., "New Fluorochromes for Thiols - Maleimide and Iodoacetamide Derivatives of a 3-Phenylcoumarin Fluorophore". J. Histochem. Cytochem. 1981, $29,(2), 314$. 
(c) Guy, J.; Caron, K.; Dufresne, S.; Michnick, S. W.; Skene, W. G.; Keillor, J. W., "Convergent preparation and photophysical characterization of dimaleimide dansyl fluorogens: Elucidation of the maleimide fluorescence quenching mechanism". J. Am. Chem. Soc. 2007, 129, (39), 11969.

19. (a) Yamamoto, K.; Sekine, T.; Kanaoka, Y., "Fluorescent Thiol Reagents .12. Fluorescent Tracer Method for Protein Sh-Groups Using N-(7-Dimethylamino-4Methyl Coumarinyl) Maleimide - Application to Proteins Separated by SdsPolyacrylamide Gel-Electrophoresis". Anal. Biochem. 1977, 79, (1-2), 83.

(b) Dubernet, M.; Caubert, V.; Guillard, J.; Viaud-Massuard, M. C., "Synthesis of substituted bis(heteroaryl)maleimides". Tetrahedron 2005, 61, (19), 4585.

20. Girouard, S.; Houle, M. H.; Grandbois, A.; Keillor, J. W.; Michnick, S. W., "Synthesis and characterization of dimaleimide fluorogens designed for specific labeling of proteins". J. Am. Chem. Soc. 2005, 127, (2), 559.

21. Lin, W. Y.; Yuan, L.; Cao, Z. M.; Feng, Y. M.; Long, L. L., "A Sensitive and Selective Fluorescent Thiol Probe in Water Based on the Conjugate 1,4-Addition of Thiols to alpha,beta-Unsaturated Ketones". Chem. Eur. J. 2009, 15, (20), 5096.

22. Ros-Lis, J. V.; Garcia, B.; Jimenez, D.; Martinez-Manez, R.; Sancenon, F.; Soto, J.; Gonzalvo, F.; Valldecabres, M. C., "Squaraines as fluoro-chromogenic probes for thiol-containing compounds and their application to the detection of biorelevant thiols". J. Am. Chem. Soc. 2004, 126, (13), 4064.

23. Sreejith, S.; Divya, K. P.; Ajayaghosh, A., "A near-infrared squaraine dye as a latent ratiometric fluorophore for the detection of aminothiol content in blood plasma". Angew. Chem., Int. Ed. 2008, 47, (41), 7883.

24. Zhang, X. J.; Ren, X. S.; Xu, Q. H.; Loh, K. P.; Chen, Z. K., "One- and TwoPhoton Turn-on Fluorescent Probe for Cysteine and Homocysteine with Large Emission Shift". Org. Lett. 2009, 11, (6), 1257.

25. Rusin, O.; St Luce, N. N.; Agbaria, R. A.; Escobedo, J. O.; Jiang, S.; Warner, I. M.; Dawan, F. B.; Lian, K.; Strongin, R. M., "Visual detection of cysteine and homocysteine". J. Am. Chem. Soc. 2004, 126, (2), 438.

26. Tanaka, F.; Mase, N.; Barbas, C. F., "Determination of cysteine concentration by fluorescence increase: reaction of cysteine with a fluorogenic aldehyde". Chem. Commun. 2004, (15), 1762.

27. Lin, W. Y.; Long, L. L.; Yuan, L.; Cao, Z. M.; Chen, B. B.; Tan, W., "A Ratiometric Fluorescent Probe for Cysteine and Homocysteine Displaying a Large Emission Shift". Org. Lett. 2008, 10, (24), 5577. 
28. Kim, T. K.; Lee, D. N.; Kim, H. J., "Highly selective fluorescent sensor for homocysteine and cysteine". Tetrahedron Lett. 2008, 49, (33), 4879.

29. Lee, K. S.; Kim, T. K.; Lee, J. H.; Kim, H. J.; Hong, J. I., "Fluorescence turn-on probe for homocysteine and cysteine in water". Chem. Commun. 2008, 46, 6173.

30. Duan, L. P.; Xu, Y. F.; Qian, X. H.; Wang, F.; Liu, J. W.; Cheng, T. Y., "Highly selective fluorescent chemosensor with red shift for cysteine in buffer solution and its bioimage: symmetrical naphthalimide aldehyde". Tetrahedron Lett. 2008, $49,(47), 6624$.

31. Esterbauer, H.; Ertl, A.; Scholz, N., "The Reaction of Cysteine with Alpha,BetaUnsaturated Aldehydes". Tetrahedron 1976, 32, (2), 285.

32. Ohmori, S.; Ikeda, M.; Hattori, H.; Hagiwara, K.; Iwase, C., "A Simple and Specific Colorimetric Determination of Cysteine with ParaDimethylaminocinnamaldehyde". J. Clin. Chem. Clin. Biochem. 1983, 21, (12), 851.

33. Sjoback, R.; Nygren, J.; Kubista, M., "Absorption and Fluorescence Properties of Fluorescein". Spectrochimica Acta Part a-Molecular and Biomolecular Spectroscopy 1995, 51, (6), L7.

34. (a) Falsey, J. R.; Renil, M.; Park, S.; Li, S. J.; Lam, K. S., "Peptide and small molecule microarray for high throughput cell adhesion and functional assays". Bioconjugate Chem. 2001, 12, (3), 346.

(b) Villain, M.; Vizzavona, J.; Rose, K., "Covalent capture: a new tool for the purification of synthetic and recombinant polypeptides". Chem. Biol. 2001, 8, (7), 673.

(c) Zhang, L. S.; Tam, J. P., "Thiazolidine formation as a general and site-specific conjugation method for synthetic peptides and proteins". Anal. Biochem. 1996, 233, (1), 87.

(d) Zhao, Z. G.; Im, J. S.; Lam, K. S.; Lake, D. F., "Site-specific modification of a single-chain antibody using a novel glyoxylyl-based labeling reagent". Bioconjugate Chem. 1999, 10, (3), 424.

(e) Tolbert, T. J.; Wong, C. H., "New methods for proteomic research: Preparation of proteins with N-terminal cysteines for labeling and conjugation". Angew. Chem., Int. Ed. 2002, 41, (12), 2171.

35. Starkey, J. R.; Dai, S.; Dratz, E. A., "Sidechain and backbone requirements for anti-invasive activity of laminin peptide 11". Biochim. Biophys. Acta, Protein Struct. Mol. Enzymol. 1998, 1429, (1), 187.

36. Jiang, S.; Escobedo, J. O.; Kim, K. K.; Alpturk, O.; Samoei, G. K.; Fakayode, S. O.; Warner, I. M.; Rusin, O.; Strongin, R. M., "Stereochemical and regiochemical 
trends in the selective detection of saccharides". J. Am. Chem. Soc. 2006, 128, (37), 12221.

37. Halo, T. L.; Appelbaum, J.; Hobert, E. M.; Balkin, D. M.; Schepartz, A., "Selective Recognition of Protein Tetraserine Motifs with a Cell-Permeable, Profluorescent Bis-boronic Acid". J. Am. Chem. Soc. 2009, 131, (2), 438.

38. Rusin, O.; Escobedo, J. O.; Strongin, R. M., "Chemosensors: Case Studies of Chemosemsors for Organic Molecules ". Wiley: 2011.

39. Lim, S.; Escobedo, J. O.; Lowry, M.; Xu, X. Y.; Strongin, R., "Selective fluorescence detection of cysteine and N-terminal cysteine peptide residues". Chem. Commun. 2010, 46, (31), 5707.

40. Chiang, P. K.; Gordon, R. K.; Tal, J.; Zeng, G. C.; Doctor, B. P.; Pardhasaradhi, K.; McCann, P. P., "S-adenosylmethionine and methylation". FASEB J. 1996, 10, (4), 471.

41. Kim, K. K.; Escobedo, J. O.; St Luce, N. N.; Rusin, O.; Wong, D.; Strongin, R. M., "Postcolumn HPLC detection of mono- and oligosaccharides with a chemosensor". Org. Lett. 2003, 5, (26), 5007.

42. Martinez, A. W.; Phillips, S. T.; Carrilho, E.; Thomas, S. W.; Sindi, H.; Whitesides, G. M., "Simple telemedicine for developing regions: Camera phones and paper-based microfluidic devices for real-time, off-site diagnosis". Anal. Chem. 2008, 80, (10), 3699.

43. (a) Abugo, O. O.; Herman, P.; Lakowicz, J. R., "Fluorescent measurements in whole blood and plasma using red emitting dyes". Biophys. J. 2000, 78, (1), 280a.

(b) Abugo, O. O.; Herman, P.; Lakowicz, J. R., "Fluorescence properties of albumin blue 633 and 670 in plasma and whole blood". J. Biomed. Opt. 2001, 6, (3), 359 .

44. Jurecka, A., "Inborn errors of purine and pyrimidine metabolism". Journal of Inherited Metabolic Disease 2009, 32, (2), 247.

45. Ciardo, F.; Salerno, C.; Curatolo, P., "Neurologic aspects of adenylosuccinate lyase deficiency". Journal of Child Neurology 2001, 16, (5), 301.

46. Jurecka, A.; Zikanova, M.; Tylki-Szymanska, A.; Krijt, J.; Bogdanska, A.; Gradowska, W.; Mullerova, K.; Sykut-Cegielska, J.; Kmoch, S.; Pronicka, E., "Clinical, biochemical and molecular findings in seven Polish patients with adenylosuccinate lyase deficiency". Mol. Genet. Metab. 2008, 94, (4), 435. 
47. Olivieri, A. C.; Arancibia, J. A.; de la Pena, A. M.; Duran-Meras, I.; Mansilla, A. E., "Second-order advantage achieved with four-way fluorescence excitationemission-kinetic data processed by parallel factor analysis and trilinear leastsquares. Determination of methotrexate and leucovorin in human urine". Anal. Chem. 2004, 76, (19), 5657.

48. Sena, M. M.; Trevisan, M. G.; Poppi, R. J., "Combining standard addition method and second-order advantage for direct determination of salicylate in undiluted human plasma by spectrofluorimetry". Talanta 2006, 68, (5), 1707.

49. Sadecka, J.; Tothova, J., "Fluorescence spectroscopy and chemometrics in the food classification - a review". Czech J. Food Sci. 2007, 25, (4), 159.

50. Chen, W.; Westerhoff, P.; Leenheer, J. A.; Booksh, K., "Fluorescence excitation Emission matrix regional integration to quantify spectra for dissolved organic matter". Environ. Sci. Technol. 2003, 37, (24), 5701.

51. Marie, S.; Heron, B.; Bitoun, P.; Timmerman, T.; Van den Berghe, G.; Vincent, M. F., "AICA-ribosiduria: A novel, neurologically devastating inborn error of purine biosynthesis caused by mutation of ATIC". Am. J. Hum. Genet. 2004, 74, (6), 1276.

52. (a) Nyhan, W. L., "Disorders of purine and pyrimidine metabolism". Mol. Genet. Metab. 2005, 86, (1-2), 25.

(b) Spiegel, E. K.; Colman, R. F.; Patterson, D., "Adenylosuccinate lyase deficiency". Mol. Genet. Metab. 2006, 89, (1-2), 19.

53. Andersen, C. M.; Bro, R., "Practical aspects of PARAFAC modeling of fluorescence excitation-emission data". J. Chemom. 2003, 17, (4), 200.

54. Lim, S.; Escobedo, J. O.; Lowry, M.; Strongin, R., "Detecting specific saccharides via a single indicator". Chem. Commun. 2011, 47, 8295. 
APPENDIX A. CHARACTERIZATION DATA FOR COMPOUND 2.1

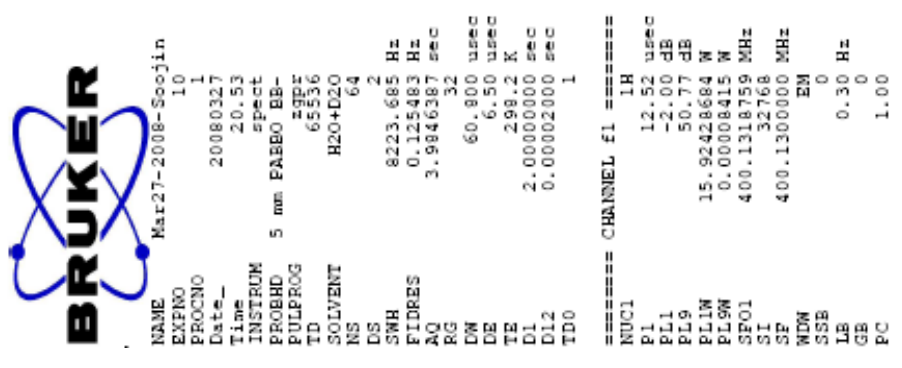

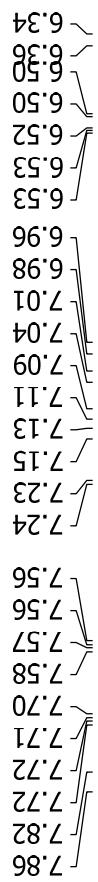

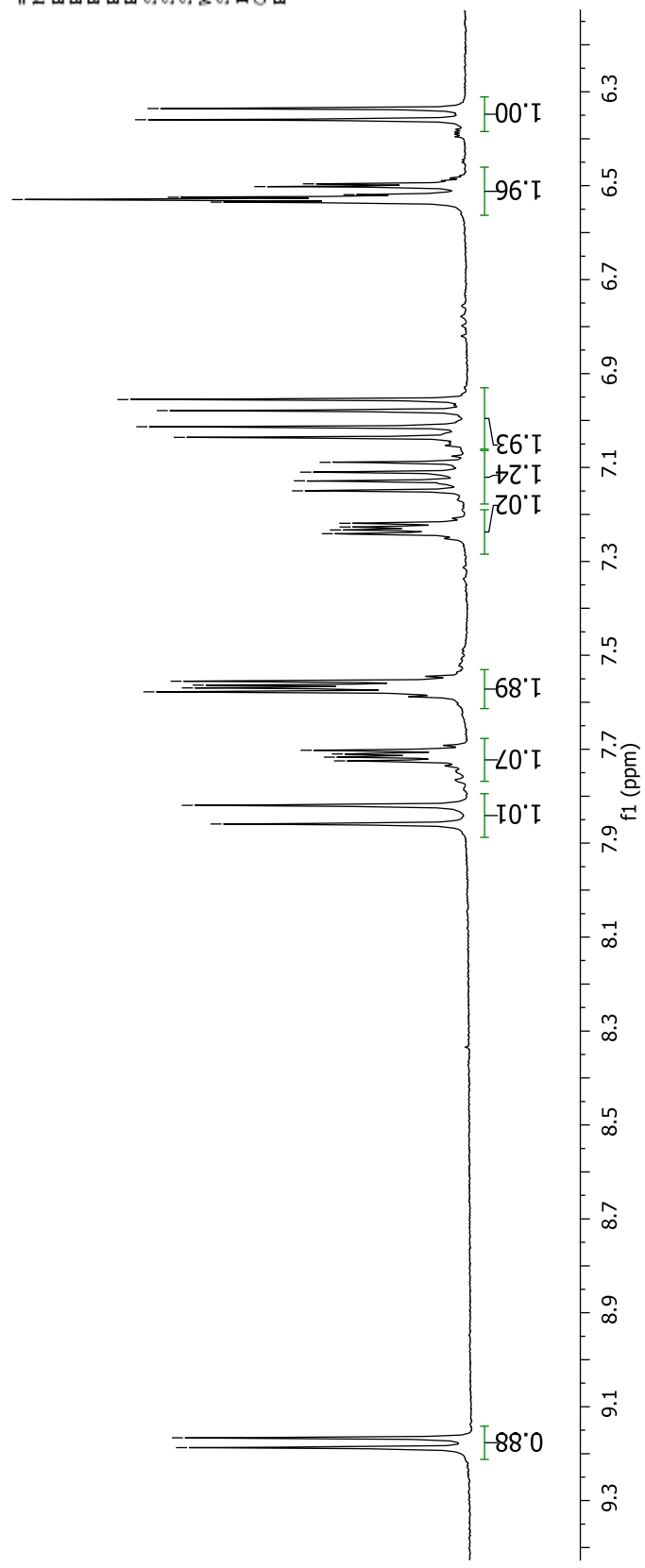

Figure A1. ${ }^{1} \mathrm{H}$ NMR of compound 2.1

(400 MHz, 0.1 M pH 7.4 phosphate buffer/ $\mathrm{D}_{2} \mathrm{O}$ 9:1) 


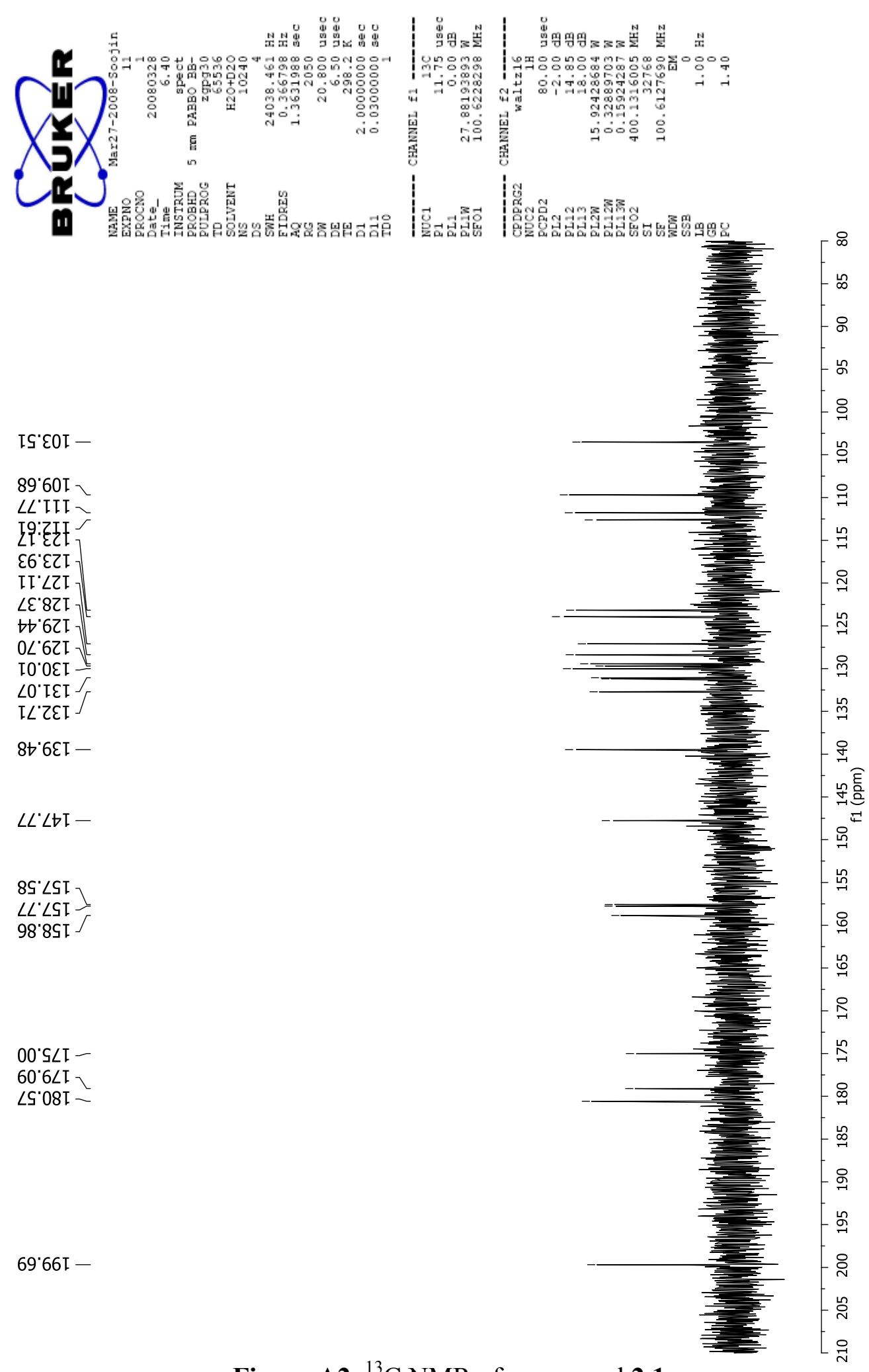

Figure A2. ${ }^{13} \mathrm{C}$ NMR of compound 2.1

(101 MHz, 0.1 M pH 7.4 phosphate buffer/ $/ \mathrm{D}_{2} \mathrm{O}$ 9:1) 


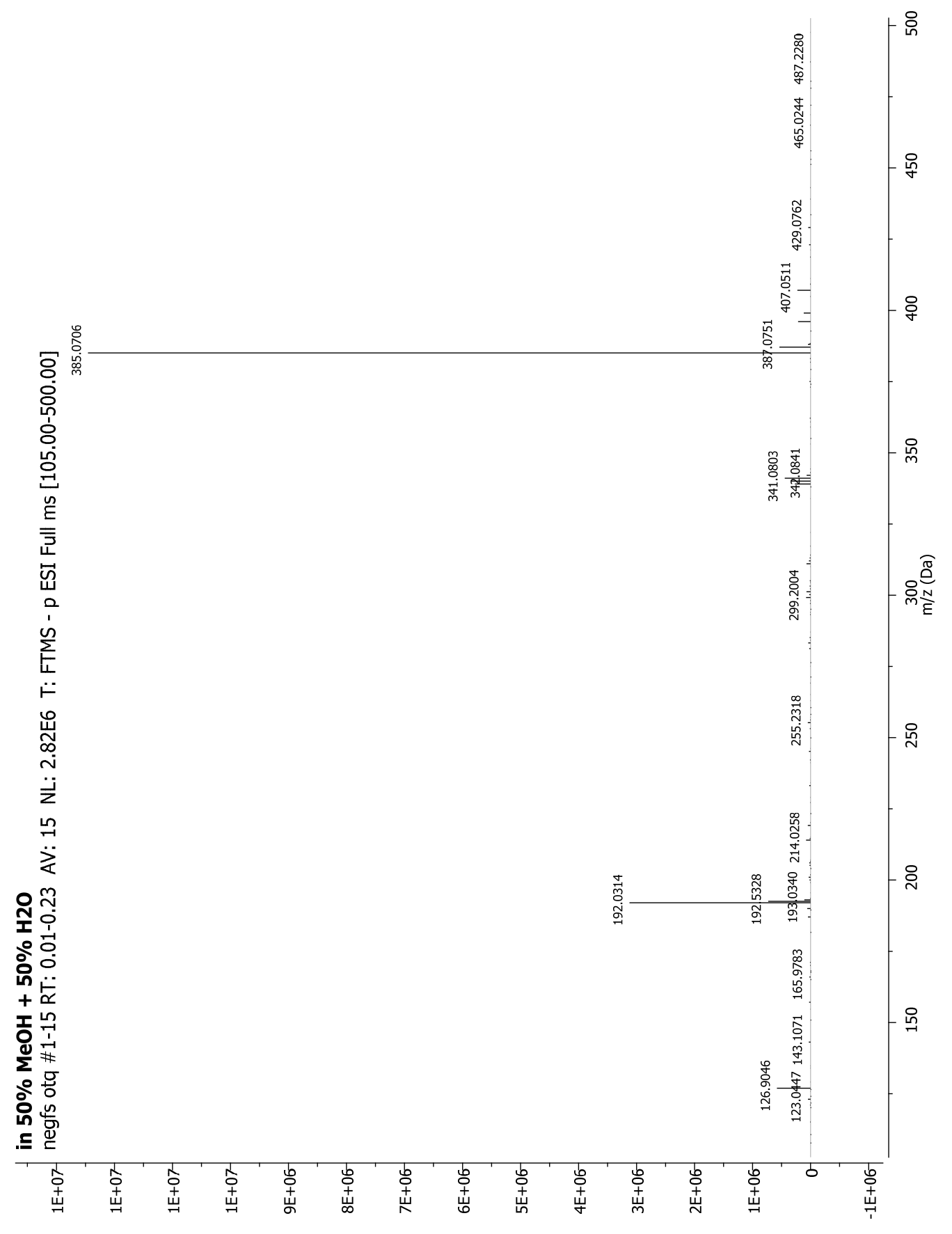

Figure A3. ESI-FTMS of compound 2.1 


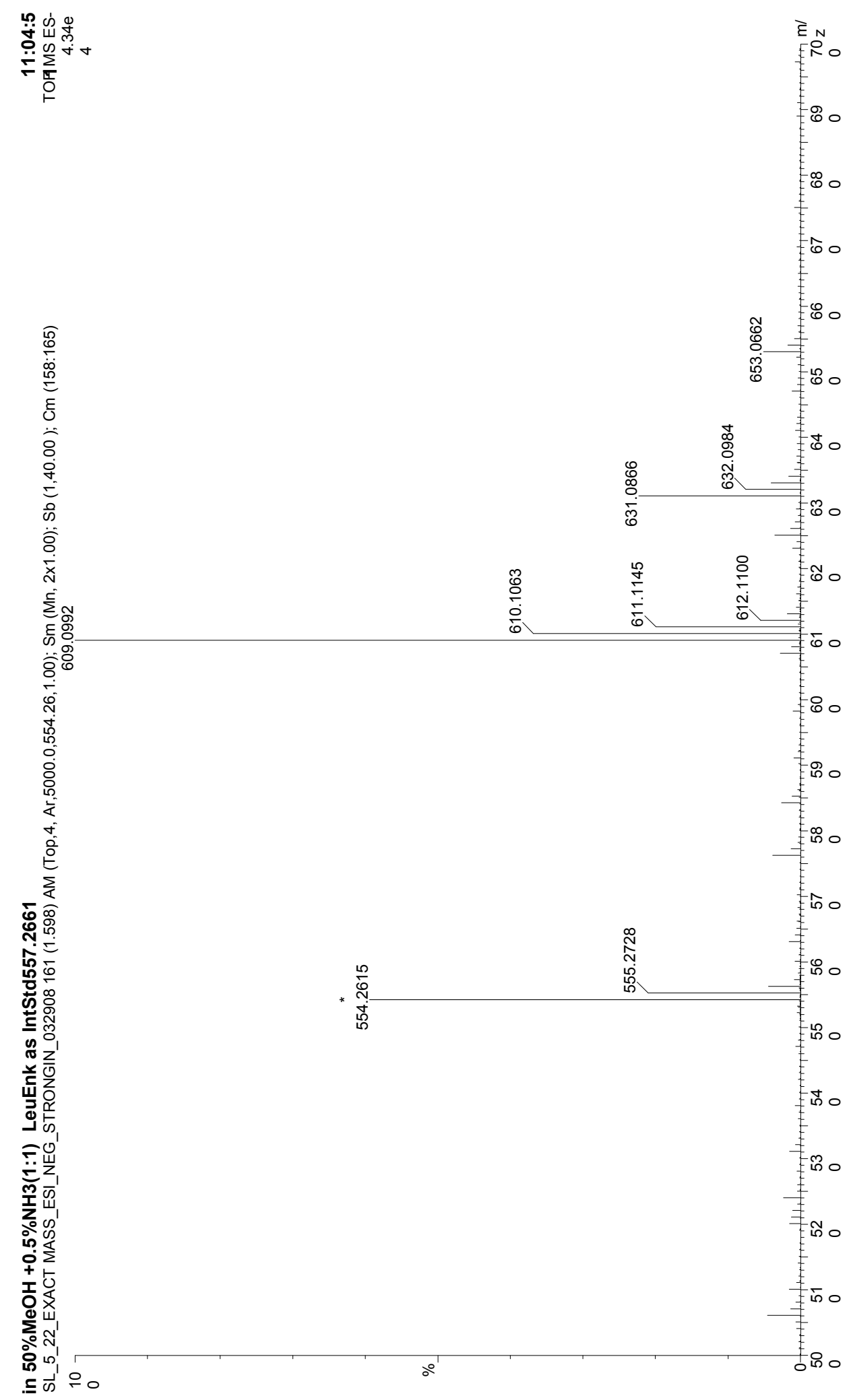

Figure A4. ESI-TOF HRMS of complex of 2.1 with Cys. $m / z=609.0992$ [M-H]', calc. 609.1007 for $\mathrm{C}_{29} \mathrm{H}_{26} \mathrm{~N}_{2} \mathrm{O}_{9} \mathrm{~S}_{2}$ 


\section{APPENDIX B. SELECTIVE FLUORESCENCE DETECTION OF CYSTEINE AND $N$-TERMINAL CYSTEINE PEPTIDE RESIDUES}
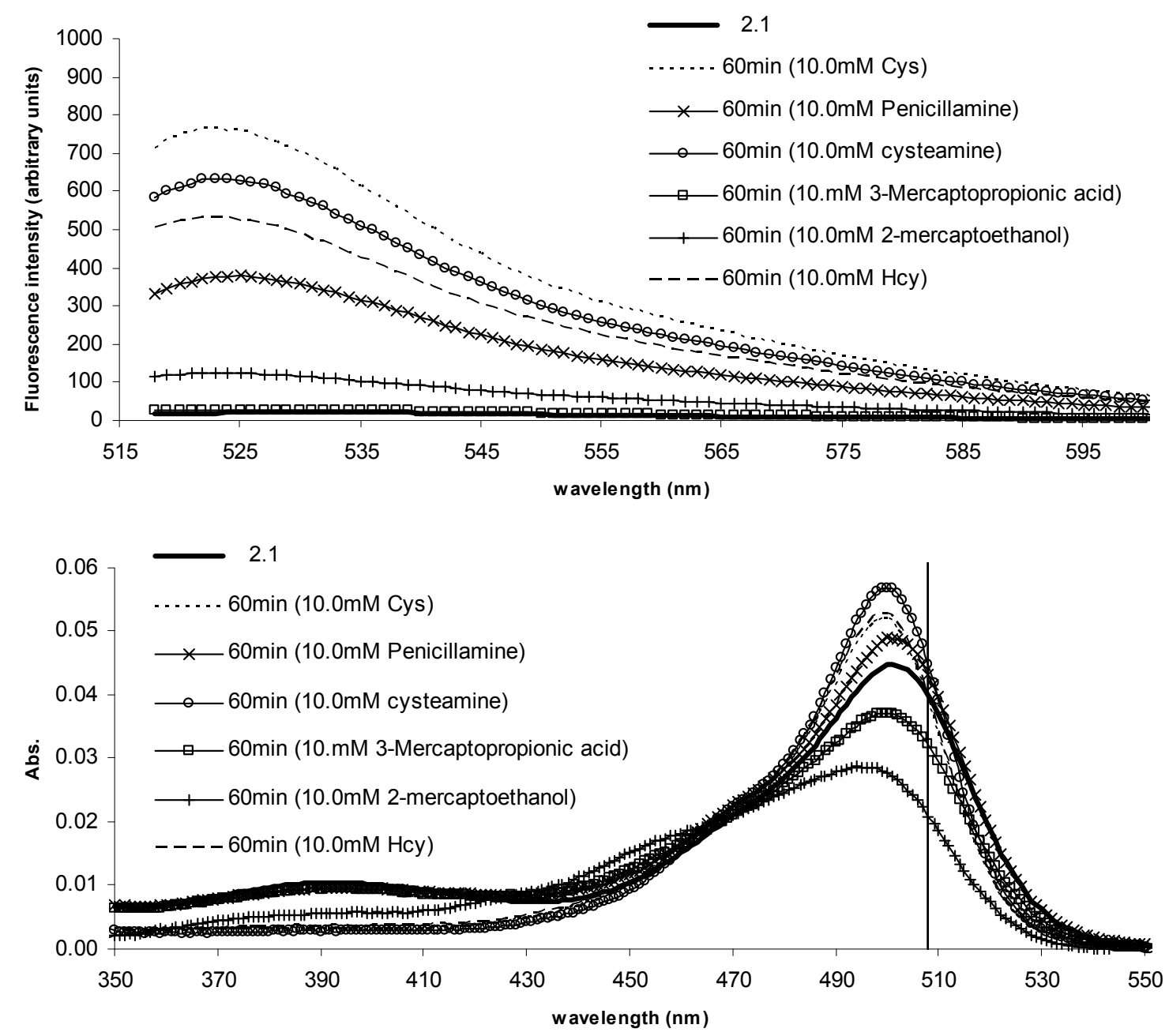

Figure B1. Response of compound 2.1 to thiols of interest and structural analogs $(10.0$ $\mathrm{mM}$ ). (top) emission spectra excited at $508 \mathrm{~nm}$ (60 min). (bottom) absorbance spectra (60 $\mathrm{min})$. The vertical line represents the $508 \mathrm{~nm}$ excitation wavelength. 


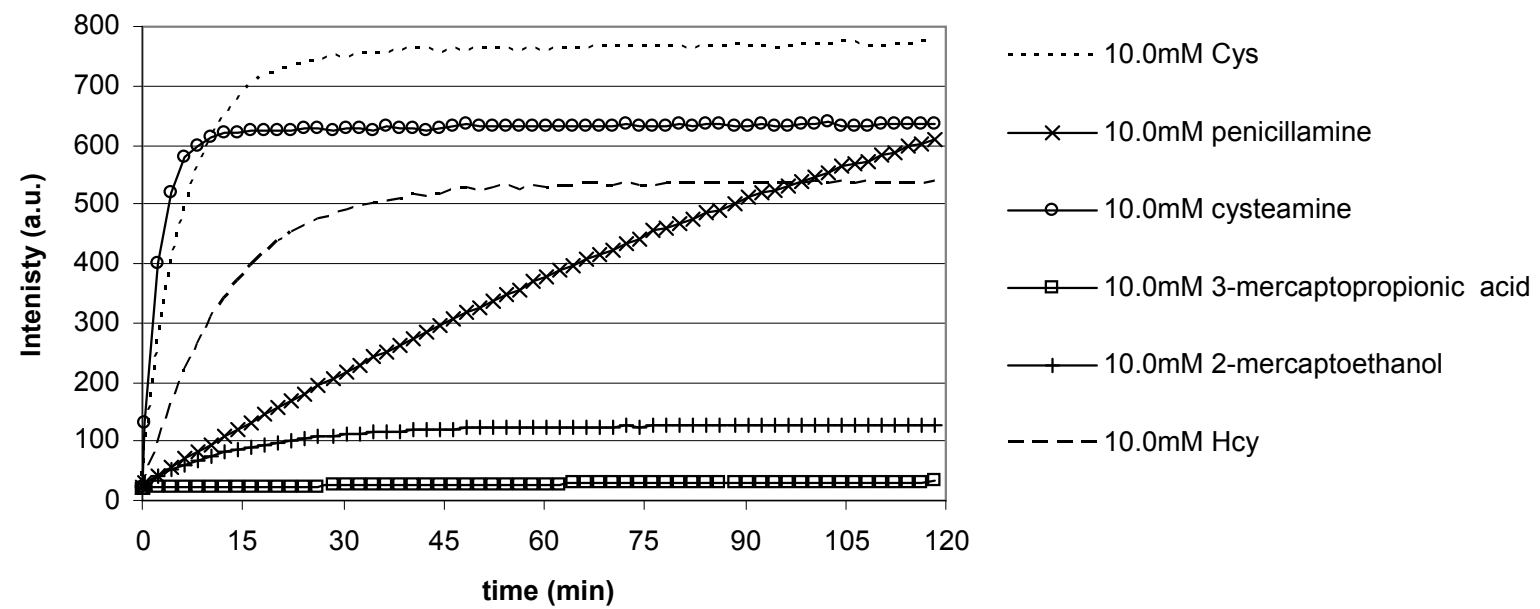

Figure B2. Evolution of fluorogenic response. Emission at $524 \mathrm{~nm}$ upon $508 \mathrm{~nm}$ excitation of $1 \mu \mathrm{M} 2.1$ in the presence of excess thiols of interest and their structural analogs $(10.0 \mathrm{mM})$. 

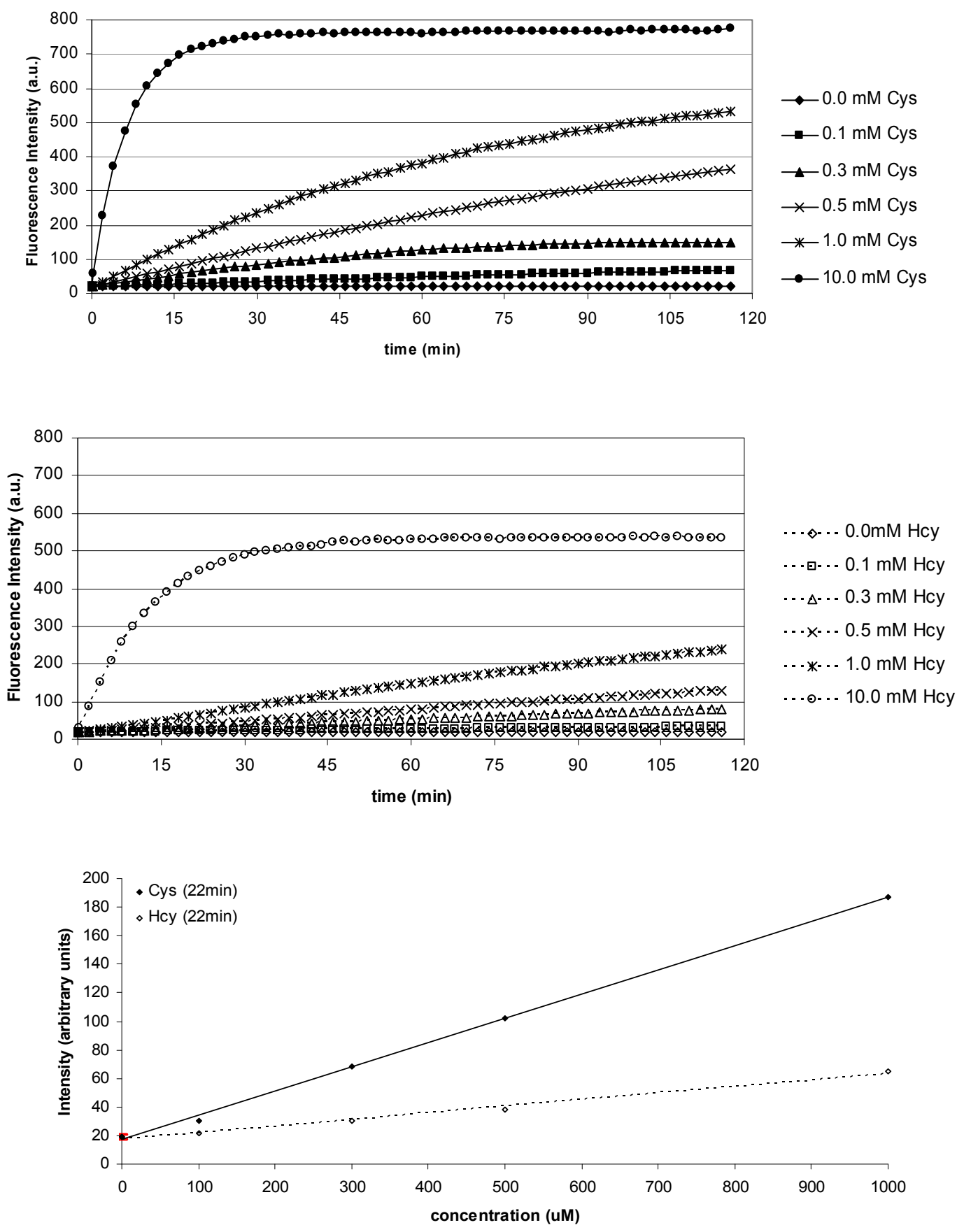

Figure B3. Fluorescence response of $\mathbf{2 . 1}$ to Cys and Hcy as a function of time and concentration. (top) Evolution of fluorogenic response. $1 \mu \mathrm{M} 2.1$ in the presence of excess Cys and Hcy $\left(\lambda_{\mathrm{em}}=524 \mathrm{~nm}\right.$ upon excitation at $\left.508 \mathrm{~nm}\right)$. Filled symbols and solid lines $=$ Cys. Open symbols and dashed lines $=$ Hcy. (bottom) Linear response of the fluorescence intensity as a function of thiol concentration $(0-1000 \mu \mathrm{M})$ after 22 min of reaction time. The limit of detection for Cys was $\sim 3$-fold lower than that of Hcy $(39 \mu \mathrm{M}$ vs. $114 \mu \mathrm{M})$. 

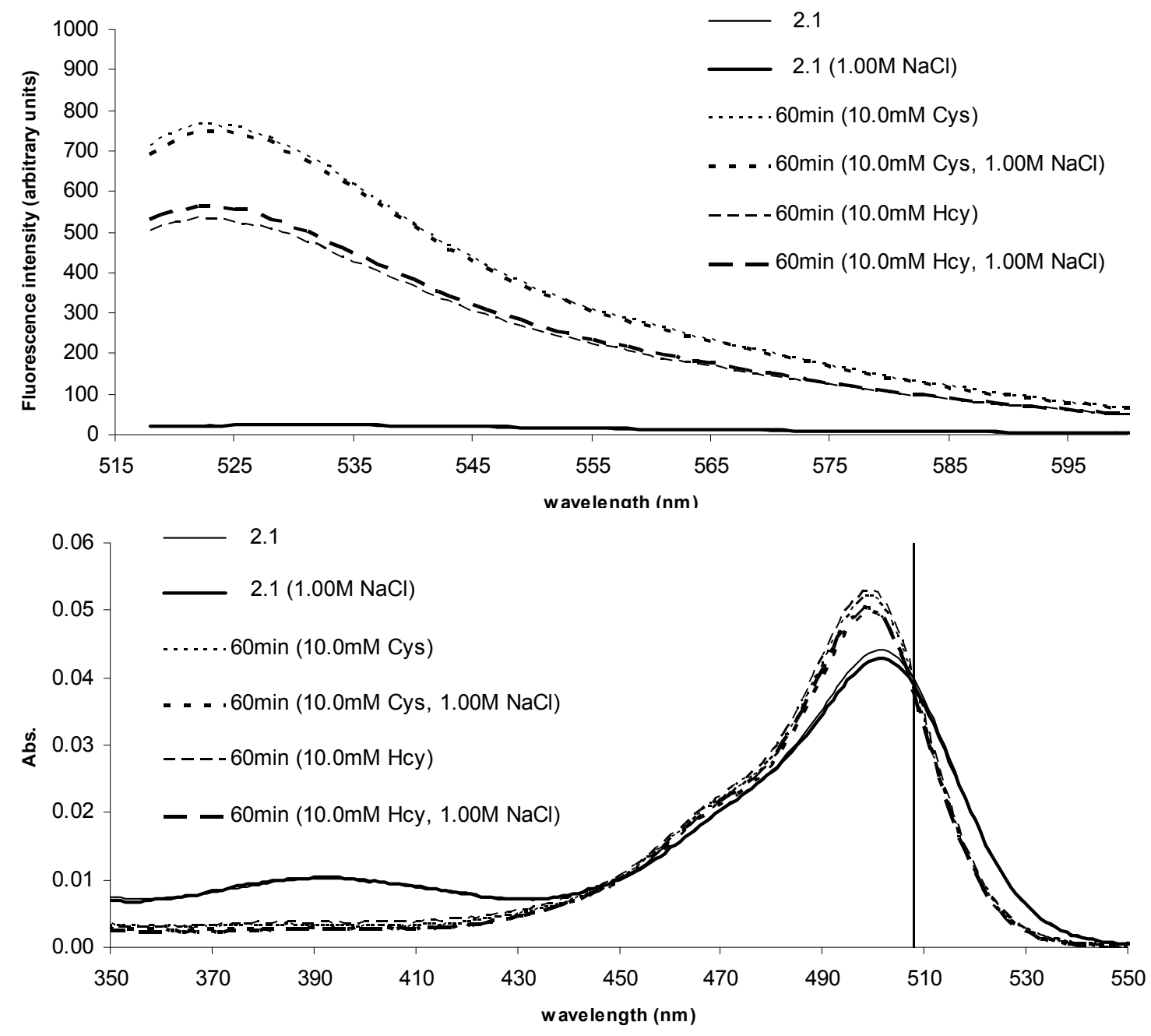

Figure B4. Effect of salt on the response of compound 2.1 to excess (10.0 mM) Cys and Hcy in buffered solution ( $0.1 \mathrm{M}$ phosphate $\mathrm{pH} 7.4)$ with and without additional $\mathrm{NaCl}(1$ M). (top) emission spectra excited at $508 \mathrm{~nm}$ (60 min). (bottom) absorbance spectra (60 min). The vertical line represents the $508 \mathrm{~nm}$ excitation wavelength. 


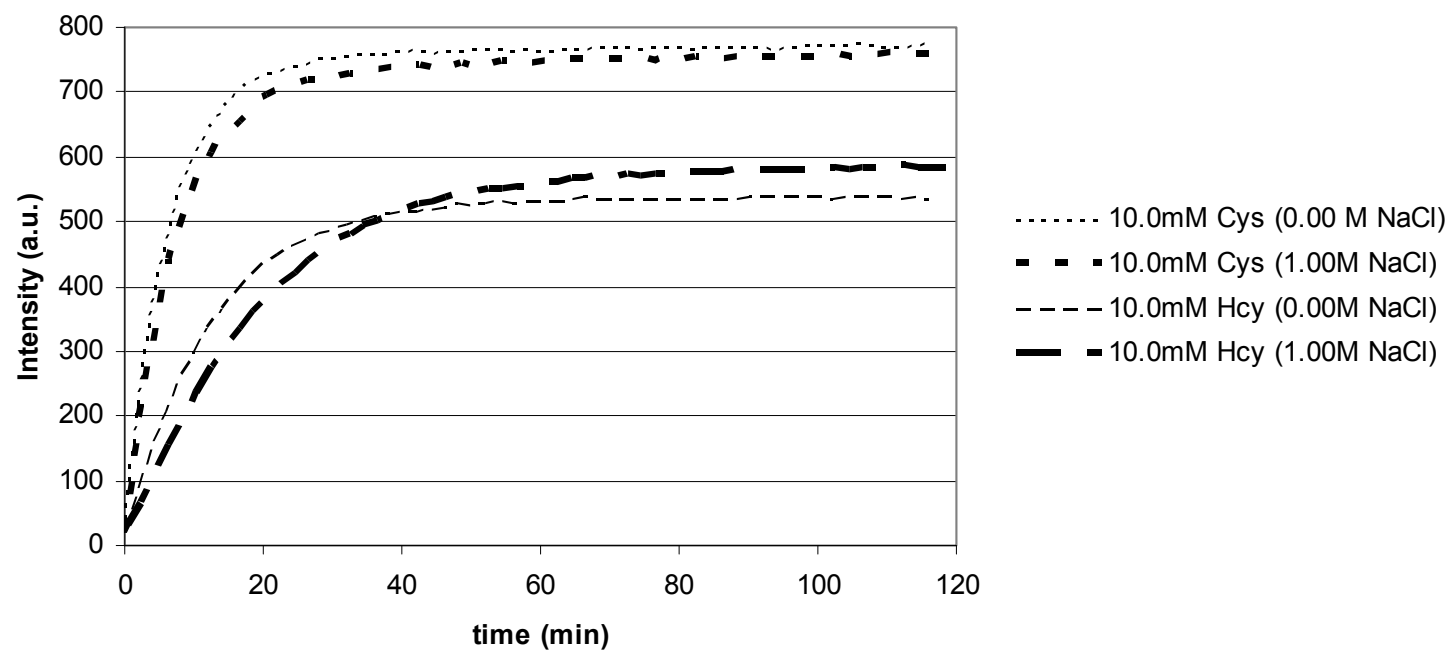

Figure B5. Effect of salt on the evolution of fluorogenic response. Emission at $524 \mathrm{~nm}$ upon $508 \mathrm{~nm}$ excitation of $1 \mu \mathrm{M} 2.1$ in the presence of excess $(10.0 \mathrm{mM})$ Cys and Hcy in buffered solution (0.1 M phosphate $\mathrm{pH} 7.4)$ with and without additional $\mathrm{NaCl}(1 \mathrm{M})$.

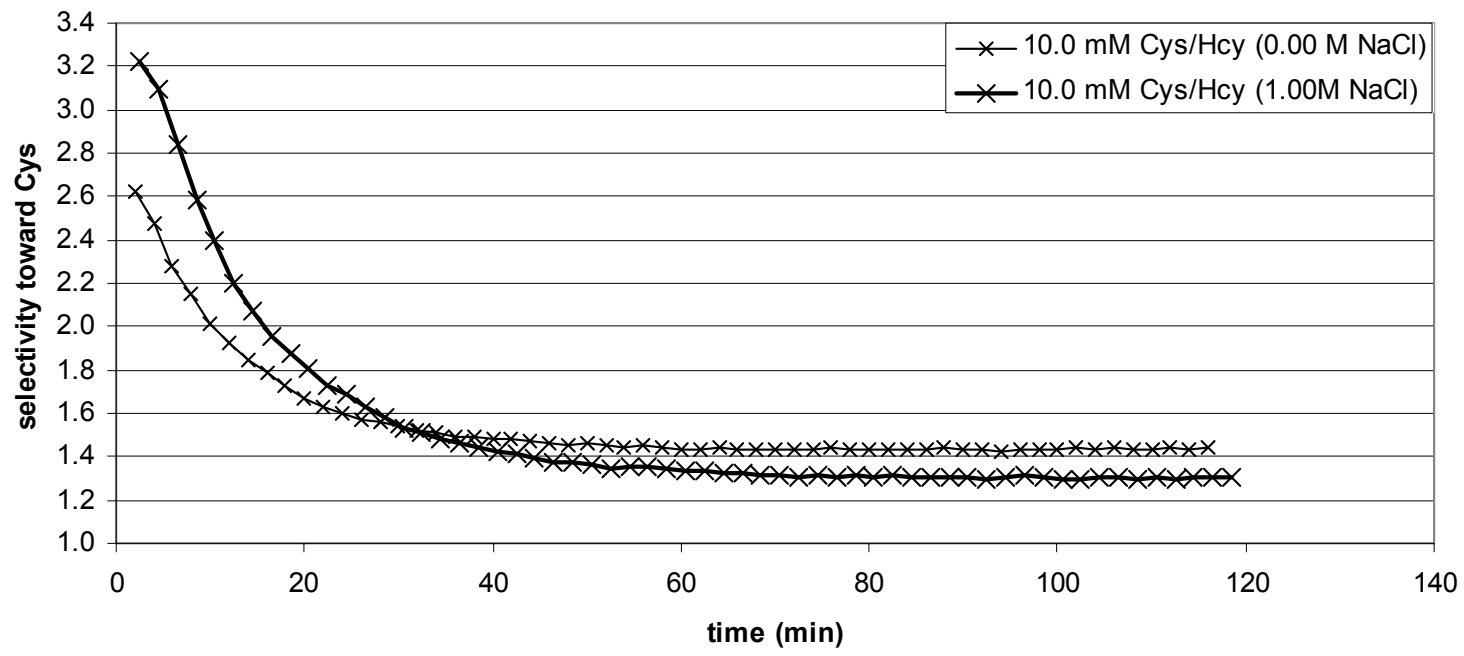

Figure B6. Effect of salt on the selectivity towards Cys over Hcy. Ratio of fluorescence emission ( $\lambda_{\mathrm{em}}=524 \mathrm{~nm}$ upon $508 \mathrm{~nm}$ excitation) of Cys and Hcy reaction products with 2.1 (1 $\mu \mathrm{M} 2.1$ : $10 \mathrm{mM}$ thiols) as they formed over time in buffered solution $(0.1 \mathrm{M}$ phosphate $\mathrm{pH} 7.4)$ with and without additional $\mathrm{NaCl}(1 \mathrm{M})$. 

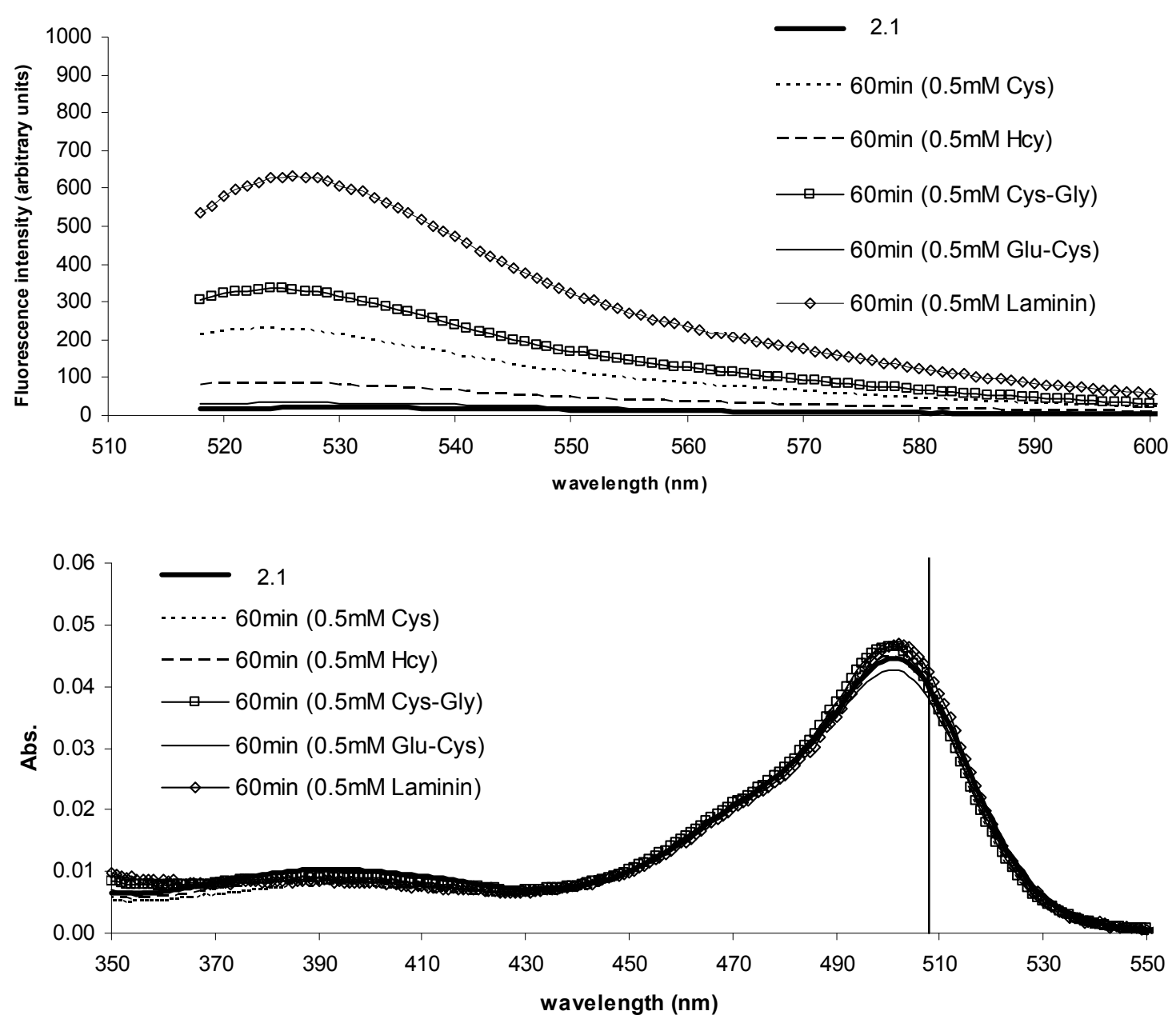

Figure B7. Response of compound 2.1 to thiols $(0.5 \mathrm{mM})$ and peptides $(0.5 \mathrm{mM})$ of interest. (top) emission spectra excited at $508 \mathrm{~nm}(60 \mathrm{~min})$. (bottom) absorbance spectra (60 min). The vertical line represents the $508 \mathrm{~nm}$ excitation wavelength. 


\section{APPENDIX C. COMPUTATIONAL PROCEDURES OF ENERGY-MINIMIZED STRUCTURES OF THE REACTION PRODUCTS OF 2.1 WITH CYS (TOP) AND HCY (BOTTOM)}

Molecular models were built using the SYBYL ${ }^{\mathrm{TM}}$ software package version X-1.1 (Tripos Inc.) and then submitted for geometry optimization and energy minimization via MOPAC2009. ${ }^{1}$

The processed file which corresponds to Fig. 2.13 in the text is presented below in mol2 file format. To read the file, copy the text between "start of mol2 file" and "end of mol2 file" and paste it in a text editor (e.g. MS notepad) and save the file with any name with the extension ".mol2"; this file can then be opened with almost any molecular viewer program (e.g. RASMOL, UCSF Chimera, Cambridgesoft Chem3D ${ }^{\mathrm{TM}}$, SYBYL ${ }^{\mathrm{TM}}$, etc.).

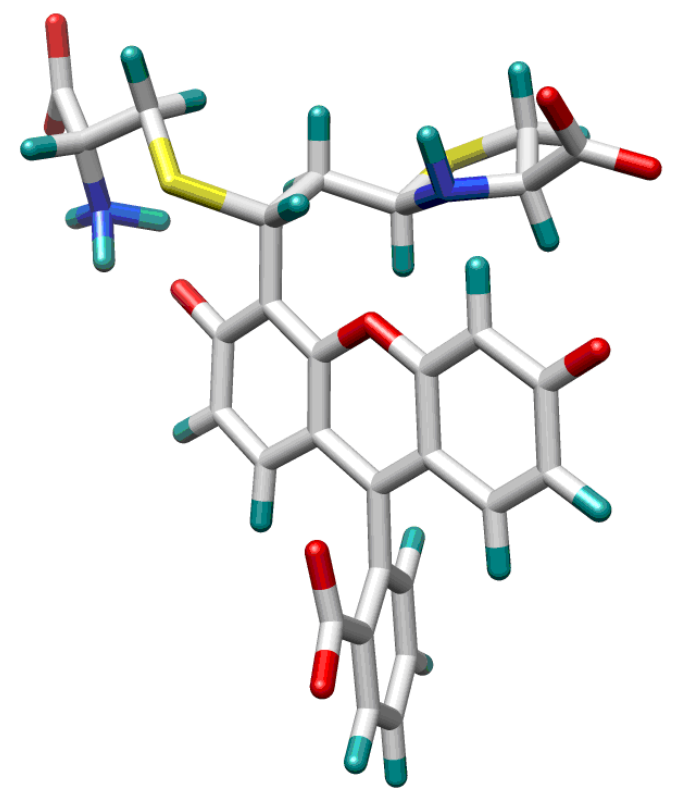

Figure C1. Reaction product of 2.1-Cys

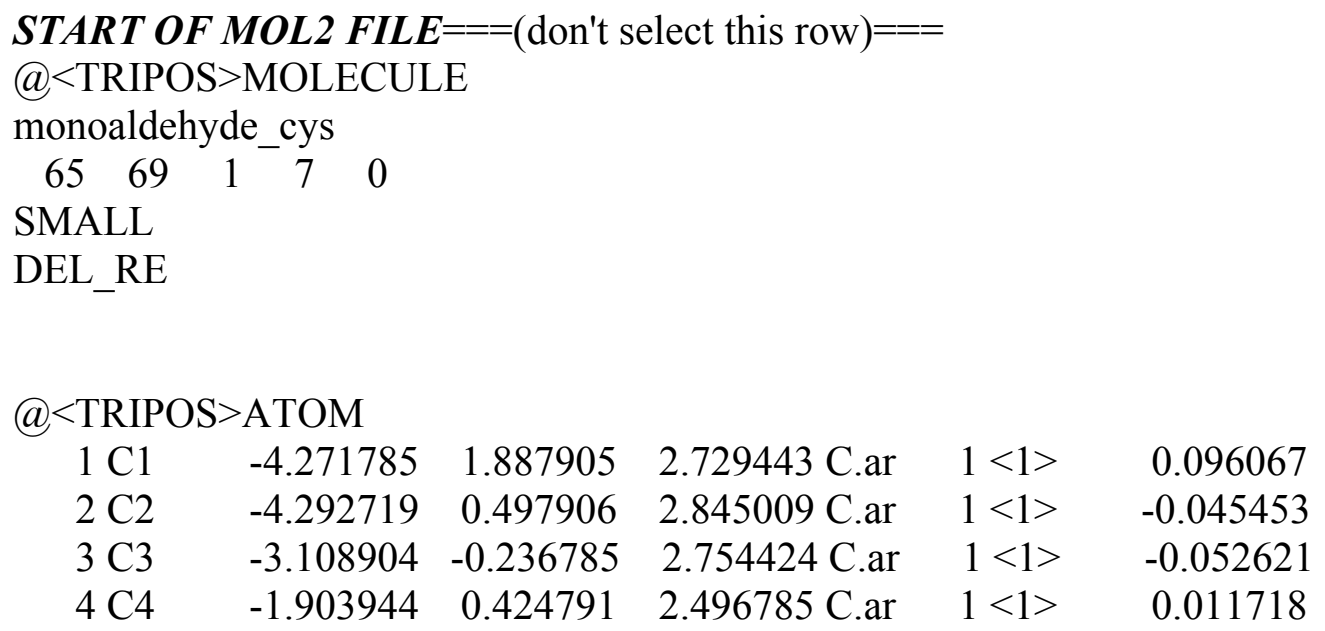




\begin{tabular}{|c|c|c|c|c|c|}
\hline $5 \mathrm{C} 5$ & -1.874445 & 1.822419 & 2.457249 C.ar & $1<1>$ & 0.101950 \\
\hline $6 \mathrm{C} 6$ & -3.054840 & 2.567616 & 2.586960 C.ar & $1<1>$ & 0.014974 \\
\hline $7 \mathrm{C} 7$ & -0.621017 & -0.336834 & 2.250014 C. 2 & $1<1>$ & 0.002651 \\
\hline $8 \mathrm{C} 8$ & 0.509681 & 0.349957 & 2.040404 C. 2 & $1<1>$ & 0.011821 \\
\hline $9 \mathrm{C} 9$ & 0.474955 & 1.830955 & 2.054087 C. 2 & $1<1>$ & 0.103500 \\
\hline $10 \mathrm{O} 10$ & -0.664246 & 2.493124 & 2.2761090 .3 & $1<1>$ & -0.251252 \\
\hline 11 C11 & 1.805274 & -0.319266 & 1.778399 C.2 & $1<1>$ & -0.053090 \\
\hline $12 \mathrm{C} 12$ & 2.919995 & 0.389104 & 1.567195 C. 2 & $1<1>$ & -0.049669 \\
\hline $13 \mathrm{C} 13$ & 2.873251 & 1.858476 & 1.589150 C. 2 & $1<1>$ & 0.073607 \\
\hline $14 \mathrm{C} 14$ & 1.590976 & 2.534409 & 1.835137 C. 2 & $1<1>$ & -0.041535 \\
\hline 15015 & 3.889731 & 2.508630 & 1.405529 O.2 & $1<1>$ & -0.080412 \\
\hline 16016 & -5.483174 & 2.580279 & 2.7576730 .3 & $1<1>$ & -1.116214 \\
\hline $17 \mathrm{C} 17$ & -0.649226 & -1.850073 & 2.216064 C.ar & $1<1>$ & 0.002968 \\
\hline $18 \mathrm{C} 18$ & -1.337378 & -2.449080 & 1.155373 C.ar & $1<1>$ & -0.054366 \\
\hline 19 C19 & -1.383091 & -3.839686 & 1.032471 C.ar & $1<1>$ & -0.053048 \\
\hline $20 \mathrm{C} 20$ & -0.730988 & -4.636954 & 1.975373 C.ar & $1<1>$ & -0.052964 \\
\hline $21 \mathrm{C} 21$ & -0.054746 & -4.039551 & 3.042615 C.ar & $1<1>$ & -0.053540 \\
\hline $22 \mathrm{C} 22$ & -0.021564 & -2.646573 & 3.185037 C.ar & $1<1>$ & 0.011078 \\
\hline $23 \mathrm{C} 23$ & 0.689398 & -2.050948 & 4.384143 C. 2 & $1<1>$ & 0.134395 \\
\hline $24 \mathrm{O} 24$ & 0.621785 & -0.814474 & 4.610588 O.co2 & $1<1>$ & -0.572901 \\
\hline $25 \mathrm{O} 25$ & 1.342332 & -2.814250 & 5.147988 O.co2 & $1<1>$ & -0.572901 \\
\hline $26 \mathrm{C} 26$ & -2.994432 & 4.108325 & 2.557814 C. 3 & $1<1>$ & -0.025966 \\
\hline $27 \mathrm{C} 27$ & -3.391875 & 4.636279 & 1.153765 C. 3 & $1<1>$ & -0.049381 \\
\hline $28 \mathrm{C} 28$ & -2.438928 & 4.110967 & 0.044950 C. 3 & $1<1>$ & 0.012867 \\
\hline $29 \mathrm{C} 29$ & -7.790990 & 6.099759 & 3.613355 C. 2 & $1<1>$ & 0.129412 \\
\hline 30 N30 & -6.876538 & 3.978853 & 3.476148 N.4 & $1<1>$ & 0.252946 \\
\hline $31 \mathrm{C} 31$ & -6.582531 & 5.316676 & 4.021755 C. 3 & $1<1>$ & 0.063027 \\
\hline 32 C32 & -5.255146 & 5.898629 & 3.472078 C. 3 & $1<1>$ & -0.079593 \\
\hline 33 S33 & -3.897826 & 4.791071 & 4.003835 S.3 & $1<1>$ & -0.049780 \\
\hline $34 \mathrm{O} 34$ & -8.742245 & 5.369425 & 3.216952 O.co2 & $1<1>$ & -0.573918 \\
\hline $35 \mathrm{O} 35$ & -7.797279 & 7.353122 & 3.679456 O.co2 & $1<1>$ & -0.573918 \\
\hline 36 N36 & -1.026538 & 4.515986 & 0.222001 N.3 & $1<1>$ & -0.346211 \\
\hline 37 C37 & -0.366051 & 4.566765 & -1.098815 C.3 & $1<1>$ & 0.055637 \\
\hline $38 \mathrm{C} 38$ & -1.334551 & 5.326736 & -2.033866 C. 3 & $1<1>$ & -0.078859 \\
\hline 39 S39 & -2.980850 & 4.715380 & -1.584108 S.3 & $1<1>$ & -0.047305 \\
\hline $40 \mathrm{C} 40$ & 0.966204 & 5.280203 & -1.059102 C.2 & $1<1>$ & 0.128495 \\
\hline $41 \mathrm{O} 41$ & 1.111826 & 6.207612 & -0.213889 O.co2 & $1<1>$ & -0.574106 \\
\hline $42 \mathrm{O} 42$ & 1.868010 & 4.926382 & -1.868709 O.co2 & $1<1>$ & -0.574106 \\
\hline $43 \mathrm{H} 45$ & 1.881826 & -1.405930 & $1.751828 \mathrm{H}$ & $1<1>$ & 0.052846 \\
\hline $44 \mathrm{H} 46$ & 3.871576 & -0.108802 & $1.377619 \mathrm{H}$ & $1<1>$ & 0.053175 \\
\hline $45 \mathrm{H} 47$ & 1.551578 & 3.624396 & $1.835576 \mathrm{H}$ & $1<1>$ & 0.053959 \\
\hline $46 \mathrm{H} 49$ & -1.838461 & -1.828675 & $0.418666 \mathrm{H}$ & $1<1>$ & 0.052723 \\
\hline $47 \mathrm{H} 50$ & -1.921112 & -4.297601 & $0.208291 \mathrm{H}$ & $1<1>$ & 0.052850 \\
\hline 48 H52 & 0.447362 & -4.670163 & $3.769218 \mathrm{H}$ & $1<1>$ & 0.052802 \\
\hline 49 H53 & -6.294709 & 3.154412 & $3.870214 \mathrm{H}$ & $1<1>$ & 0.219410 \\
\hline
\end{tabular}




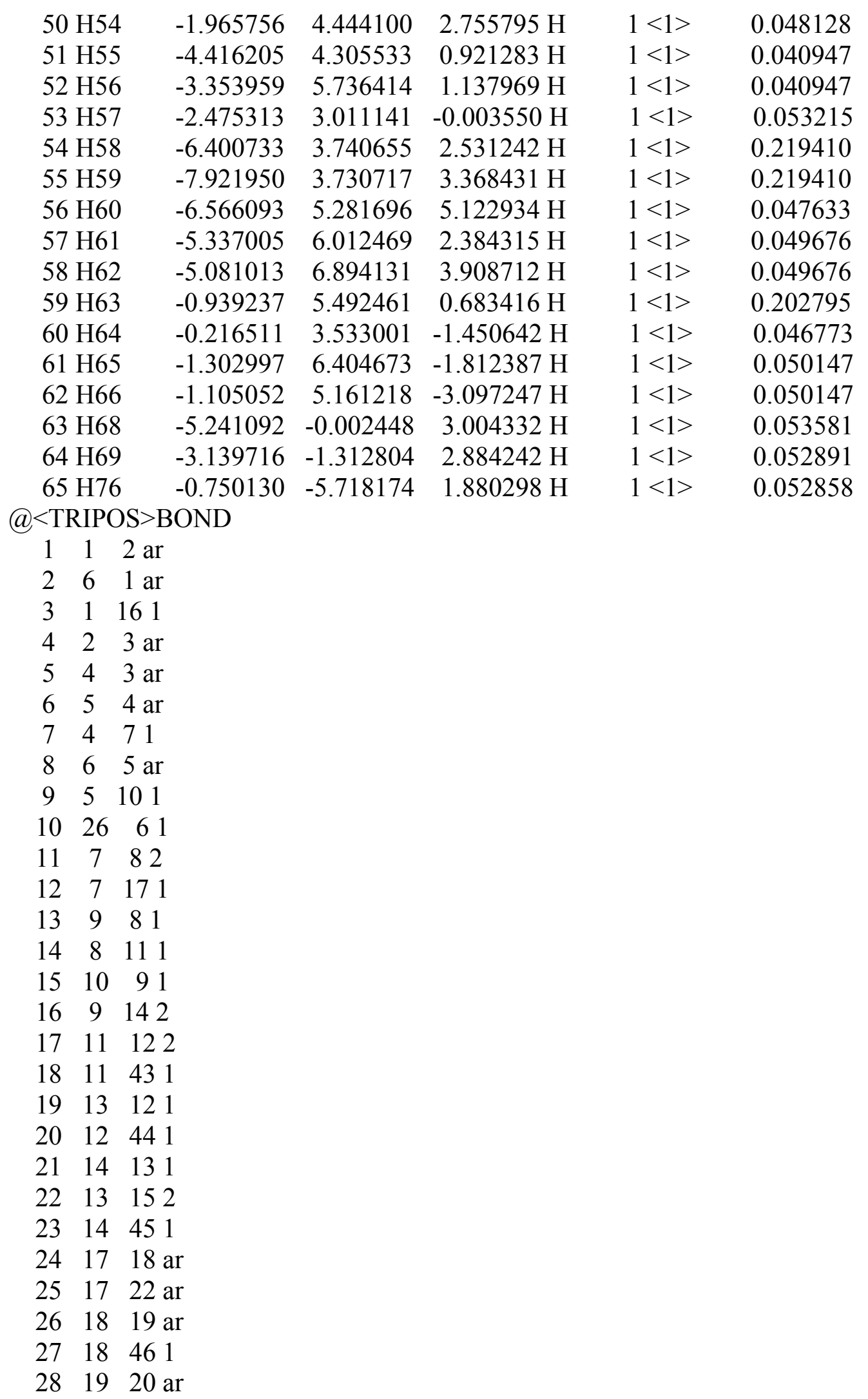




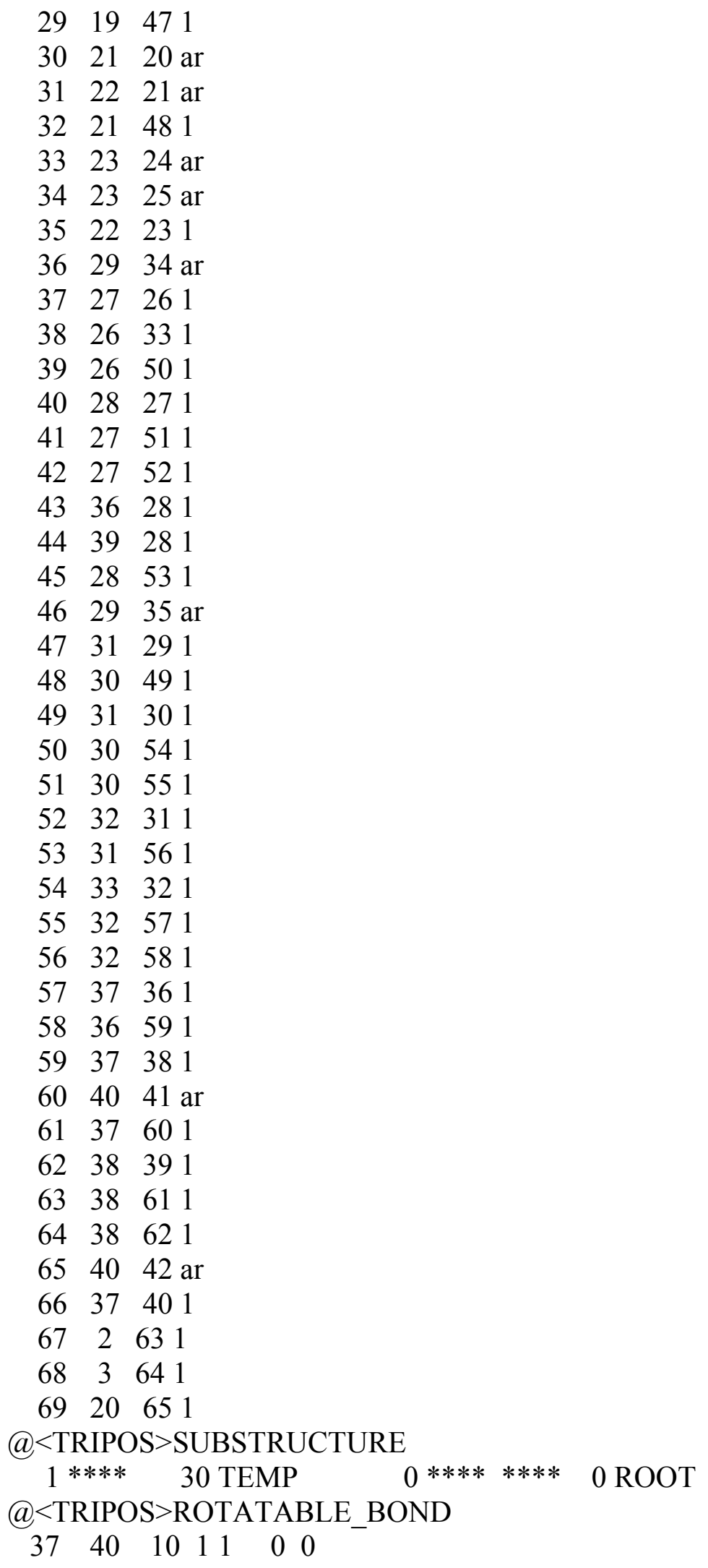



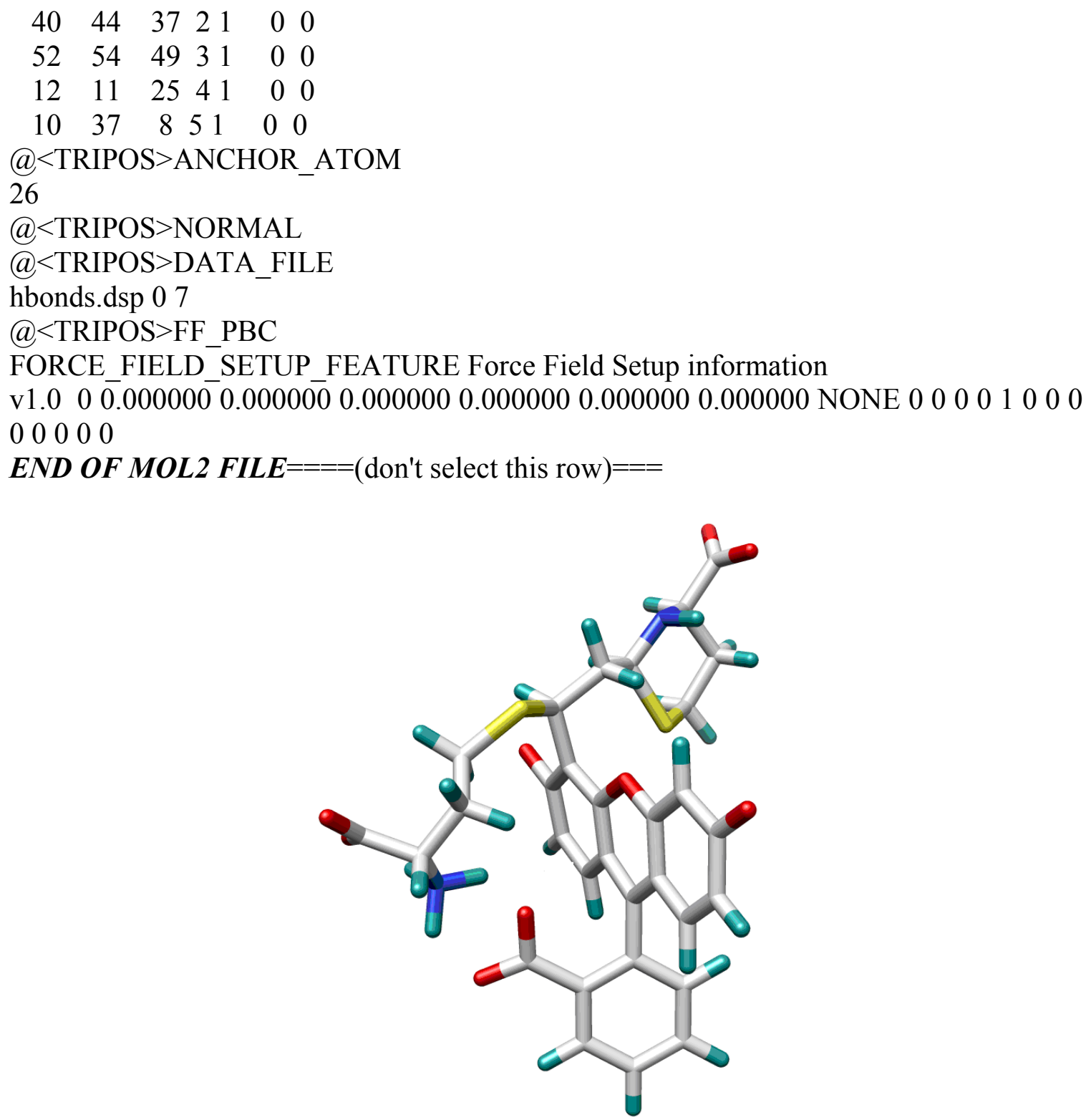

Figure C2. Reaction product of 2.1-Hcy

START OF MOL2 FILE===(don't select this row)=== @ $<$ TRIPOS $>$ MOLECULE

monoaldehyde_hcy

$\begin{array}{lllll}71 & 75 & 1 & 7 & 0\end{array}$

SMALL

GAST_HUCK

(a) $<$ TRIPOS $>$ ATOM

$\begin{array}{lllllll}1 \text { C1 } & -6.534613 & 0.422702 & -0.557650 \text { C.ar } & 1<1> & 0.124991 \\ \text { 2 C2 } & -6.570685 & -0.966615 & -0.687084 \text { C.ar } & 1<1> & -0.051937\end{array}$




\begin{tabular}{|c|c|c|c|c|c|}
\hline $3 \mathrm{C} 3$ & -5.389475 & -1.706431 & -0.609638 C.ar & $1<1>$ & -0.084925 \\
\hline $4 \mathrm{C} 4$ & -4.168483 & -1.050315 & -0.421090 C.ar & $1<1>$ & -0.022191 \\
\hline $5 \mathrm{C} 5$ & -4.125109 & 0.346475 & -0.392542 C.ar & $1<1>$ & 0.117146 \\
\hline $6 \mathrm{C} 6$ & -5.315492 & 1.084017 & -0.366590 C.ar & $1<1>$ & 0.032520 \\
\hline $7 \mathrm{C} 7$ & -2.880802 & -1.820198 & -0.233226 C. 2 & $1<1>$ & -0.056295 \\
\hline $8 \mathrm{C} 8$ & -1.727246 & -1.139742 & -0.198503 C. 2 & $1<1>$ & -0.033549 \\
\hline $9 \mathrm{C} 9$ & -1.746075 & 0.338407 & -0.330019 C. 2 & $1<1>$ & 0.083583 \\
\hline $10 \mathrm{O} 10$ & -2.900992 & 1.016373 & -0.3955120 .3 & $1<1>$ & -0.268794 \\
\hline $11 \mathrm{C} 11$ & -0.418116 & -1.810272 & -0.017067 C. 2 & $1<1>$ & -0.099875 \\
\hline $12 \mathrm{C} 12$ & 0.726603 & -1.119401 & -0.067163 C. 2 & $1<1>$ & -0.081893 \\
\hline $13 \mathrm{C} 13$ & 0.701902 & 0.333962 & -0.288849 C. 2 & $1<1>$ & 15653 \\
\hline $14 \mathrm{C} 14$ & -0.596284 & 1.021387 & -0.377969 C. 2 & $1<1>$ & 48798 \\
\hline & 1.745638 & 0.959990 & 0.2 & $1<1>$ & 113 \\
\hline 16016 & -7.723318 & 1.143142 & -0.622416 O.3 & $1<1>$ & 4283 \\
\hline $17 \mathrm{C} 17$ & -2.945653 & -3.324050 & -0.062804 C.ar & $1<1>$ & 5568 \\
\hline $18 \mathrm{C} 18$ & -2.372471 & -4.157257 & -1.028774 C.ar & $1<1>$ & 1718 \\
\hline 19 C19 & -2.465989 & -5.546204 & -0.904152 C.ar & $1<1>$ & 4928 \\
\hline $20 \mathrm{C} 20$ & -3.142632 & -6.103692 & 0.184380 C.ar & $1<1>$ & 3562 \\
\hline & -3.706565 & -5.271394 & 1.155938 C.ar & $1<1>$ & 3999 \\
\hline $22 \mathrm{C} 22$ & -3.592704 & -3.881470 & 1.050167 C.ar & $1<1>$ & 5207 \\
\hline $23 \mathrm{C} 23$ & -4.172120 & -2.997726 & 2.135807 C. 2 & $1<1>$ & 2084 \\
\hline $24 \mathrm{C} 24$ & -5.737324 & 5.297926 & -5.79678 & $1<1>$ & 909 \\
\hline $25 \mathrm{O} 25$ & -3.881314 & -1.777082 & 2.206476 O.co2 & $1<1>$ & -0.565249 \\
\hline $26 \mathrm{C} 26$ & -5.295766 & 2.602954 & -0.124000 C. 3 & $1<1>$ & 6309 \\
\hline $27 \mathrm{C} 27$ & -4.748255 & 3.389752 & -1.346116 C. 3 & $1<1>$ & -0.009821 \\
\hline $28 \mathrm{C} 28$ & -5.595687 & 3.161035 & -2.627184 C. 3 & $1<1>$ & 0.058136 \\
\hline $29 \mathrm{C} 29$ & -5.665797 & 0.634918 & 5.265128 C. 2 & $1<1>$ & 34434 \\
\hline & -5.542834 & -0.972012 & N.4 & $1<1>$ & \\
\hline $31 \mathrm{C} 31$ & -4.712298 & 0.024543 & 4.291267 C. 3 & $1<1>$ & 9081 \\
\hline $32 \mathrm{C} 32$ & -4.087549 & 1.126179 & 3.384049 C. 3 & $1<1>$ & 1511 \\
\hline $33 \mathrm{C} 33$ & -5.151741 & 1.984882 & 2.65009 & $1<1>$ & 2145 \\
\hline 34 S34 & -4.303720 & 2.975112 & 1.365720 S.3 & $1<1>$ & -0.147693 \\
\hline $35 \mathrm{O} 35$ & -4.513415 & 5.536035 & -5.988577 O.co2 & $1<1>$ & -0.567378 \\
\hline $36 \mathrm{O} 36$ & -5.243494 & 1.344377 & 6.208579 O.co2 & $1<1>$ & -0.564254 \\
\hline 37 N37 & -5.288815 & 4.196391 & -3.635747 N.3 & $1<1>$ & -0.289680 \\
\hline $38 \mathrm{C} 38$ & -6.109339 & 4.164254 & -4.869711 C. 3 & $1<1>$ & 0.062359 \\
\hline 39 C39 & -5.931275 & 2.829803 & -5.640961 C.3 & $1<1>$ & -0.016543 \\
\hline $40 \mathrm{C} 40$ & -6.341852 & 1.609093 & -4.781135 C. 3 & $1<1>$ & -0.001891 \\
\hline $41 \mathrm{~S} 41$ & -5.253006 & 1.515403 & -3.329831 S.3 & $1<1>$ & -0.141588 \\
\hline $42 \mathrm{O} 42$ & -6.665557 & 5.954671 & -6.345124 O.co2 & $1<1>$ & -0.567378 \\
\hline $43 \mathrm{O} 43$ & -4.997437 & -3.388496 & 3.009389 O.co2 & $1<1>$ & -0.565249 \\
\hline $44 \mathrm{O} 44$ & -6.868612 & 0.345931 & 5.019639 O.co2 & $1<1>$ & -0.564254 \\
\hline $45 \mathrm{H} 45$ & -7.519450 & -1.468382 & $-0.845392 \mathrm{H}$ & $1<1>$ & 0.044353 \\
\hline $46 \mathrm{H} 1$ & -6.665333 & 3.228499 & $-2.370902 \mathrm{H}$ & $1<1>$ & 0.057808 \\
\hline $47 \mathrm{H} 47$ & -0.355547 & -2.882651 & $0.164829 \mathrm{H}$ & $1<1>$ & 0.045622 \\
\hline
\end{tabular}




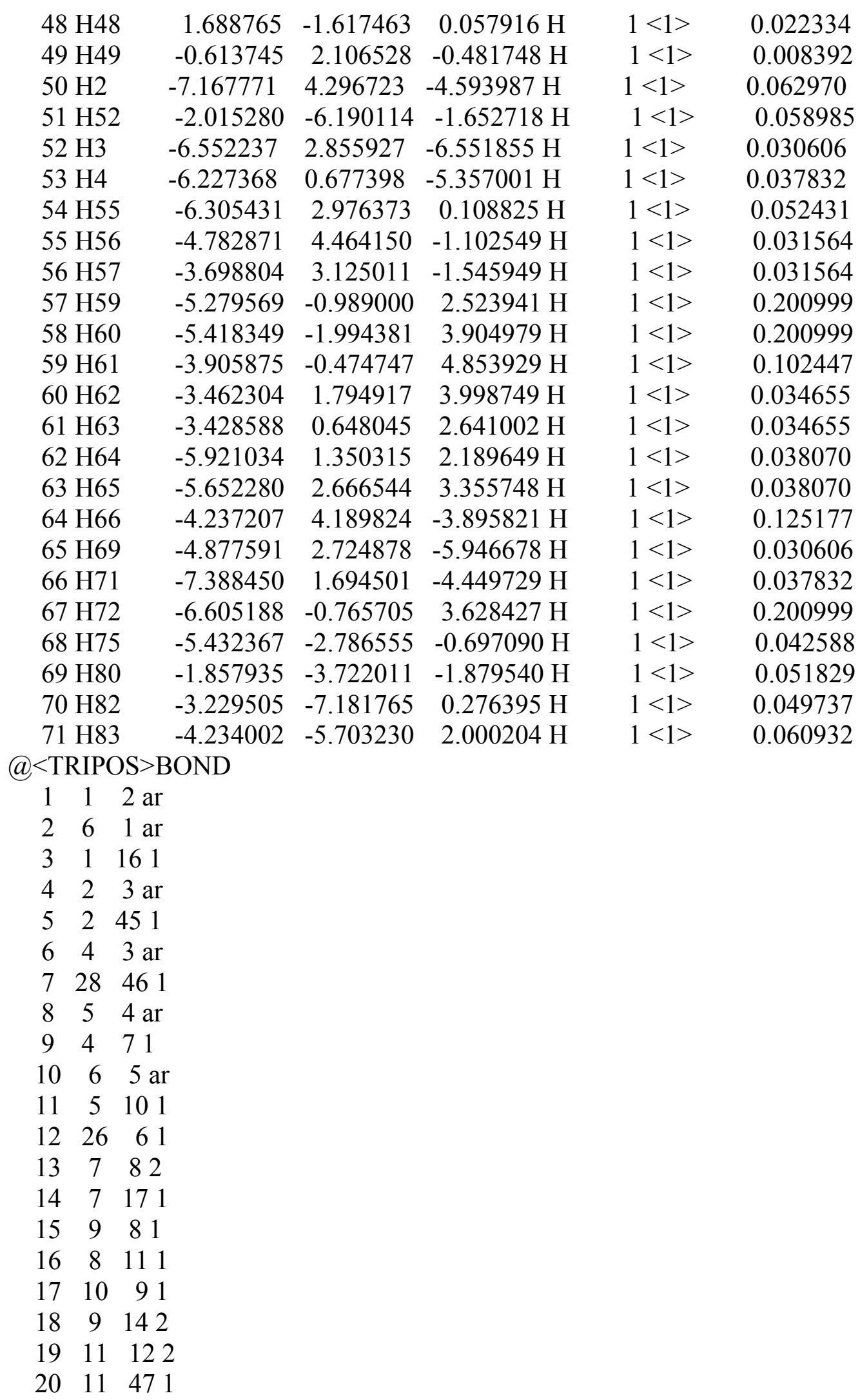




$$
\begin{aligned}
& \begin{array}{lll}
21 & 13 & 12
\end{array} \\
& \begin{array}{llll}
22 & 12 & 48 & 1
\end{array} \\
& \begin{array}{llll}
23 & 14 & 13 & 1
\end{array} \\
& \begin{array}{lll}
24 & 13 & 152
\end{array} \\
& \begin{array}{llll}
25 & 14 & 49 & 1
\end{array} \\
& \begin{array}{lll}
26 & 17 \quad 18 \text { ar }
\end{array} \\
& \begin{array}{lll}
27 & 17 & 22 \\
\text { ar }
\end{array} \\
& 28 \quad 18 \quad 19 \text { ar } \\
& \begin{array}{lll}
29 & 38 & 50
\end{array} \\
& \begin{array}{lll}
30 & 19 & 20 \\
31 & \text { ar }
\end{array} \\
& \begin{array}{llll}
31 & 19 & 51 & 1
\end{array} \\
& 32 \quad 21 \quad 20 \text { ar }
\end{aligned}
$$

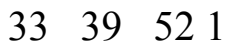

$$
\begin{aligned}
& 34 \quad 22 \quad 21 \text { ar } \\
& \begin{array}{llll}
35 & 40 & 53 & 1
\end{array} \\
& 36 \quad 23 \quad 25 \text { ar } \\
& \begin{array}{lll}
37 & 24 & 35 \\
\text { ar }
\end{array} \\
& 38 \quad 23 \quad 43 \text { ar } \\
& 39 \quad 24 \quad 42 \text { ar } \\
& \begin{array}{llll}
40 & 27 & 261
\end{array} \\
& \begin{array}{llll}
41 & 26 & 34 & 1
\end{array} \\
& \begin{array}{llll}
42 & 26 & 54 & 1
\end{array} \\
& \begin{array}{llll}
43 & 28 & 27 & 1
\end{array} \\
& \begin{array}{lll}
44 & 27 & 551
\end{array} \\
& \begin{array}{llll}
45 & 27 & 561
\end{array} \\
& \begin{array}{llll}
46 & 37 & 28 & 1
\end{array} \\
& \begin{array}{llll}
47 & 28 & 41 & 1
\end{array} \\
& 48 \quad 29 \quad 36 \text { ar } \\
& \begin{array}{llll}
49 & 38 & 24 & 1
\end{array} \\
& \begin{array}{lll}
50 & 29 & 44 \text { ar }
\end{array} \\
& \begin{array}{llll}
51 & 31 & 30 & 1
\end{array} \\
& \begin{array}{llll}
52 & 30 & 571
\end{array} \\
& \begin{array}{llll}
53 & 30 & 58 & 1
\end{array} \\
& \begin{array}{llll}
54 & 32 & 31 & 1
\end{array} \\
& \begin{array}{llll}
55 & 31 & 59 & 1
\end{array} \\
& \begin{array}{llll}
56 & 33 & 32 & 1
\end{array} \\
& \begin{array}{llll}
57 & 32 & 60 & 1
\end{array} \\
& \begin{array}{llll}
58 & 32 & 61 & 1
\end{array} \\
& \begin{array}{llll}
59 & 34 & 33 & 1
\end{array} \\
& \begin{array}{llll}
60 & 33 & 62 & 1
\end{array} \\
& \begin{array}{llll}
61 & 33 & 63 & 1
\end{array} \\
& \begin{array}{llll}
62 & 22 & 23 & 1
\end{array} \\
& \begin{array}{llll}
63 & 38 & 37 & 1
\end{array} \\
& \begin{array}{llll}
64 & 37 & 64 & 1
\end{array} \\
& \begin{array}{lll}
65 & 39 & 38
\end{array}
\end{aligned}
$$




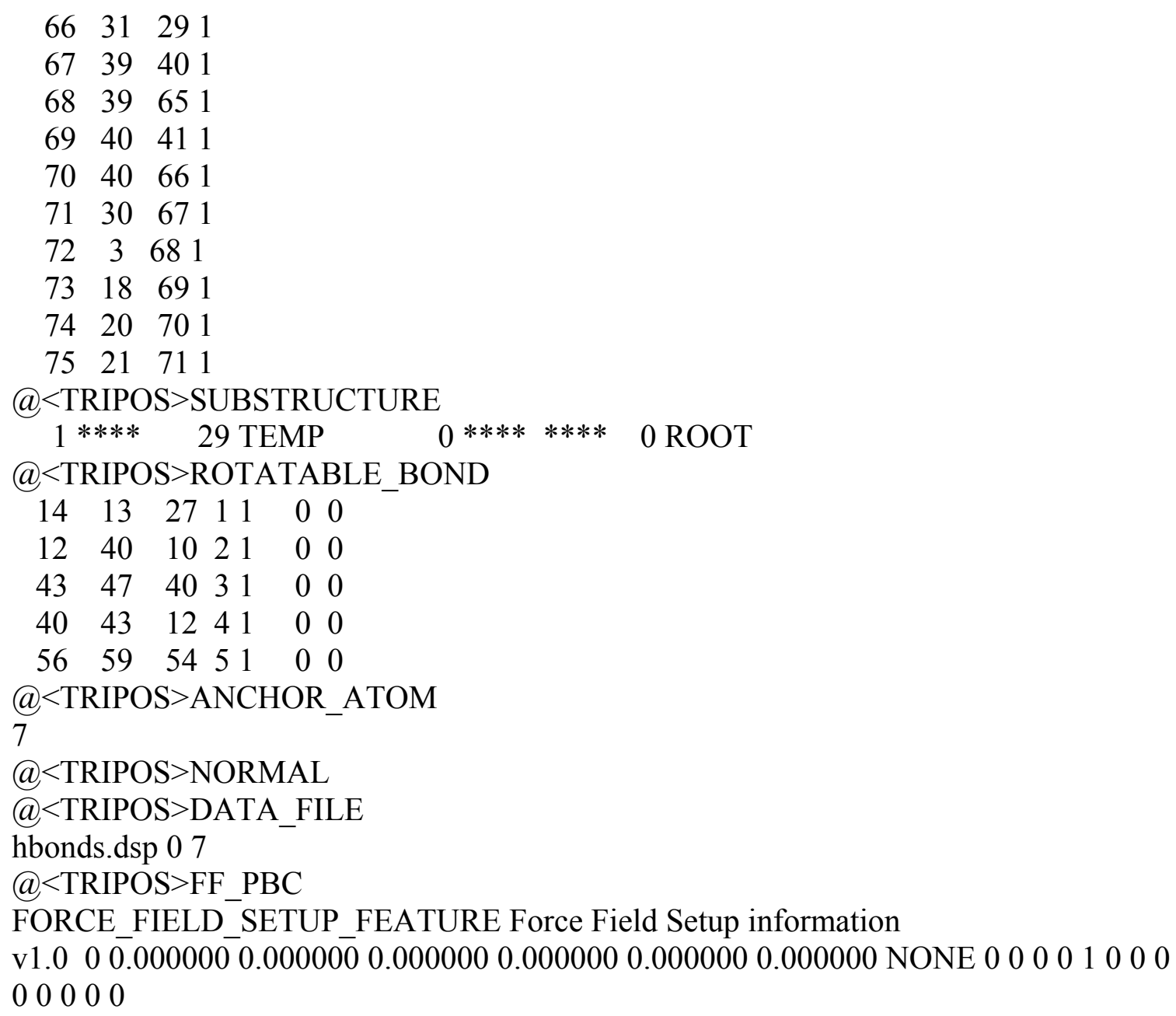

Molecular graphics images were produced using the UCSF Chimera ${ }^{2}$ package from the Resource for Biocomputing, Visualization, and Informatics at the University of California, San Francisco (supported by NIH P41 RR001081).

\section{References}

1. MOPAC2009, James J. P. Stewart, Stewart Computational Chemistry, Colorado Springs, CO, USA, HTTP://OpenMOPAC.net (2008).

2. UCSF Chimera--a visualization system for exploratory research and analysis. Pettersen, E. F.; Goddard, T. D.; Huang, C. C.; Couch, G. S.; Greenblatt, D. M.; Meng, E. C.; Ferrin, T. E. J. Comput. Chem. 2004, 25(13), 1605-1612. 


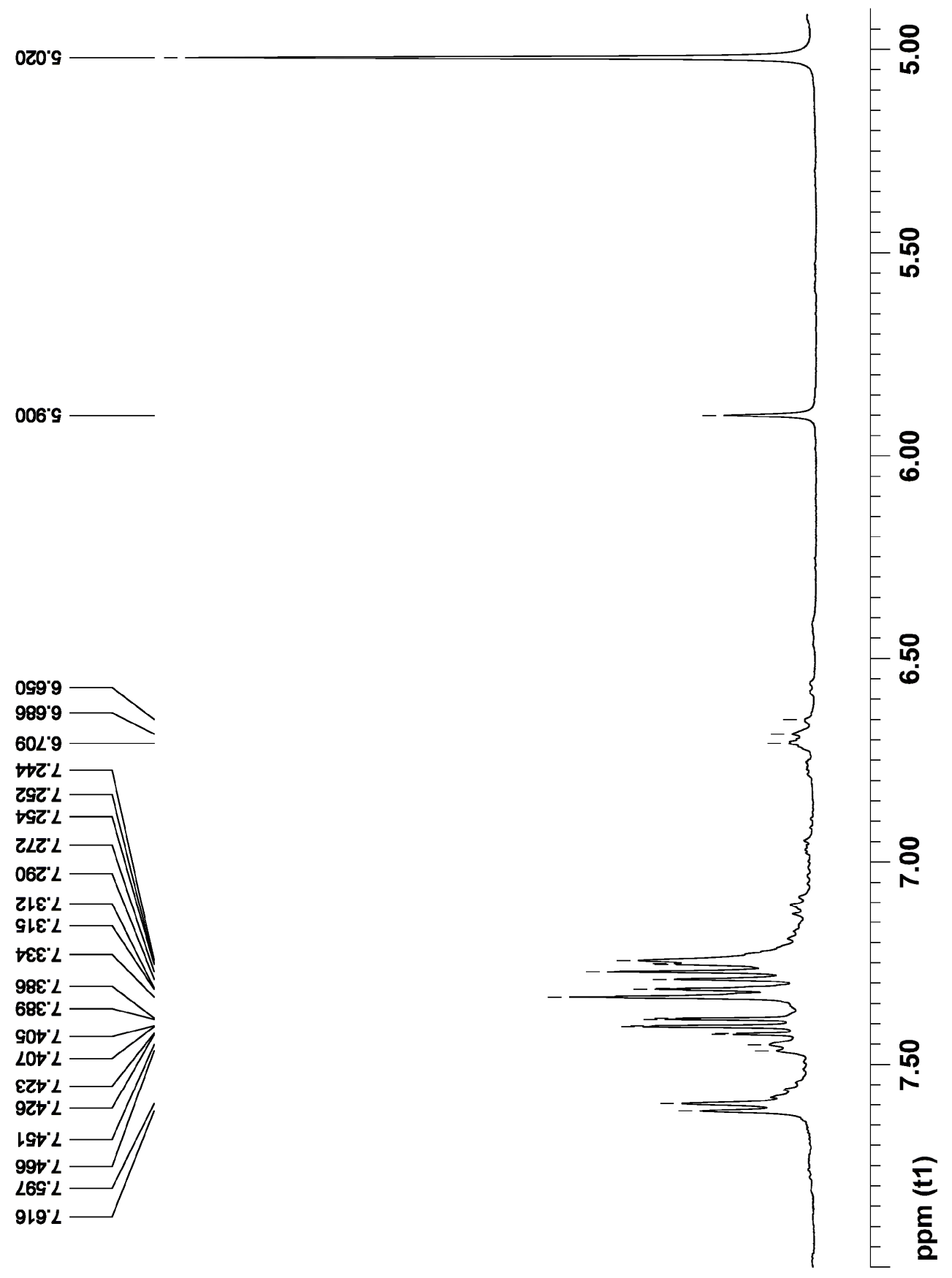

Figure D1. ${ }^{1} \mathrm{H}$ NMR of 3.1 in $\mathrm{CD}_{3} \mathrm{OD}(400 \mathrm{MHz})$ 


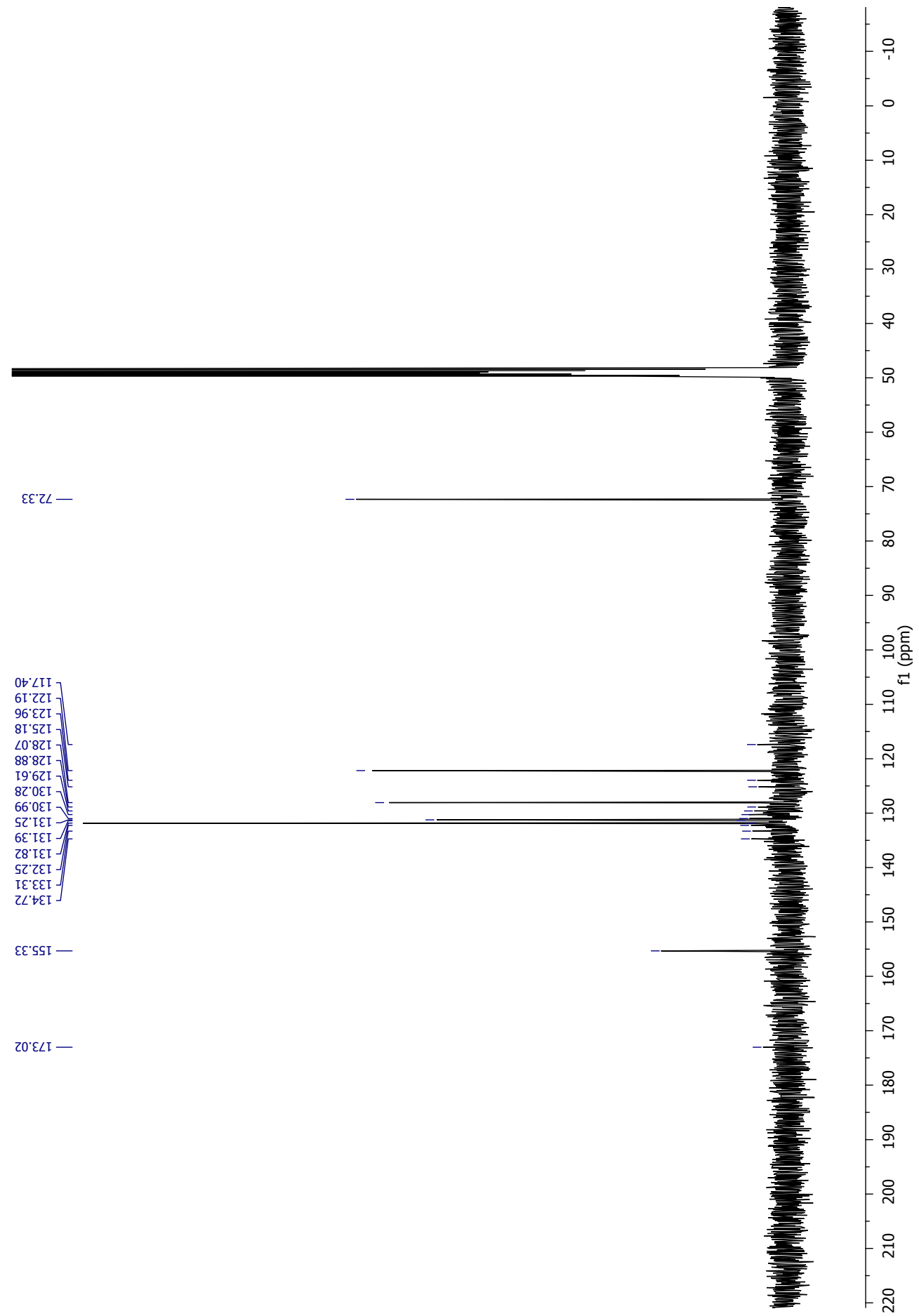

Figure D2. ${ }^{13} \mathrm{C}$ NMR of 3.1 (in $\mathrm{CD}_{3} \mathrm{OD} 101 \mathrm{MHz}$ ) 


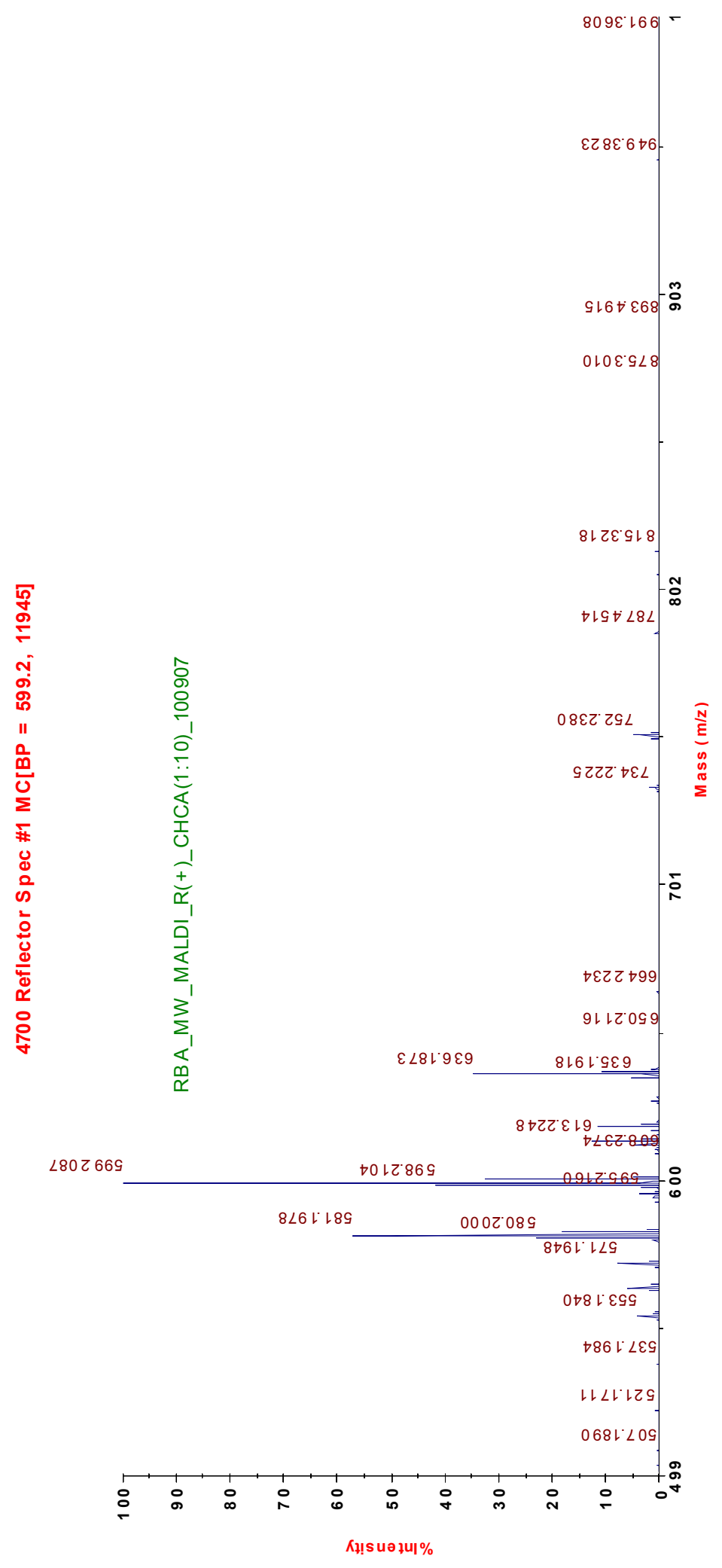

Figure D3. MALDI-TOF of $\mathbf{3 . 1}$ 


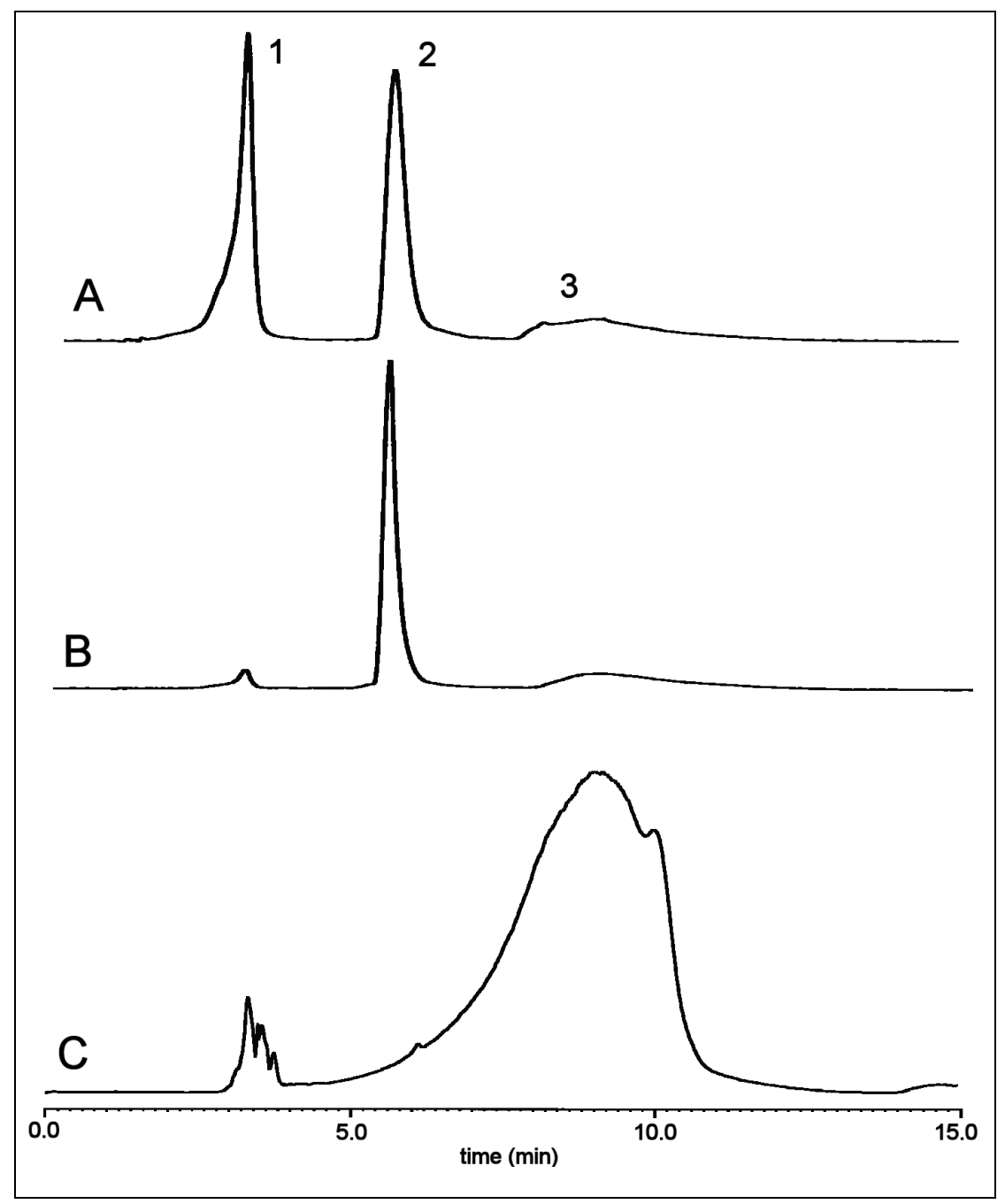

Figure D4. HPLC chromatograms from the preparation of $\mathbf{3 . 1}$ at various conditions. Peak 1 corresponds to rhodamine 110 and peak 3 to compound 3.1. A) using 2 equivalents of 2-formylphenylboronic acid and irradiated to keep the reaction at $90{ }^{\circ} \mathrm{C}$ for 8 min. B) same as above but increasing the temperature to $110^{\circ} \mathrm{C}$ and time to $10 \mathrm{~min}$. C) using 5 equivalents of 2-formylphenylboronic acid and keeping the temperature at 130 ${ }^{\circ} \mathrm{C}$ for $20 \mathrm{~min}$. HPLC conditions: sample size: $20 \mu \mathrm{L}$; flow rate: $1 \mathrm{~mL} / \mathrm{min}$; mobile phase: gradient $50 \% \mathrm{MeOH} / \mathrm{H}_{2} \mathrm{O}$ to $100 \% \mathrm{MeOH}$ in $10 \mathrm{~min}$ ); detection wavelength: 520 nm. 


\section{APPENDIX E. COMPUTATIONAL PROCEDURES OF ENERGY-MINIMIZED MODEL OF THE BORONATE ESTER FORMED AFTER CONDENSATION OF ONE EQUIVALENT OF AN AICAR TO 3.1.}

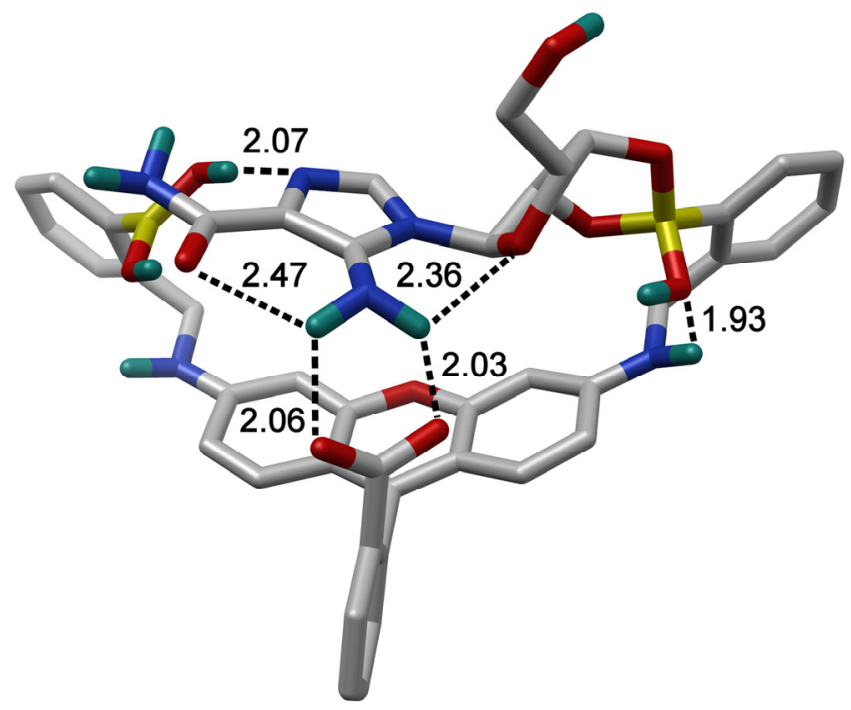

Molecular models were built using the SYBYL ${ }^{\text {TM }}$ software package version X-1.1 (Tripos Inc.) and then submitted for geometry optimization and energy minimization via MOPAC $2009^{1}$ with the following command keywords: PM6 CHARGE=-2 EF GEO-OK GNORM $=0.100$ MMOK SHIFT $=80$.

The processed file which corresponds to Fig. 3.2 in the text is presented below in mol2 file format. To read the file, copy the text between "start of mol2 file" and "end of mol2 file" and paste it in a text editor (e.g. MS notepad) and save the file with any name with the extension ".mol2"; this file can then be opened with almost any molecular viewer program (e.g. RASMOL, UCSF Chimera, Cambridgesoft Chem3D ${ }^{\mathrm{TM}}$, SYBYL ${ }^{\mathrm{TM}}$, etc.).

START OF MOL2 FILE $===($ don't select this row $)==$ (a) $<$ TRIPOS $>$ MOLECULE

AICAr-1_monoboronate

$101109 \overline{1} 00$

SMALL

USER_CHARGES

$\begin{array}{crllllll}\text { @ }<\text { TRIPOS }>\text { ATOM } & & & & & \\ 1 \mathrm{~N} & 1.5071 & -0.3078 & 4.0600 \mathrm{~N} . \mathrm{am} & 1 & * * * * & 0.0000 \\ 2 \mathrm{H} & 0.7189 & -0.5053 & 4.6623 \mathrm{H} & 1 & * * * * & 0.0000 \\ 3 \mathrm{H} & 2.3333 & -0.0232 & 4.5717 \mathrm{H} & 1 & * * * * & 0.0000 \\ 4 \mathrm{C} & 1.0662 & -4.8262 & 0.4011 \mathrm{C} .2 & 1 & * * * * & 0.0000 \\ 5 \mathrm{C} & -0.2354 & -4.6591 & -0.1163 \mathrm{C} .2 & 1 & * * * * & 0.0000\end{array}$




\begin{tabular}{|c|c|c|c|c|c|c|}
\hline $6 \mathrm{C}$ & -0.4057 & -3.7731 & -1.1764 C. 2 & 1 & $* * * *$ & 0.0000 \\
\hline $7 \mathrm{C}$ & 0.6529 & -3.0825 & -1.8135 C.2 & 1 & $* * * *$ & 0.0000 \\
\hline $8 \mathrm{C}$ & 1.9629 & -3.3105 & -1.2934 C.2 & 1 & $* * * *$ & 0.0000 \\
\hline $9 \mathrm{C}$ & 2.1692 & -4.1477 & -0.2259 C. 2 & 1 & $* * * *$ & 0.0000 \\
\hline $10 \mathrm{C}$ & 0.2384 & -6.2043 & 2.3200 C. 3 & 1 & $* * * *$ & 0.0000 \\
\hline $11 \mathrm{C}$ & 0.7133 & -6.3840 & 3.7399 C.ar & 1 & $* * * *$ & 0.0000 \\
\hline $12 \mathrm{C}$ & 0.9297 & -5.2744 & 4.5651 C.ar & 1 & $* * * *$ & 0.0000 \\
\hline $13 \mathrm{C}$ & 1.3413 & -5.4381 & 5.8870 C.ar & 1 & $* * * *$ & 0.0000 \\
\hline $14 \mathrm{C}$ & 1.5442 & -6.7262 & 6.3949 C.ar & 1 & $* * * *$ & 0.0000 \\
\hline $15 \mathrm{C}$ & 1.3377 & -7.8412 & 5.5760 C.ar & 1 & $* * * *$ & 0.0000 \\
\hline $16 \mathrm{C}$ & 0.9251 & -7.6733 & 4.2512 C.ar & 1 & $* * * *$ & 0.0000 \\
\hline $17 \mathrm{~N}$ & 1.3396 & -5.6831 & 1.4587 N.pl3 & 1 & $* * * *$ & 1.0000 \\
\hline $18 \mathrm{~B}$ & 0.7329 & -3.8259 & $4.0038 \mathrm{~B}$ & 1 & $* * * *$ & 0.0000 \\
\hline $19 \mathrm{O}$ & -0.4326 & -3.1644 & 4.22700 .3 & 1 & $* * * *$ & 0.0000 \\
\hline $20 \mathrm{O}$ & 1.7574 & -3.2744 & 3.28200 .3 & 1 & $* * * *$ & 0.0000 \\
\hline $21 \mathrm{O}$ & -1.7252 & -3.6081 & -1.56860 .3 & 1 & $* * * *$ & 0.0000 \\
\hline $22 \mathrm{C}$ & -2.0254 & -2.5689 & -2.4473 C.ar & 1 & $* * * *$ & 0.0000 \\
\hline $23 \mathrm{C}$ & -0.9729 & -1.8349 & -3.1000 C.ar & 1 & $* * * *$ & 0.0000 \\
\hline $24 \mathrm{C}$ & 0.3585 & -2.1295 & -2.8414 C. 2 & 1 & $* * * *$ & 0.0000 \\
\hline $25 \mathrm{C}$ & -3.3643 & -2.3359 & -2.6164 C.ar & 1 & $* * * *$ & 0.0000 \\
\hline $26 \mathrm{C}$ & -3.7612 & -1.1988 & -3.3994 C.ar & 1 & $* * * *$ & 0.0000 \\
\hline $27 \mathrm{C}$ & -2.7266 & -0.4142 & -4.0530 C.ar & 1 & $* * * *$ & 0.0000 \\
\hline $28 \mathrm{C}$ & -1.4085 & -0.7133 & -3.9123 C.ar & 1 & $* * * *$ & 0.0000 \\
\hline $29 \mathrm{~N}$ & -5.0554 & -0.8580 & -3.6066 N.pl3 & 1 & $* * * *$ & 0.0000 \\
\hline $30 \mathrm{C}$ & -6.1730 & -1.4786 & -2.8335 C. 3 & 1 & $* * * *$ & 0.0000 \\
\hline $31 \mathrm{C}$ & -7.3361 & -0.5252 & -2.7250 C.ar & 1 & $* * * *$ & 0.0000 \\
\hline $32 \mathrm{C}$ & -8.5923 & -0.8997 & -3.2282 C.ar & 1 & $* * * *$ & 0.0000 \\
\hline $33 \mathrm{C}$ & -9.6868 & -0.0459 & -3.0788 C.ar & 1 & & 0.0000 \\
\hline $34 \mathrm{C}$ & -9.5302 & 1.1863 & -2.4300 C.ar & 1 & $* * * *$ & 0.0000 \\
\hline $35 \mathrm{C}$ & -8.2792 & 1.5632 & -1.9387 C.ar & 1 & $* * * *$ & 0.0000 \\
\hline $36 \mathrm{C}$ & -7.1789 & 0.7125 & -2.0856 C.ar & 1 & $* * * *$ & 0.0000 \\
\hline $37 \mathrm{C}$ & 1.4684 & -1.5381 & -3.6250 C.ar & 1 & $* * * *$ & 0.0000 \\
\hline $38 \mathrm{C}$ & 2.0618 & -2.3331 & -4.6243 C.ar & 1 & $* * * *$ & 0.0000 \\
\hline $39 \mathrm{C}$ & 3.1056 & -1.8199 & -5.3919 C.ar & 1 & $* * * *$ & 0.0000 \\
\hline $40 \mathrm{C}$ & 3.5748 & -0.5194 & -5.1585 C.ar & 1 & $* * * *$ & 0.0000 \\
\hline $41 \mathrm{C}$ & 2.9939 & 0.2625 & -4.1609 C.ar & 1 & $* * * *$ & 0.0000 \\
\hline $42 \mathrm{C}$ & 1.9322 & -0.2392 & -3.3956 C.ar & 1 & $* * * *$ & 0.0000 \\
\hline $43 \mathrm{C}$ & 1.3186 & 0.6600 & -2.3080 C.2 & 1 & $* * * *$ & 0.0000 \\
\hline $44 \mathrm{O}$ & 0.0767 & 0.8090 & -2.3486 O.co2 & 1 & $* * * *$ & -1.0000 \\
\hline $45 \mathrm{O}$ & 2.1030 & 1.1522 & -1.4837 O.co2 & 1 & $* * * *$ & 0.0000 \\
\hline $46 \mathrm{~B}$ & -5.7555 & 1.2022 & $-1.5675 \mathrm{~B}$ & 1 & $* * * *$ & -1.0000 \\
\hline $47 \mathrm{O}$ & -4.9794 & 0.0960 & -0.87730 .3 & 1 & $* * * *$ & 0.0000 \\
\hline $48 \mathrm{O}$ & -5.8321 & 2.2922 & -0.54500 .3 & 1 & $* * * *$ & 0.0000 \\
\hline $49 \mathrm{O}$ & -4.9750 & 1.6431 & -2.72120 .3 & 1 & $* * * *$ & 0.0000 \\
\hline $50 \mathrm{H}$ & -0.5969 & -2.2830 & $3.8337 \mathrm{H}$ & 1 & $* * * *$ & 0.0000 \\
\hline
\end{tabular}




\begin{tabular}{|c|c|c|c|c|c|c|}
\hline $51 \mathrm{~N}$ & -1.8427 & 0.4574 & 0.8811 N.ar & 1 & $* * * *$ & 0.0000 \\
\hline $52 \mathrm{C}$ & -3.0164 & 3.6762 & 1.3770 C. 3 & 1 & $* * * *$ & 0.0000 \\
\hline $53 \mathrm{C}$ & -4.2702 & 0.6449 & 0.1849 C. 3 & 1 & $* * * *$ & 0.0000 \\
\hline $54 \mathrm{C}$ & -4.8215 & 2.0984 & 0.3992 C. 3 & 1 & $* * * *$ & 0.0000 \\
\hline $55 \mathrm{C}$ & -3.6205 & 3.0377 & 0.1211 C. 3 & 1 & $* * * *$ & 0.0000 \\
\hline $56 \mathrm{O}$ & -2.5823 & 2.2273 & -0.49530 .3 & 1 & $* * * *$ & 0.0000 \\
\hline $57 \mathrm{C}$ & -2.7739 & 0.8374 & -0.2204 C. 3 & 1 & $* * * *$ & 0.0000 \\
\hline $58 \mathrm{O}$ & -3.7581 & 4.8424 & 1.76350 .3 & 1 & $* * * *$ & 0.0000 \\
\hline $59 \mathrm{C}$ & -2.1197 & -0.4250 & 1.9773 C.ar & 1 & $* * * *$ & 0.0000 \\
\hline $60 \mathrm{~N}$ & -1.0637 & -0.5628 & 2.7749 N.ar & 1 & $* * * *$ & 0.0000 \\
\hline $61 \mathrm{C}$ & -0.0362 & 0.2434 & 2.2382 C.ar & 1 & $* * * *$ & 0.0000 \\
\hline $62 \mathrm{C}$ & -0.4961 & 0.8803 & 1.0421 C.ar & 1 & $* * * *$ & 0.0000 \\
\hline $63 \mathrm{C}$ & 1.2625 & 0.4125 & 2.8468 C. 2 & 1 & $* * * *$ & 0.0000 \\
\hline $64 \mathrm{O}$ & 2.1849 & 1.0730 & 2.3890 O.2 & 1 & $* * * *$ & 0.0000 \\
\hline $65 \mathrm{~N}$ & 0.1294 & 1.8007 & 0.2542 N.3 & 1 & $* * * *$ & 0.0000 \\
\hline $66 \mathrm{H}$ & -1.1005 & -5.1575 & $0.3106 \mathrm{H}$ & 1 & $* * * *$ & 0.0000 \\
\hline $67 \mathrm{H}$ & 2.8023 & -2.7755 & $-1.7532 \mathrm{H}$ & 1 & $* * * *$ & 0.0000 \\
\hline $68 \mathrm{H}$ & 3.1713 & -4.2802 & $0.1787 \mathrm{H}$ & 1 & $* * * *$ & 0.0000 \\
\hline $69 \mathrm{H}$ & -0.6513 & -5.5243 & $2.3070 \mathrm{H}$ & 1 & $* * * *$ & 0.0000 \\
\hline $70 \mathrm{H}$ & -0.1033 & -7.1708 & $1.8797 \mathrm{H}$ & 1 & $* * * *$ & 0.0000 \\
\hline $71 \mathrm{H}$ & 1.5016 & -4.5688 & $6.5239 \mathrm{H}$ & 1 & $* * * *$ & 0.0000 \\
\hline $72 \mathrm{H}$ & 1.8628 & -6.8597 & $7.4264 \mathrm{H}$ & 1 & $* * * *$ & 0.0000 \\
\hline $73 \mathrm{H}$ & 1.4981 & -8.8421 & $5.9700 \mathrm{H}$ & 1 & $* * * *$ & 0.0000 \\
\hline $74 \mathrm{H}$ & 0.7688 & -8.5445 & $3.6182 \mathrm{H}$ & 1 & $* * * *$ & 0.0000 \\
\hline $75 \mathrm{H}$ & 1.7073 & -2.3481 & $3.0040 \mathrm{H}$ & 1 & $* * * *$ & 0.0000 \\
\hline $76 \mathrm{H}$ & -4.1052 & -2.9354 & $-2.0943 \mathrm{H}$ & 1 & $* * * *$ & 0.0000 \\
\hline $77 \mathrm{H}$ & -3.0346 & 0.4709 & $-4.6138 \mathrm{H}$ & 1 & $* * * *$ & 0.0000 \\
\hline $78 \mathrm{H}$ & -0.6285 & -0.0862 & $-4.3648 \mathrm{H}$ & 1 & $* * * *$ & 0.0000 \\
\hline $79 \mathrm{H}$ & -5.2464 & 0.1377 & $-3.8985 \mathrm{H}$ & 1 & $* * * *$ & 0.0000 \\
\hline $80 \mathrm{H}$ & -5.8319 & -1.7242 & $-1.7892 \mathrm{H}$ & 1 & $* * * *$ & 0.0000 \\
\hline $81 \mathrm{H}$ & -6.4563 & -2.4293 & $-3.3341 \mathrm{H}$ & 1 & $* * * *$ & 0.0000 \\
\hline $82 \mathrm{H}$ & -8.7168 & -1.8533 & $-3.7328 \mathrm{H}$ & 1 & $* * * *$ & 0.0000 \\
\hline $83 \mathrm{H}$ & -10.6581 & -0.3356 & $-3.4655 \mathrm{H}$ & 1 & $* * * *$ & 0.0000 \\
\hline $84 \mathrm{H}$ & -10.3836 & 1.8483 & $-2.3126 \mathrm{H}$ & 1 & $* * * *$ & 0.0000 \\
\hline $85 \mathrm{H}$ & -8.1394 & 2.5203 & $-1.4326 \mathrm{H}$ & 1 & $* * * *$ & 0.0000 \\
\hline $86 \mathrm{H}$ & 1.7007 & -3.3445 & $-4.7984 \mathrm{H}$ & 1 & $* * * *$ & 0.0000 \\
\hline $87 \mathrm{H}$ & 3.5588 & -2.4290 & $-6.1699 \mathrm{H}$ & 1 & $* * * *$ & 0.0000 \\
\hline $88 \mathrm{H}$ & 4.3948 & -0.1236 & $-5.7536 \mathrm{H}$ & 1 & $* * * *$ & 0.0000 \\
\hline $89 \mathrm{H}$ & 3.3628 & 1.2693 & $-3.9504 \mathrm{H}$ & 1 & $* * * *$ & 0.0000 \\
\hline $90 \mathrm{H}$ & -4.1496 & 2.0436 & $-2.4744 \mathrm{H}$ & 1 & $* * * *$ & 0.0000 \\
\hline $91 \mathrm{H}$ & -1.9984 & 4.0682 & $1.1726 \mathrm{H}$ & 1 & $* * * *$ & 0.0000 \\
\hline $92 \mathrm{H}$ & -2.9658 & 2.9816 & $2.2326 \mathrm{H}$ & 1 & $* * * *$ & 0.0000 \\
\hline $93 \mathrm{H}$ & -4.4170 & -0.0225 & $1.0543 \mathrm{H}$ & 1 & $* * * *$ & 0.0000 \\
\hline $94 \mathrm{H}$ & -5.2763 & 2.2593 & $1.3938 \mathrm{H}$ & 1 & $* * * *$ & 0.0000 \\
\hline $95 \mathrm{H}$ & -3.8617 & 3.7962 & $-0.6567 \mathrm{H}$ & 1 & $* * * *$ & 0.0000 \\
\hline
\end{tabular}




$$
\begin{aligned}
& \begin{array}{lllllll}
96 \mathrm{H} & -2.4686 & 0.3275 & -1.1699 \mathrm{H} & 1 & * * * * & 0.0000
\end{array} \\
& \begin{array}{lllllll}
97 \mathrm{H} & -4.7158 & 4.6465 & 1.7839 \mathrm{H} & 1 & * * * * & 0.0000
\end{array} \\
& \begin{array}{lllllll}
98 \mathrm{H} & -3.0796 & -0.9071 & 2.0882 \mathrm{H} & 1 & * * * * & 0.0000
\end{array} \\
& \begin{array}{lllllll}
99 \mathrm{H} & 1.1708 & 1.7766 & 0.2468 \mathrm{H} & 1 & * * * * & 0.0000
\end{array} \\
& 100 \mathrm{H} \quad-0.2472 \quad 1.9518 \quad-0.7034 \mathrm{H} \quad 1 \quad * * * * \quad 0.0000 \\
& \begin{array}{lllllll}
101 \mathrm{H} & 2.2215 & -5.5267 & 1.9622 \mathrm{H} & 1 & * * * * & 0.0000
\end{array} \\
& \text { @ }<\text { TRIPOS }>\text { BOND } \\
& \begin{array}{llll}
1 & 1 & 2 & 1
\end{array} \\
& \begin{array}{llll}
2 & 1 & 3 & 1
\end{array} \\
& \begin{array}{llll}
3 & 1 & 63 & 1
\end{array} \\
& \begin{array}{llll}
4 & 4 & 5 & 1
\end{array} \\
& \begin{array}{llll}
5 & 4 & 9 & 1
\end{array} \\
& \begin{array}{llll}
6 & 4 & 17 & 2
\end{array} \\
& \begin{array}{llll}
7 & 5 & 6 & 2
\end{array} \\
& \begin{array}{llll}
8 & 5 & 66 & 1
\end{array} \\
& \begin{array}{llll}
9 & 6 & 7 & 1
\end{array} \\
& \begin{array}{llll}
10 & 6 & 21 & 1
\end{array} \\
& \begin{array}{llll}
11 & 7 & 8 & 1
\end{array} \\
& \begin{array}{llll}
12 & 7 & 24 & 2
\end{array} \\
& \begin{array}{llll}
13 & 8 & 9 & 2
\end{array} \\
& \begin{array}{llll}
14 & 8 & 67 & 1
\end{array} \\
& \begin{array}{llll}
15 & 9 & 68 & 1
\end{array} \\
& \begin{array}{llll}
16 & 10 & 11 & 1
\end{array} \\
& \begin{array}{llll}
17 & 10 & 17 & 1
\end{array} \\
& \begin{array}{llll}
18 & 10 & 69 & 1
\end{array} \\
& \begin{array}{llll}
19 & 10 & 70 & 1
\end{array} \\
& \begin{array}{llll}
20 & 11 & 12 & 2
\end{array} \\
& \begin{array}{llll}
21 & 11 & 16 & 1
\end{array} \\
& \begin{array}{llll}
22 & 12 & 13 & 1
\end{array} \\
& \begin{array}{llll}
23 & 12 & 18 & 1
\end{array} \\
& \begin{array}{llll}
24 & 13 & 14 & 2
\end{array} \\
& \begin{array}{llll}
25 & 13 & 71 & 1
\end{array} \\
& \begin{array}{llll}
26 & 14 & 15 & 1
\end{array} \\
& \begin{array}{llll}
27 & 14 & 72 & 1
\end{array} \\
& \begin{array}{llll}
28 & 15 & 16 & 2
\end{array} \\
& \begin{array}{llll}
29 & 15 & 73 & 1
\end{array} \\
& \begin{array}{llll}
30 & 16 & 74 & 1
\end{array} \\
& \begin{array}{llll}
31 & 17 & 101 & 1
\end{array} \\
& \begin{array}{llll}
32 & 18 & 19 & 1
\end{array} \\
& \begin{array}{llll}
33 & 18 & 20 & 1
\end{array} \\
& \begin{array}{llll}
34 & 19 & 50 & 1
\end{array} \\
& \begin{array}{llll}
35 & 20 & 75 & 1
\end{array} \\
& \begin{array}{llll}
36 & 21 & 22 & 1
\end{array} \\
& \begin{array}{llll}
37 & 22 & 23 & 2
\end{array} \\
& \begin{array}{llll}
38 & 22 & 25 & 1
\end{array}
\end{aligned}
$$




$\begin{array}{llll}39 & 23 & 24 & 1 \\ 40 & 23 & 28 & 1 \\ 41 & 24 & 37 & 1 \\ 42 & 25 & 26 & 2 \\ 43 & 25 & 76 & 1 \\ 44 & 26 & 27 & 1 \\ 45 & 26 & 29 & 1 \\ 46 & 27 & 28 & 2 \\ 47 & 27 & 77 & 1 \\ 48 & 28 & 78 & 1 \\ 49 & 29 & 30 & 1 \\ 50 & 29 & 79 & 1 \\ 51 & 30 & 31 & 1 \\ 52 & 30 & 80 & 1 \\ 53 & 30 & 81 & 1 \\ 54 & 31 & 32 & 2 \\ 55 & 31 & 36 & 1 \\ 56 & 32 & 33 & 1 \\ 57 & 32 & 82 & 1 \\ 58 & 33 & 34 & 2 \\ 59 & 33 & 83 & 1 \\ 60 & 34 & 35 & 1 \\ 61 & 34 & 84 & 1 \\ 62 & 35 & 36 & 2 \\ 63 & 35 & 85 & 1 \\ 64 & 36 & 46 & 1 \\ 65 & 37 & 38 & 2 \\ 66 & 37 & 42 & 1 \\ 67 & 38 & 39 & 1 \\ 68 & 38 & 86 & 1 \\ 69 & 39 & 40 & 2 \\ 70 & 39 & 87 & 1 \\ 71 & 40 & 41 & 1 \\ 72 & 40 & 88 & 1 \\ 73 & 41 & 42 & 2 \\ 74 & 41 & 89 & 1 \\ 75 & 42 & 43 & 1 \\ 76 & 43 & 44 & 1 \\ 77 & 43 & 45 & 2 \\ 78 & 46 & 47 & 1 \\ 79 & 46 & 48 & 1 \\ 80 & 46 & 49 & 1 \\ 81 & 47 & 53 & 1 \\ 82 & 48 & 54 & 1 \\ 83 & 49 & 90 & 1 \\ & & & \end{array}$




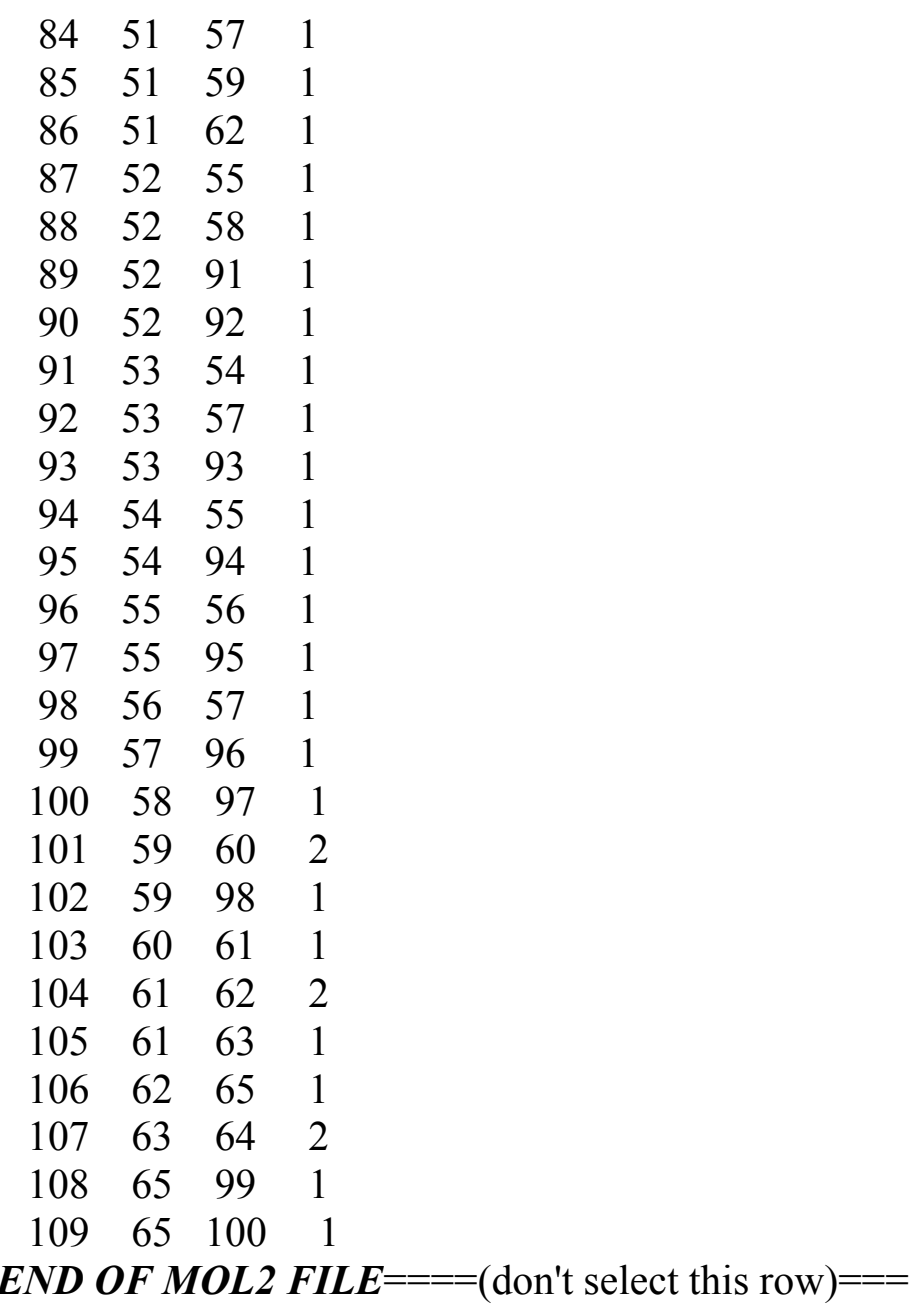

Molecular graphics images were produced using the UCSF Chimera ${ }^{2}$ package from the Resource for Biocomputing, Visualization, and Informatics at the University of California, San Francisco (supported by NIH P41 RR001081).

\section{References}

1. MOPAC2009, James J. P. Stewart, Stewart Computational Chemistry, Colorado Springs, CO, USA, HTTP://OpenMOPAC.net (2008).

2. UCSF Chimera--a visualization system for exploratory research and analysis. Pettersen, E. F.; Goddard, T. D.; Huang, C. C.; Couch, G. S.; Greenblatt, D. M.; Meng, E. C.; Ferrin, T. E. J. Comput. Chem. 2004, 25(13), 1605-1612. 


\section{APPENDIX F. LETTER OF PERMISSION}

\section{RE: Website Email: Permission request}

CONTRACTS-COPYRIGHT (shared) <Contracts-Copyright@rsc.org>

To: SOOJIN LIM <slim@pdx.edu>

Wed, Nov 2, 2011 at 8:43 AM

Dear Dr Lim

The Royal Society of Chemistry (RSC) hereby grants permission for the use of your paper(s) specified below in the printed and microfilm version of your thesis. You may also make available the PDF version of your paper(s) that the RSC sent to the corresponding author(s) of your paper(s) upon publication of the paper(s) in the following ways: in your thesis via any website that your university may have for the deposition of theses, via your university's Intranet or via your own personal website. We are however unable to grant you permission to include the PDF version of the paper(s) on its own in your institutional repository. The Royal Society of Chemistry is a signatory to the STM Guidelines on Permissions (available on request).

Please note that if the material specified below or any part of it appears with credit or acknowledgement to a third party then you must also secure permission from that third party before reproducing that material.

Please ensure that the thesis states the following:

Reproduced by permission of The Royal Society of Chemistry

and include a link to the paper on the Royal Society of Chemistry's website.

Please ensure that your co-authors are aware that you are including the paper in your thesis.

Regards

Gill Cockhead

Publishing Contracts \& Copyright Executive

Gill Cockhead (Mrs), Publishing Contracts \& Copyright Executive 
Royal Society of Chemistry, Thomas Graham House

Science Park, Milton Road, Cambridge CB4 OWF, UK

$\mathrm{Tel}+\underline{+44(0) 1223432134}, \mathrm{Fax} \underline{+44(0) 1223423623}$

http://mun.rsc.org

-----Original Message-----

From: SOOJIN LIM [mailto:slim@pdx.edu]

Sent: 01 November $201100: 49$

To: CONTRACTS-COPYRIGHT (shared)

Subject: Website Email: Permission request

To: Contracts

This Email was sent from the following RSC.ORG page:

This is Soojin Lim, a graduate student in the Department of Chemistry at Portland State University. I am writing to obtain the permission for the use of my contributions to two articles published in the "Chemical Communications". I am the first author on the articles and would like to include my contributions to the articles in my doctoral dissertation. The articles are:

"Selective fluorescence detection of cysteine and N-terminal cysteine peptide residues"

DOI: $10.1039 / \mathrm{c0cc01398f}$

"Detecting specific saccharides via a single indicator"

DOI: $10.1039 / \mathrm{c} 1 \mathrm{cc} 11343 \mathrm{~g}$

Thank you so much for your concern. 


\section{RE: Permission request - Our Ref: CP2011-213}

Carla.Flores@csiro.au <Carla.Flores@csiro.au>

To: slim@pdx.edu

Sun, Nov 13, 2011 at 9:52 PM

Dear Soojin Lim

Thank you for your email.

You may include your contributions to the $A J C$ paper noted below in your doctoral thesis, provided there is no commercial gain involved, that they are your own materials, and the original publication source, the authors and CSIRO PUBLISHING are fully acknowledged / referenced, including citing the link to your paper on our website. The links are: http://www.publish.csiro.au/?paper $=\mathrm{CH} 11328$.

As a courtesy to your co-authors, you may wish to advise them of this use.

With best wishes

Casla

Carla Flores

Rights \& Permissions

CSIRO PUBLISHING

150 Oxford Street (PO Box 1139)

Collingwood VIC 3066

$\mathrm{Fax}+61396627595$

www.publish.csiro.au 
From: inyfile@gmail.com [mailto:inyfile@gmail.com] On Behalf Of Soojin Lim

Sent: Tuesday, 1 November 2011 12:04 PM

To: PUBLISHING - General Info

Subject: Permission request

This is Soojin Lim, a graduate student in the Department of Chemistry at Portland State University.

I am writing to obtain the permission for the use of my contributions to the article published in the "Australian Journal of Chemistry".

I am the first author on the article and would like to include my contributions to the article in my doctoral dissertation. The article is:

"Progress Towards Simple and Direct Detection of Adenylosuccinate Lyase Deficiency in Human Urine"

http://dx.doi.orq/10.1071/CH11328

Thank you so much for your concern.

Soojin Lim 


\begin{abstract}
APPENDIX G. VITA
Soojin Lim was born in Seoul, the republic of Korea, on March 11, 1980.

In 1999, she entered Sookmyung Women's University, where she received her bachelor's degree in chemistry. After graduation in 2004, she entered the English Language and Orientation Program at Louisiana State University, and next year enrolled in the doctoral program in the Department of Chemistry and joined Professor Robert M. Strongin's group. While at LSU, she worked as a Graduate Teaching Assistant.

In 2007, Strongin group moved to Oregon and she transferred to Portland State University. Since then, she worked as a Graduate Research Assistant and had publications involved in the research of organic sensing probes for disease biomarkers. She is a current member of the American Chemical Society and a candidate for the Doctor of Philosophy in chemistry.
\end{abstract}

